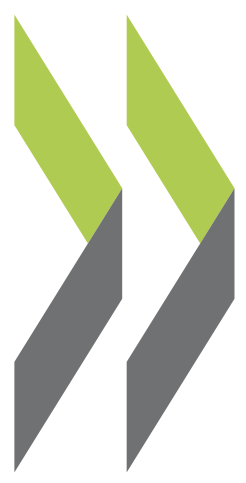

OECD Economics Department Working Papers No. 1485

Políticas estructurales para impulsar la productividad y Lisa Meehan la inclusión en Costa Rica 
OECD

ECONOMICS DEPARTMENT

4 July 2018

POLÍTICAS ESTRUCTURALES PARA IMPULSAR LA PRODUCTIVIDAD Y LA INCLUSIÓN EN COSTA RICA

ECONOMICS DEPARTMENT WORKING PAPERS No. 1485

\section{By Lisa Meehan}

OECD Working Papers should not be reported as representing the official views of the OECD or of its member countries. The opinions expressed and arguments employed are those of the author(s).

Authorised for publication by Isabell Koske, Deputy Director, Country Studies Branch, Economics Department.

All Economics Department Working Papers are available at www.oecd.org/eco/workingpapers. 
OECD Working Papers should not be reported as representing the official views of the OECD or of its member countries. The opinions expressed and arguments employed are those of the author(s).

Working Papers describe preliminary results or research in progress by the author(s) and are published to stimulate discussion on a broad range of issues on which the OECD works.

Comments on Working Papers are welcomed, and may be sent to OECD Economics Department, 2 rue André Pascal, 75775 Paris Cedex 16, France, or by e-mail to eco.contact@oecd.org.

All Economics Department Working Papers are available at www.oecd.org/eco/workingpapers.

On 3 May 2018, the OECD Council invited Lithuania to become a Member. At the time of publication the deposit of Lithuania's instrument of accession to the OECD Convention was pending and therefore Lithuania does not appear in the list of OECD Members and is not included in the OECD zone aggregates.

On 25 May 2018, the OECD Council invited Colombia to become a Member. At the time of publication the deposit of Colombia's instrument of accession to the OECD Convention was pending and therefore Colombia does not appear in the list of OECD Members and is not included in the OECD zone aggregates.

Tanto este documento como cualquier mapa que se incluya en él no conllevan perjuicio alguno respecto al estatus o la soberanía de cualquier territorio, a la delimitación de fronteras y límites internacionales, ni al nombre de cualquier territorio, ciudad o área.

Los datos estadísticos para Israel son suministrados por y bajo la responsabilidad de las autoridades israelíes competentes. El uso de estos datos por la OCDE es sin perjuicio del estatuto de los Altos del Golán, Jerusalén Este y los asentamientos israelíes en Cisjordania bajo los términos del derecho internacional.

La OCDE no garantiza la exacta precisión de esta traducción y no se hace de ninguna manera responsable de cualquier consecuencia por su uso o interpretación.

\section{(c) OECD (2018)}

Usted puede copiar, descargar o imprimir los contenidos de la OCDE para su propio uso y puede incluir extractos de publicaciones, bases de datos y productos de multimedia en sus propios documentos, presentaciones, blogs, sitios web y materiales docentes, siempre y cuando se dé el adecuado reconocimiento a la fuente y al propietario del copyright. Toda solicitud para uso público o comercial y derechos de traducción deberá dirigirse a rights@oecd.org. 


\section{Resumen/Abstract}

\section{Políticas estructurales para impulsar la productividad y la inclusión en Costa Rica}

Debido a las anteriores reformas estructurales, Costa Rica ha disfrutado de un considerable crecimiento del PIB y los niveles de productividad están convergiendo gradualmente hacia el promedio de los países de la OCDE. Sin embargo, persisten grandes brechas en cuanto al PIB per cápita y a la productividad, y no todas las personas se han beneficiado de este crecimiento. La desigualdad ha aumentado y las condiciones del mercado laboral son fuente de preocupación. En Costa Rica existe una menor proporción de la población de trabajadores empleados de la que existe en casi todos los países de la OCDE, el desempleo continúa estando muy por encima del nivel que tenía durante la crisis financiera mundial, la participación en el mercado laboral ha disminuido y la proporción de empleos informales es alta. Reconociendo estos desafíos, se ha acelerado recientemente el impulso a la reforma estructural, incluyendo reformas de políticas en curso o planificadas en varias áreas que presentan oportunidades de beneficio para todas las personas, fomentando tanto la productividad como la inclusión. Estos incluyen esfuerzos para combatir la informalidad del mercado laboral, simplificar la estructura del salario mínimo, aumentar la competencia y reducir las cargas reglamentarias. Además de reformas adicionales en estas áreas prioritarias, también es necesario hacer mejoras en la política estructural para mejorar los resultados y reducir las desigualdades en la educación, y abordar brechas importantes en la infraestructura del transporte.

Este documento de trabajo se relaciona con el Estudio Económico de Costa Rica de 2018 de la OCDE. (www.oecd.org/eco/surveys/economic-survey-costa-rica.htm). Clasificación JEL: I28; I31; J14; J16; J21; J24; J32; J46; J48; J58; L40; L51; L53; O18; O33; O38; R48

Palabras Clave: Costa Rica; productividad; crecimiento inclusivo

\section{Structural policies to boost productivity and inclusion in Costa Rica}

Owing to past structural reforms, Costa Rica has enjoyed robust GDP growth and productivity levels are gradually converging towards the OECD average. However, large GDP per capita and productivity gaps persist. In addition, not everyone has benefited from this growth. Inequality has increased and labour market conditions are a concern. Costa Rica has a lower share of employed workers in the population than almost all OECD countries, unemployment remains well above its pre-global-financial-crisis level, labour market participation has decreased and the share of informal jobs is high. Recognising these challenges, Costa Rica has accelerated its structural reform momentum recently, with policy reforms underway or planned in several areas that present win-win opportunities to boost both productivity and inclusion. These include efforts to tackle labour market informality, simplify the minimum wage structure, increase competition and reduce regulatory burdens. In addition to further reforms in these priority areas, structural policy improvements are also needed to increase outcomes and reduce inequalities in education and address significant transport infrastructure gaps. Este documento de trabajo se relaciona con el Estudio Económico de Costa Rica de 2018 de la OCDE.

This Working Paper relates to the 2018 OECD Economic Survey of Costa Rica.

(www.oecd.org/eco/surveys/economic-survey-costa-rica.htm).

Clasificación JEL: I28; I31; J14; J16; J21; J24; J32; J46; J48; J58; L40; L51; L53; O18; O33; O38; R48

Keywords: Costa Rica; productivity; inclusive growth 
Políticas Estructurales para Impulsar la Productividad y la Inclusión en Costa Rica .................... 6

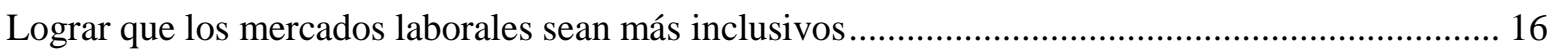

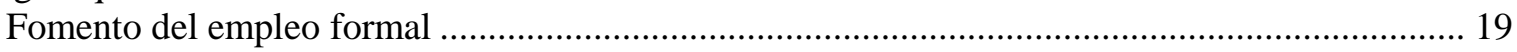

Simplificación de la estructura del salario mínimo .......................................................................... 23

Fortalecimiento de los mecanismos para asegurar el cumplimiento de los reglamentos laborales 27

Facilitación del mercado laboral y la integración social de los inmigrantes ................................. 28

Mejoras en la calidad y la eficiencia del sistema educativo................................................................ 29

Lograr que los resultados educativos se conviertan en el principal objetivo de la política, y

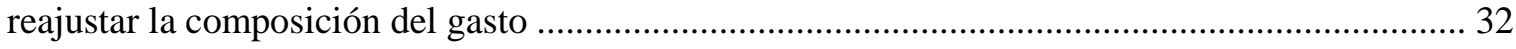

Aumento en el acceso a la educación y atención de la primera infancia de calidad ........................ 33

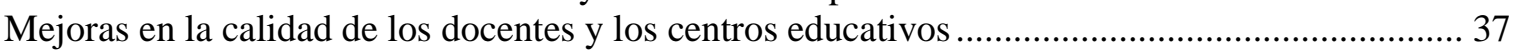

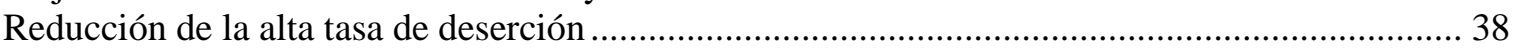

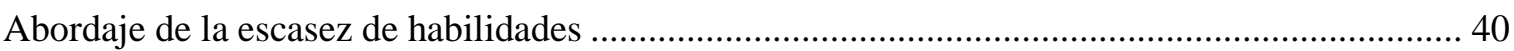

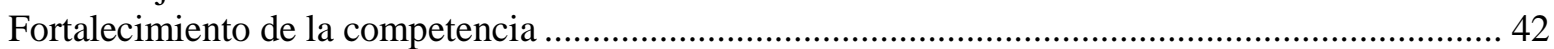

Otorgar a la autoridad para la competencia más independencia y recursos ................................. 43

Evaluación y eliminación de las exenciones antimonopolio injustificadas..........................................4

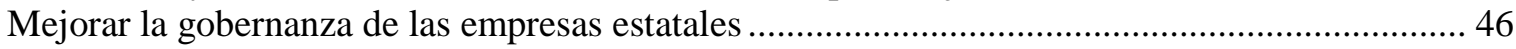

Reducción de las barreras al emprendedurismo y simplificación de los trámites regulatorios ....... 48

Mejoras en el régimen de insolvencia para facilitar el cierre de empresas inviables...................... 50

Continuación de los esfuerzos para aumentar el perfil y la coordinación de las políticas

relacionadas con la productividad ............................................................................................... 51

Promoción de la innovación, la difusión tecnológica y la integración a las cadenas globales de

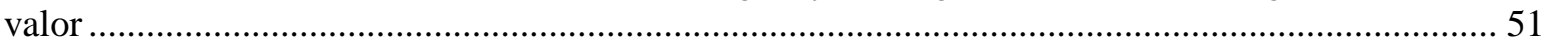

Fortalecimiento de la coordinación para mejorar los vínculos entre las empresas y la

contribución de la investigación pública a la innovación.............................................................. 57

Impulso a la integración regional a través de una mejor facilitación del comercio ......................... 58

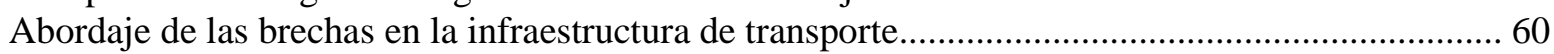

Simplificación del marco institucional para la inversión en infraestructura de transporte ................62 62

Reforma de los entornos institucionales para atraer más inversión del sector privado ................... 64

Referencias ............................................................................................................................................................... 68

\section{Cuadros}

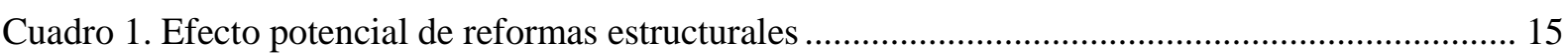

Cuadro 2. Resultados en el mercado laboral son inferiores al promedio de la OCDE ............................ 17

Cuadro 3. Costa Rica está revisando sectores exentos de la ley de competencia.................................... 46 


\section{Figuras}

Figura 1. El PIB per cápita y la productividad del trabajo están convergiendo, pero permanecen aún en niveles bajos

Figura 2. El crecimiento de la productividad multifactorial ha repuntado ........................................... 7

Figura 3. La brecha del PIB per cápita refleja muestra bajos niveles de productividad y empleo, aunque con largos horarios de trabajo ............................................................................................ 9

Figura 4. Los beneficios en especie moderan los altos niveles de desigualdad en los ingresos

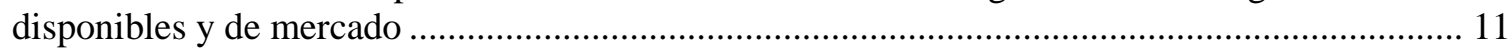

Figura 5. Las condiciones en el mercado laboral siguen siendo preocupantes .................................... 12

Figura 6. Los resultados en el mercado de trabajo son particularmente pobres para los grupos más desfavorecidos

Figura 7. La participación femenina en el mercado laboral está por debajo de la mayoría de países

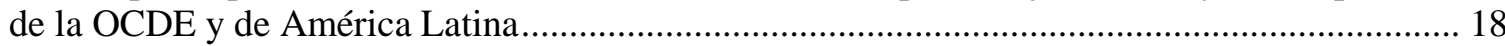

Figura 8. Las responsabilidades familiares son una barrera para la participación de la mujer en el

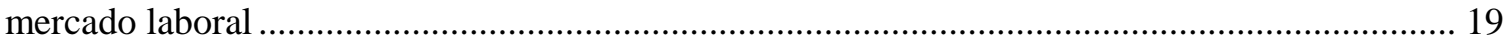

Figura 9. Los altos costos laborales no salariales desincentivan la formalidad.................................... 21

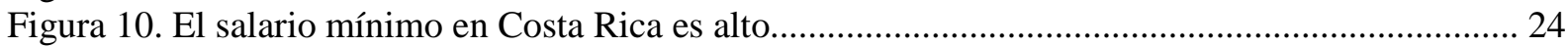

Figura 11. Los bajos resultados y las desigualdades persisten en la educación a pesar de los altos

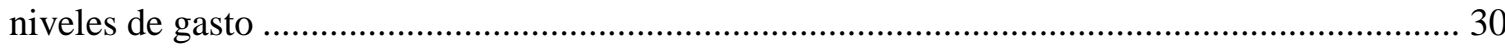

Figura 12. Las brechas socioeconómicas en las tasas de matriculación en educación terciaria están

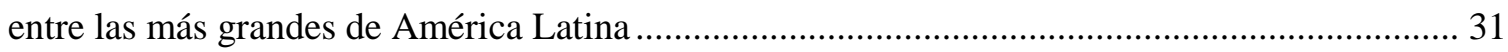

Figura 13. Las regulaciones del mercado de productos son restrictivas............................................ 43

Figura 14. Los controles del Estado y barreras al emprendimiento limitan la competencia ................. 45

Figura 15. Costa Rica se está especializando en productos complejos ................................................ 52

Figura 16. Los servicios intensivos en conocimiento cada vez son una parte más importante de la

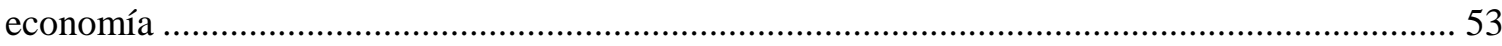

Figura 17. Las restricciones regulatorias de IED son, en general, relativamente bajas......................... 54

Figura 18. Las restricciones al comercio de servicios son elevadas, sobres todo en el ámbito del

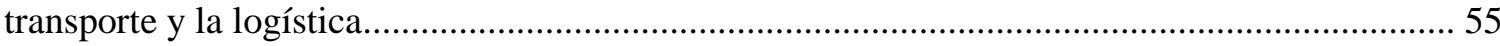

Figura 19. La inversión en capital basado en conocimiento está retrasado......................................... 56

Figura 20. Una gran y creciente proporción de I+D es financiada por el gobierno.................................. 57

Figura 21. Costa Rica está bien integrada en las CGV desde la perspectiva de la participación hacia

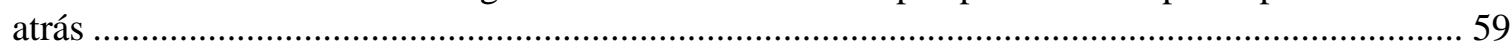

Figura 22. La calidad percibida de la infraestructura de transporte es baja.......................................... 62

\section{Recuardos}

Recuardo 1. Impacto potencial de las reformas estructurales.............................................................. 14

Recuadro 2. Ejemplos de políticas para reducir los niveles de informalidad........................................ 22

Recuardo 3. Establecimiento de los salarios mínimos en los países de la OCDE ................................. 26

Recuadro 4. Recomendaciones de políticas estructurales para impulsar la productividad y la inclusión 


\title{
Políticas Estructurales para Impulsar la Productividad y la Inclusión en Costa Rica
}

\author{
Por Lisa Meehan ${ }^{1}$
}

A pesar de que los logros económicos y sociales de Costa Rica han sido significativos, es necesario que haya un mayor crecimiento de la productividad y la inclusión a fin de mejorar aún más los niveles de vida y lograr que los beneficios del progreso se distribuyan de manera más amplia. La recuperación del crecimiento de la producción después de la crisis financiera mundial fue rápida y robusta, con un crecimiento del PIB superior al $4 \%$ en la mayoría de los años desde 2010. Además, después de muchos años de crecimiento lento de la productividad, el rendimiento ha mejorado desde mediados de la década de 2000 y ahora impulsa la convergencia hacia el promedio de los países de la OCDE (Monge-González, 2016; Escobar y Meehan, 2018). El crecimiento promedio de la productividad laboral anual aumentó del 0,6\% entre 1993 y 2005 al 3,7\% entre 2006 y 2016, y de manera similar, el crecimiento de la productividad multifactorial (PMF) pasó del 0,5\% al 2,9\% (Figura 1 y Figura 2). Esta aceleración ha sido generalizada, con la mayoría de industrias experimentando un cambio estructural hacia un crecimiento de la productividad más alto (Escobar y Meehan, 2018). Sin embargo, sigue existiendo un margen significativo para que haya una mayor convergencia. El PIB per cápita es 39\% del promedio de la OCDE y se mantiene por debajo del de México y Chile (Figura 3). Esta brecha refleja la baja productividad laboral, que representa el 36\% del promedio de la OCDE, mientras que la utilización de la mano de obra está por encima del promedio de la OCDE (Figura 1). Además, incluso a la tasa de crecimiento más rápida experimentada en la última década del $3.7 \%$ anual, tomará casi 30 años alcanzar el nivel de productividad laboral promedio actual de la OCDE. Por lo tanto, mejorar la productividad será clave para elevar los niveles de vida.

Además, para que el crecimiento económico contribuya a mejorar la vida de todos los costarricenses, sus beneficios deben distribuirse de manera más amplia. La desigualdad es alta en comparación con los países de la OCDE y, a diferencia de otros países de América Latina, ha venido aumentando (González Pandiella y Gabriel, 2017). Esta desigualdad en cuanto al nivel de ingresos se ve atenuada gracias a los servicios públicos de atención médica y educación, que han sido componentes clave para el progreso social de Costa

\footnotetext{
${ }^{1}$ Lisa Meehan es Economista de la oficina para Costa Rica / México en el Departamento de Economía de la OCDE. La autora desea agradecer a Álvaro Pereira, Patrick Lenain, Sónia Araújo, Daniel Blume, Sara Calligaris, Thomas Dannequin, Gernot Hutschenreiter, Manuela Fitzpatrick, Andrea Marin Odio, Iota Nassr, Dirk Pilat y Anna Pons por su valiosos comentarios. La autora agradece también a Damien Azzopardi, Pedro Herrera Gimenez y Alex Linares por la asistencia estadística y a Stephanie Henry por la asistencia en la edición.
} 
Rica. De hecho, aunque la desigualdad del ingreso disponible y del mercado es similar a la de Perú y México, la distribución del ingreso final es más equitativa debido a estos beneficios en especie (Figura 4). Sin embargo, existe evidencia de que los costarricenses están cada vez más insatisfechos con la calidad de estos servicios públicos y el gasto del propio bolsillo en servicios de atención médica ha venido aumentando (Estado de la Nación, 2016; Estado de la Nación 2017; OCDE, 2017a; Araújo and Guichard, 2018).

Figura 1. El PIB per cápita y la productividad del trabajo están convergiendo, pero permanecen aún en niveles bajos
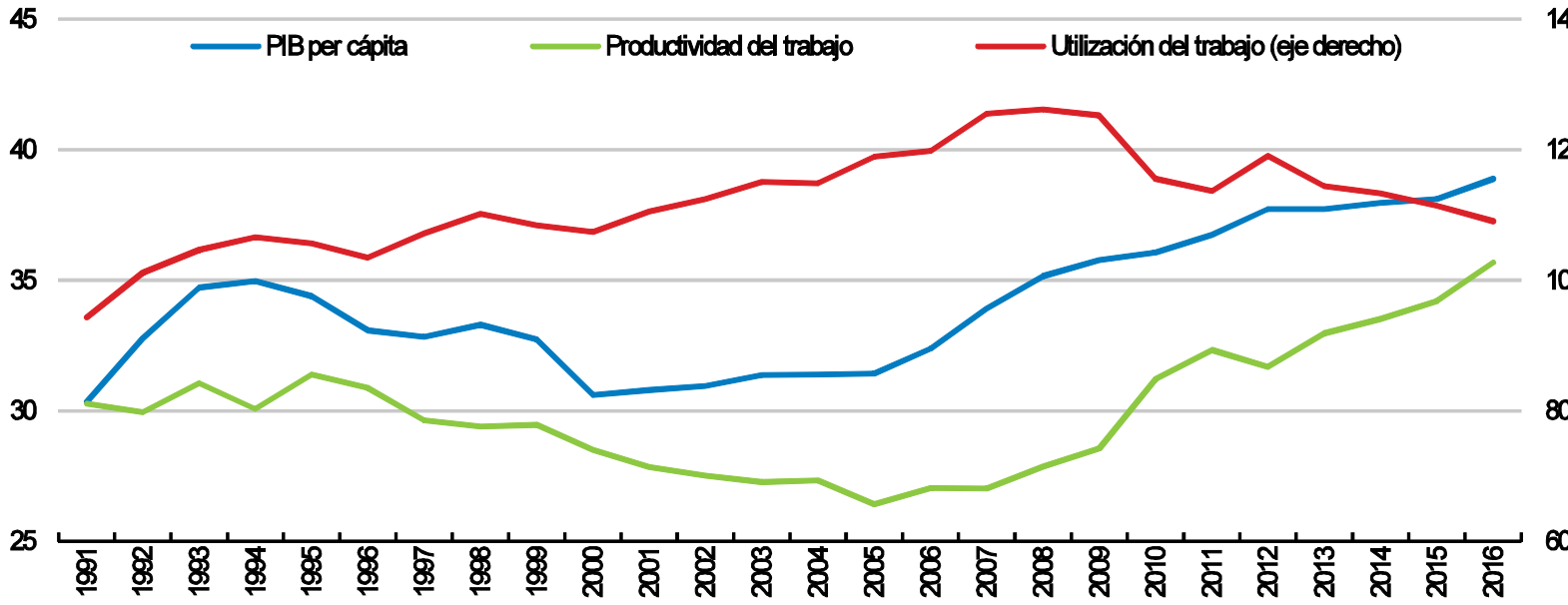

Fuente: OCDE, base de datos de productividad.

Figura 2. El crecimiento de la productividad multifactorial ha repuntado

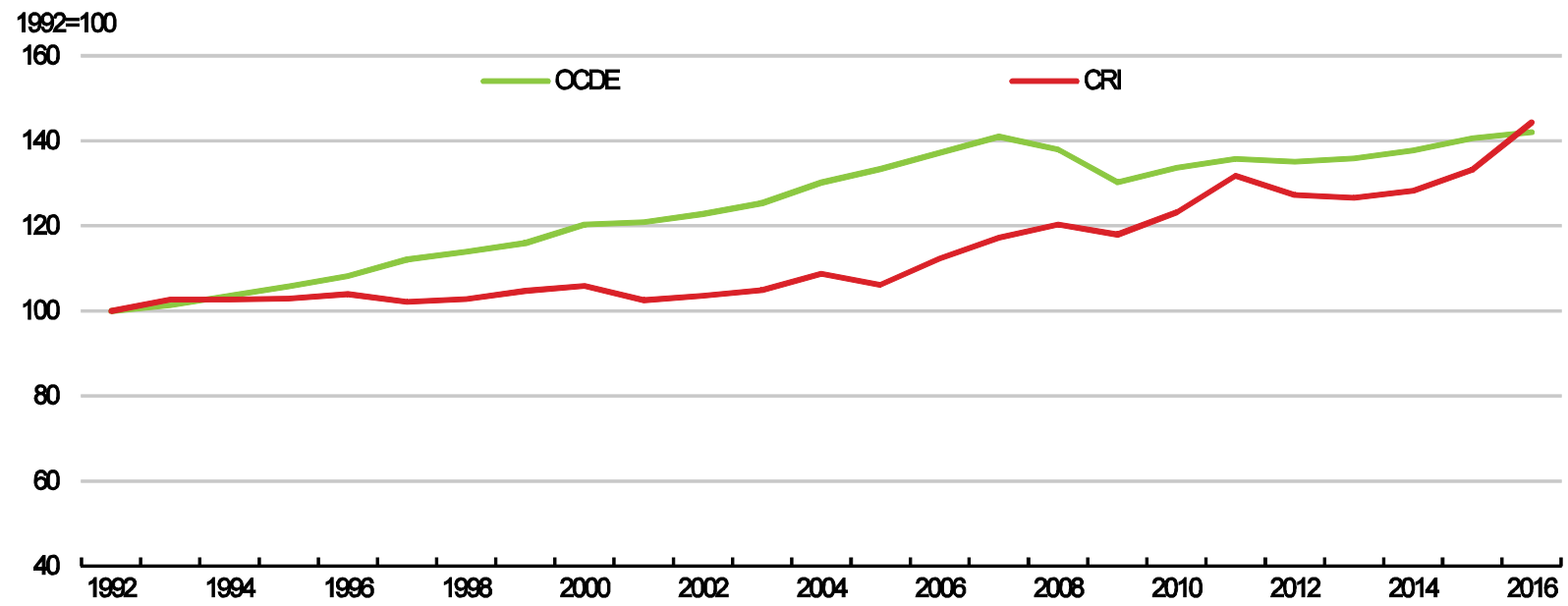

Nota: Para la OCDE, el dato corresponde al promedio sin ponderar de las tasas de crecimiento de la productividad multifactorial de los países miembros de la OCDE. Fuente: OCDE, base de datos de Perspectivas Económicas. 
Este fuerte crecimiento económico tampoco se ha traducido en resultados positivos en el mercado laboral. Si bien la utilización laboral de Costa Rica (horas trabajadas per cápita) es superior al promedio de la OCDE, también indica que los empleados trabajan más horas que en todos los países de la OCDE, pero tasas de empleo inferiores al promedio (trabajadores como porcentaje de la población total), debido al alto desempleo y la baja participación en la fuerza laboral (Figura 3, Panel B, Figura 5, Paneles A y B). De hecho, la proporción de trabajadores empleados en la población es más baja que en todos los países de la OCDE, excepto en Grecia y Turquía (Figura 3, Panel B). El desempleo se ha mantenido elevado desde la crisis financiera global, y gran parte de este incremento se debe a cambios estructurales, ya que las industrias que tradicionalmente absorbían mano de obra poco calificada han crecido más lentamente que los sectores manufactureros y de servicios altamente calificados (Banco Central de Costa Rica, 2016; OCDE, 2017b; Sandoval et al., 2017). Esto se refleja en el aumento del desempleo de larga duración: en 2016, el 16,7\% de los desempleados llevaba más de un año sin trabajo, frente al 9,8\% en 2012, lo que, combinado con la disminución de las tasas de participación en el mercado laboral, sugiere que muchos trabajadores se han desanimado (Estado de la Nación, 2017, Figura 5).

Además, aunque la proporción de trabajadores en trabajos informales es menor que en otros países de la región, como Colombia, Brasil y México, es alta según los estándares de la OCDE (Figura 5, Panel C). La proporción de trabajadores con empleos informales también ha aumentado en los últimos años y continúa siendo persistentemente alta, alrededor del 41\% (Figura 5, Panel B). Esto contrasta con otros países de América Latina donde la informalidad ha estado disminuyendo (OCDE, 2017b, Recuadro 2). El impacto negativo de estas tendencias se siente con más intensidad en los grupos desfavorecidos y entre quienes están menos preparados para adaptarse a los niveles de calificación más altos que requiere el mercado laboral, incluyendo a quienes tienen un bajo nivel educativo, la juventud, las mujeres, y quienes viven en zonas rurales (Figura 6). Este desajuste entre las habilidades que demanda el mercado laboral y las suministradas también es evidente en las crecientes primas salariales para los trabajadores calificados, lo que contribuye aún más al aumento de la desigualdad (González Pandiella y Gabriel, 2017).

Es necesario adoptar reformas de política estructural a fin de evitar trampas de pobreza donde los individuos poco calificados y que carecen de acceso a oportunidades se ven limitados a desempeñar empleos de baja productividad con bajos salarios, lo que a su vez reduce la productividad agregada y empeora aún más la desigualdad (Ferreira et al., 2014; OCDE, 2016a). Para poner en marcha un "círculo virtuoso" será necesario adoptar reformas coordinadas y concertadas en una amplia gama de áreas de políticas que brinden oportunidades que beneficien a todos los actores, a fin de impulsar tanto la productividad como la inclusión (OCDE, 2016a). En este documento se analizan primero las políticas para fomentar la inclusión que ayudarán a las personas a alcanzar su potencial y a sentar las bases para un mayor crecimiento de la productividad en el futuro, incluyendo medidas para lograr que los mercados laborales sean más inclusivos y mejorar la educación. Después, se analizan las políticas para aumentar el crecimiento de la productividad y ayudar a las empresas a alcanzar su potencial, lo que a su vez permitirá ofrecer igualdad de condiciones y reducir las desigualdades económicas, incluyendo las reformas para fortalecer la competencia, promover la innovación y abordar las brechas en la infraestructura del transporte. 
Figura 3. La brecha del PIB per cápita refleja muestra bajos niveles de productividad y empleo, aunque con largos horarios de trabajo

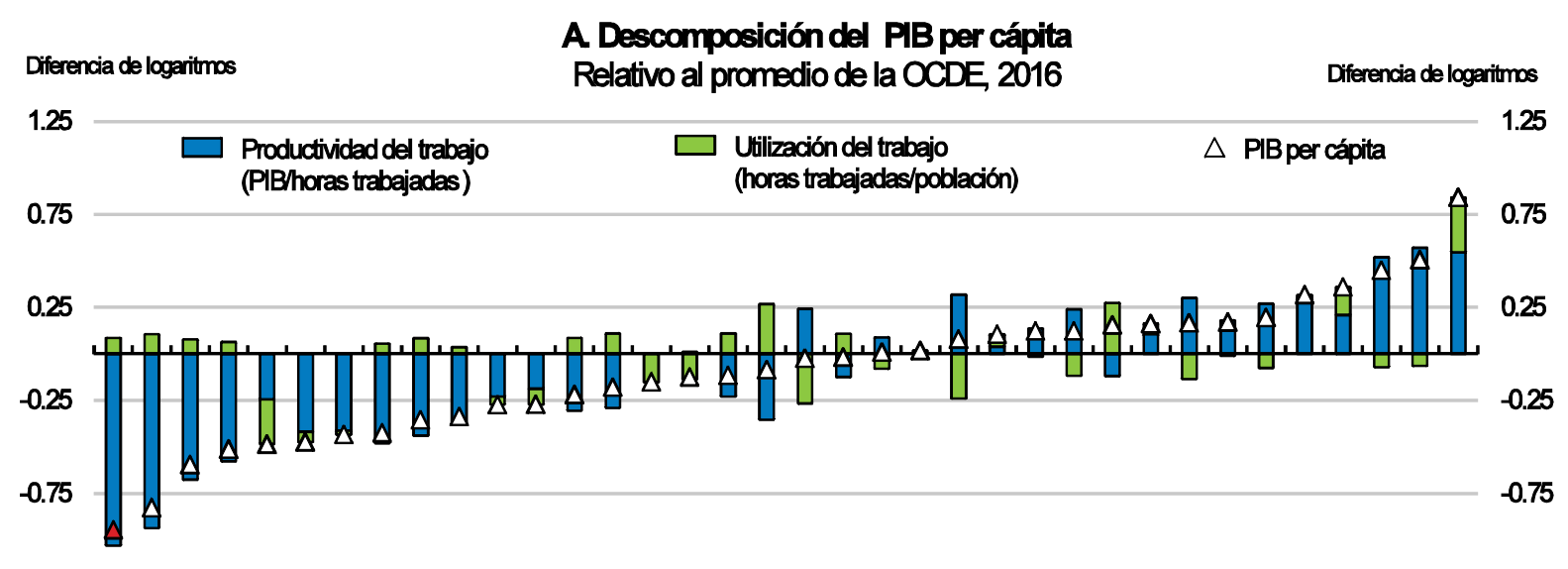

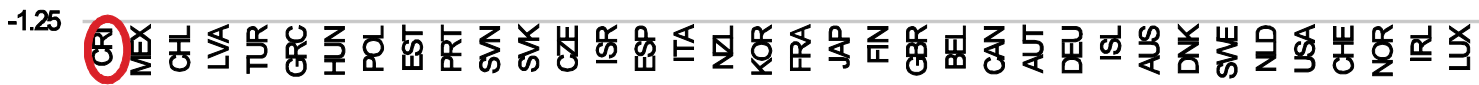

$-1.25$

\section{B. Descomposición de la utilización del trabajo Relativo al promedio de la OCDE, 2016}

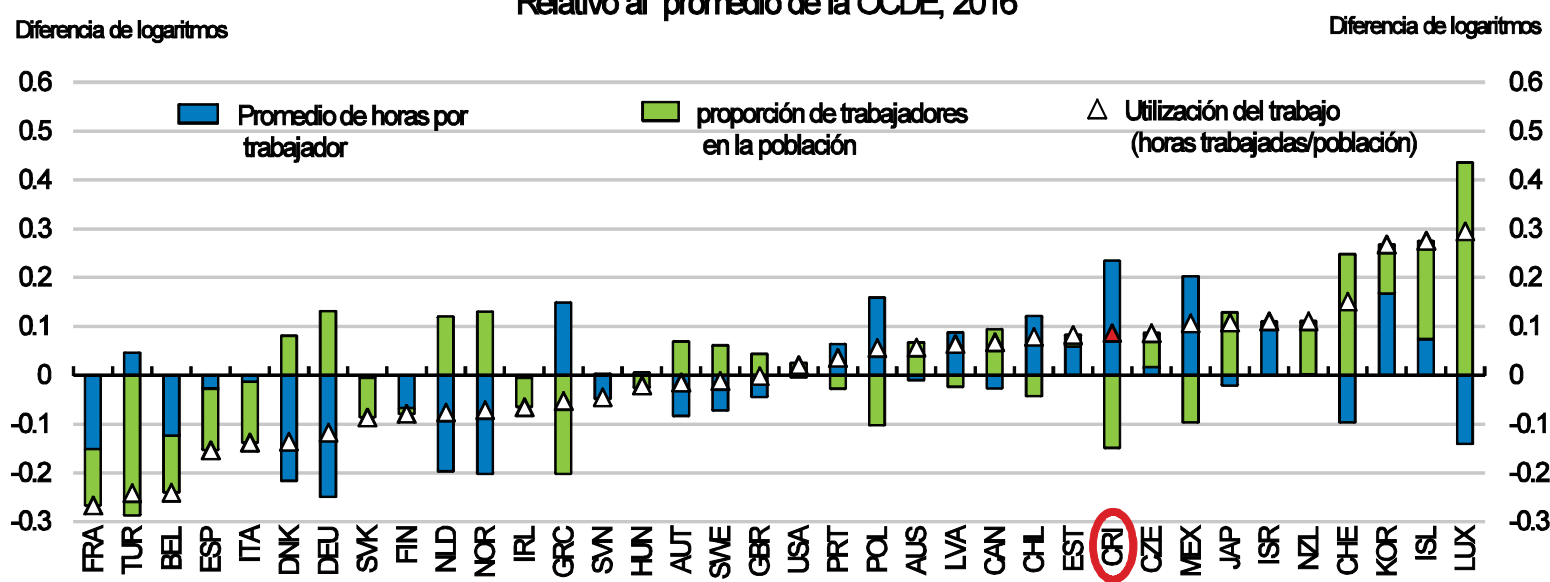

Fuente: OCDE, base de datos de productividad.

En reconocimiento del doble desafío que representa mejorar la productividad y la inclusión, en Costa Rica recientemente se aceleró el impulso a la reforma estructural, con iniciativas para mejorar la formulación de políticas en varias áreas. Algunas de las áreas en las que se han realizado cambios legislativos u otras iniciativas están muy avanzadas incluyen una reforma a las leyes laborales para mejorar la protección de los trabajadores, que entró en vigencia en julio de 2017, el desarrollo de un plan de estudios modernizado que estaría completado en 2018, modificaciones a las contribuciones a la seguridad social destinadas a aumentar la cobertura entre los grupos beneficiarios de trabajadores, y una reducción de la cantidad de categorías de salario mínimo. La implementación efectiva de reformas aún plantea un desafío significativo en algunas de estas áreas, particularmente dado el alto grado de fragmentación institucional y la falta de mecanismos de coordinación, dirección y rendición de cuentas en muchas áreas del sector público (OCDE, 2015a, OCDE, 2016b, OCDE, 2017a; OCDE, 2017b; OCDE, 2017c; OCDE, 2017d; OCDE, 2017e; Araújo and Guichard, 2018). Por ejemplo, es necesario brindar una mayor formación a los docentes para implementar con éxito el nuevo plan de estudios, ya 
que la mitad de los docentes encuestados no pudieron explicar la diferencia entre el plan de estudios anterior y el nuevo (OCDE, 2017c). Otras iniciativas positivas se encuentran actualmente en la etapa de planificación o consulta. Por ejemplo, un proyecto de ley para aumentar la autonomía y los recursos del organismo para la competencia, la formulación de un proyecto de ley para unificar y simplificar el marco regulatorio para casos de insolvencia empresarial, y el desarrollo de una estrategia nacional para la transición hacia una economía formal. Se recomienda hacer mayores esfuerzos de reforma en algunas áreas importantes, como cambiar el enfoque de la educación hacia los resultados y mejorar la infraestructura del transporte. Sin embargo, muchas iniciativas que procuran llevar a Costa Rica hacia las recomendaciones anteriores de la OCDE han estado en marcha durante los dos años transcurridos desde la última Evaluación Económica de la OCDE 2016.

La amplitud y profundidad de las posibles mejoras en materia de política estructural destacadas en la Encuesta Económica de 2016, así como en distintas revisiones detalladas de política de Costa Rica realizadas por la OCDE recientemente, también se subraya la importancia de dirigir los esfuerzos inmediatos de reforma hacia áreas que probablemente generen grandes beneficios o que permitan establecer las condiciones marco necesarias para que los beneficios de reformas futuras puedan materializarse plenamente. Con base en investigaciones disponibles en las que se cuantifican los potenciales beneficios de las reformas (ver Cuadro 1) y las experiencias de otros países, se destacan como áreas prioritarias las reformas para reducir la informalidad del mercado laboral, mejorar los resultados educativos, fortalecer la competencia, reducir las cargas regulatorias y abordar las brechas de infraestructura del transporte. Acciones prioritarias en los mercados laborales y la educación incluyen expandir la atención y educación a los niños en edad temprana, reorientar el gasto hacia educación pre-terciaria y seguir progresando hacia un salario mínimo más simple. Para impulsar la productividad, las reformas se deben centrar en fortalecer la competencia, incluyendo adoptar e implementar el proyecto de ley que le da más poderes, independencia y recursos a la autoridad de competencia. Otras prioridades incluyen restringir el número de exenciones antimonopolio, y reducir regulación onerosa que limita la entrada y salida de negocios, así como su formalización. 
Figura 4. Los beneficios en especie moderan los altos niveles de desigualdad en los ingresos disponibles y de mercado

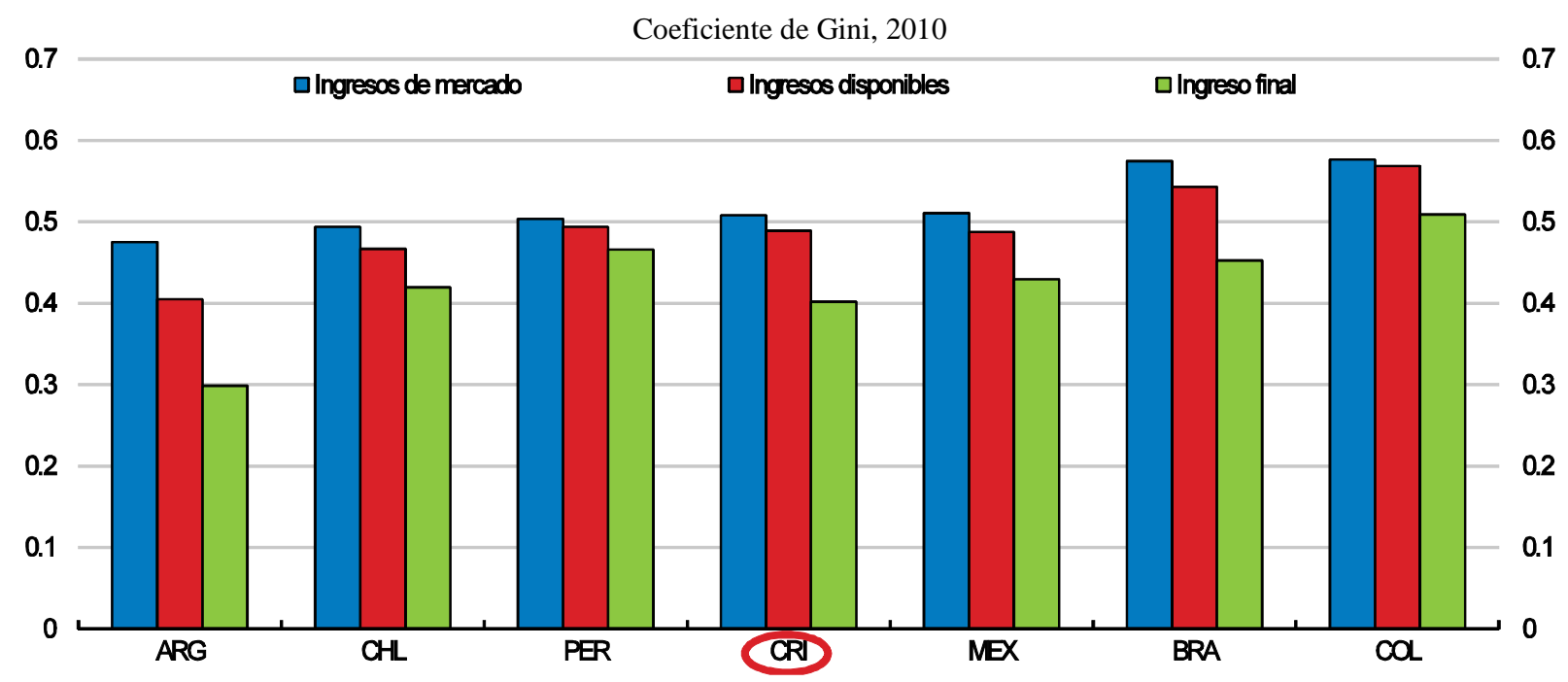

Nota: El año de referencia es 2013 para Chile y 2009 para Perú y Brasil. Fuente: Lustig (2017). 
Figura 5. Las condiciones en el mercado laboral siguen siendo preocupantes

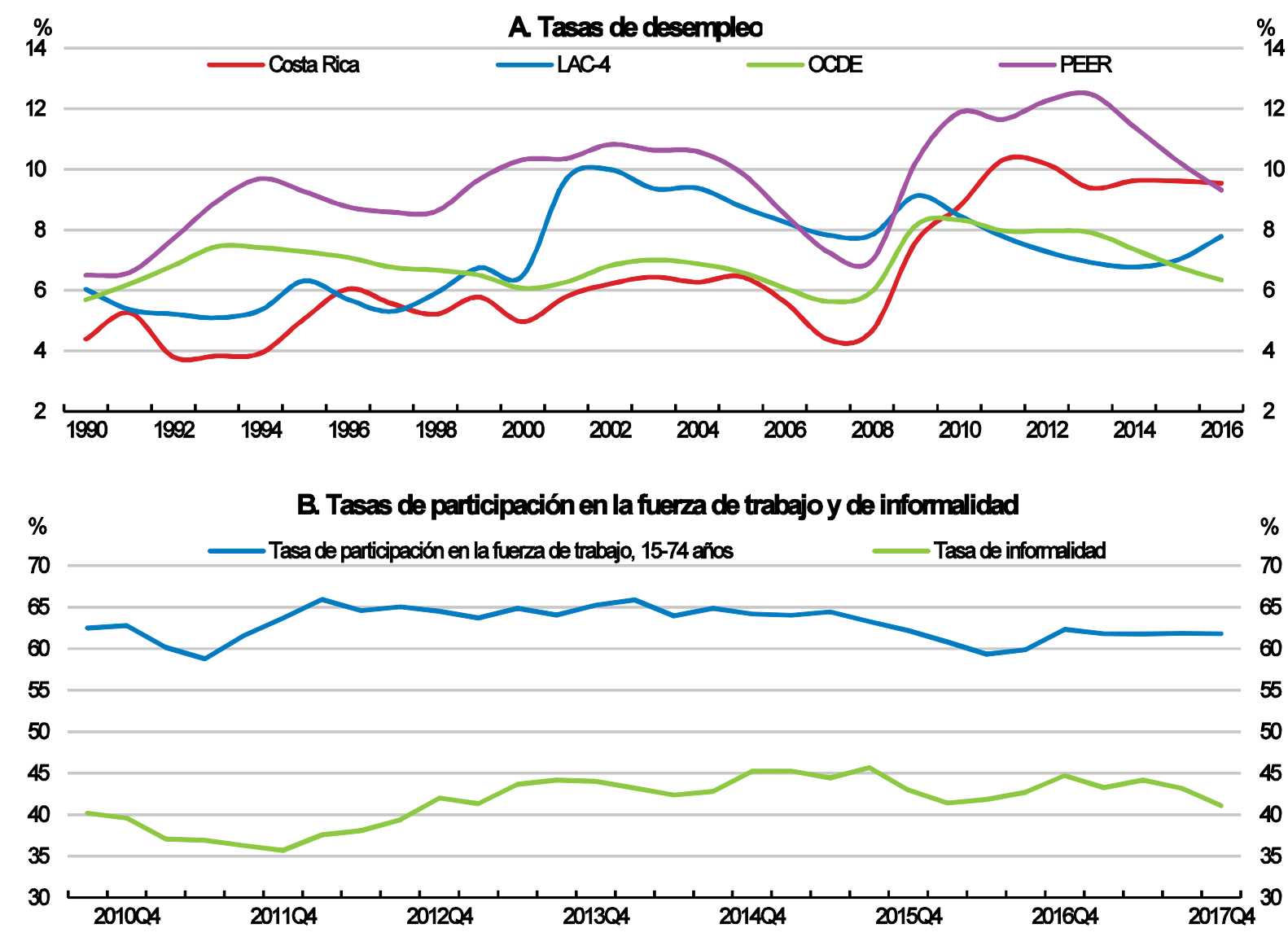

\section{Tasas de informalidad" para el total de empleados de 15-64 años, útimo año disponible}

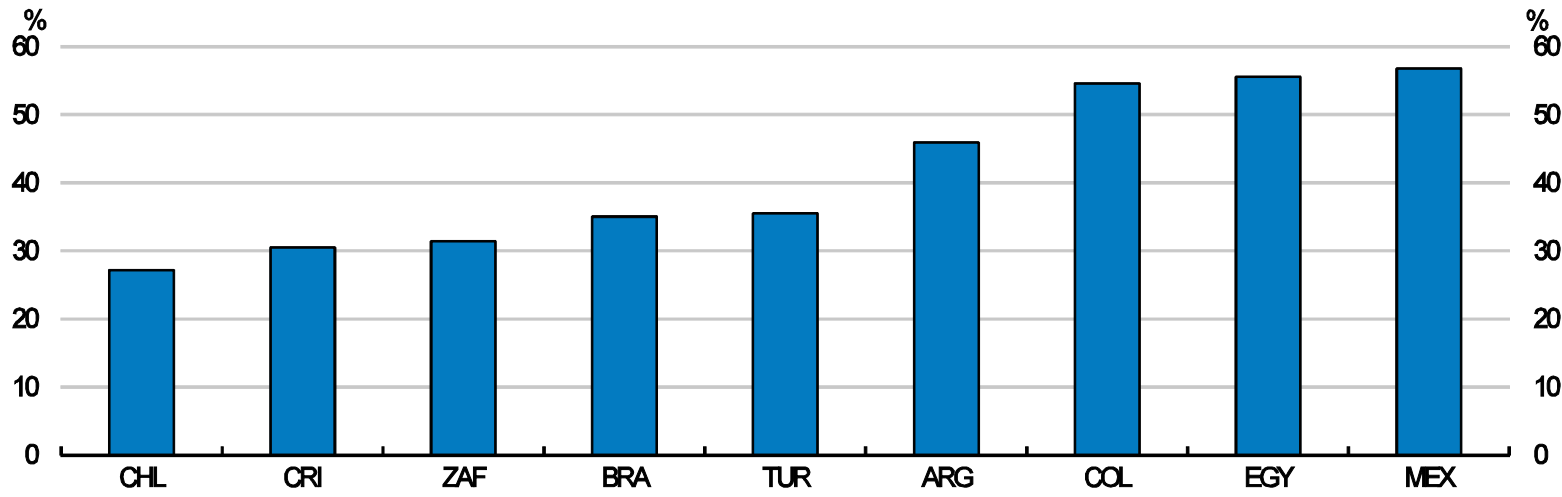

1. La informalidad tal como se ha definido incluye include i) Trabajadores por cuenta ajena que no pagan contribución a la seguridad social, y ii) trabajadores por cuenta propia que no pagan contribuciones a la seguridad social (Chile, Costa Rica y Turquía), o cuyas empresas no están registradas (Argentina, Brasil, Colombia, Egipto, México, Perú and Sudáfrica). Para facilitar la comparabilidad internacional se ha utilizado una definición de tasa de informalidad para Costa Rica que difiere de utilizada por el INEC en la medición oficial de informalidad (see OECD, 2017b).

Nota: LAC-4 es el promedio sin ponderar de Brasil, Colombia, Chile y México. PEER hace referencia a los 10 países miembros de la OCDE, no latinoamericanos, con el PIB per cápita más bajo: República Checa, Estonia, Grecia, Hungría, Letonia, Polonia, Portugal, República Eslovaca, Eslovenia y Turquía.

Fuente: OCDE, Perspectivas Económicas 102; INEC Encuesta Continua de Empleo; OCDE (2017b). 
Figura 6. Los resultados en el mercado de trabajo son particularmente pobres para los grupos más desfavorecidos

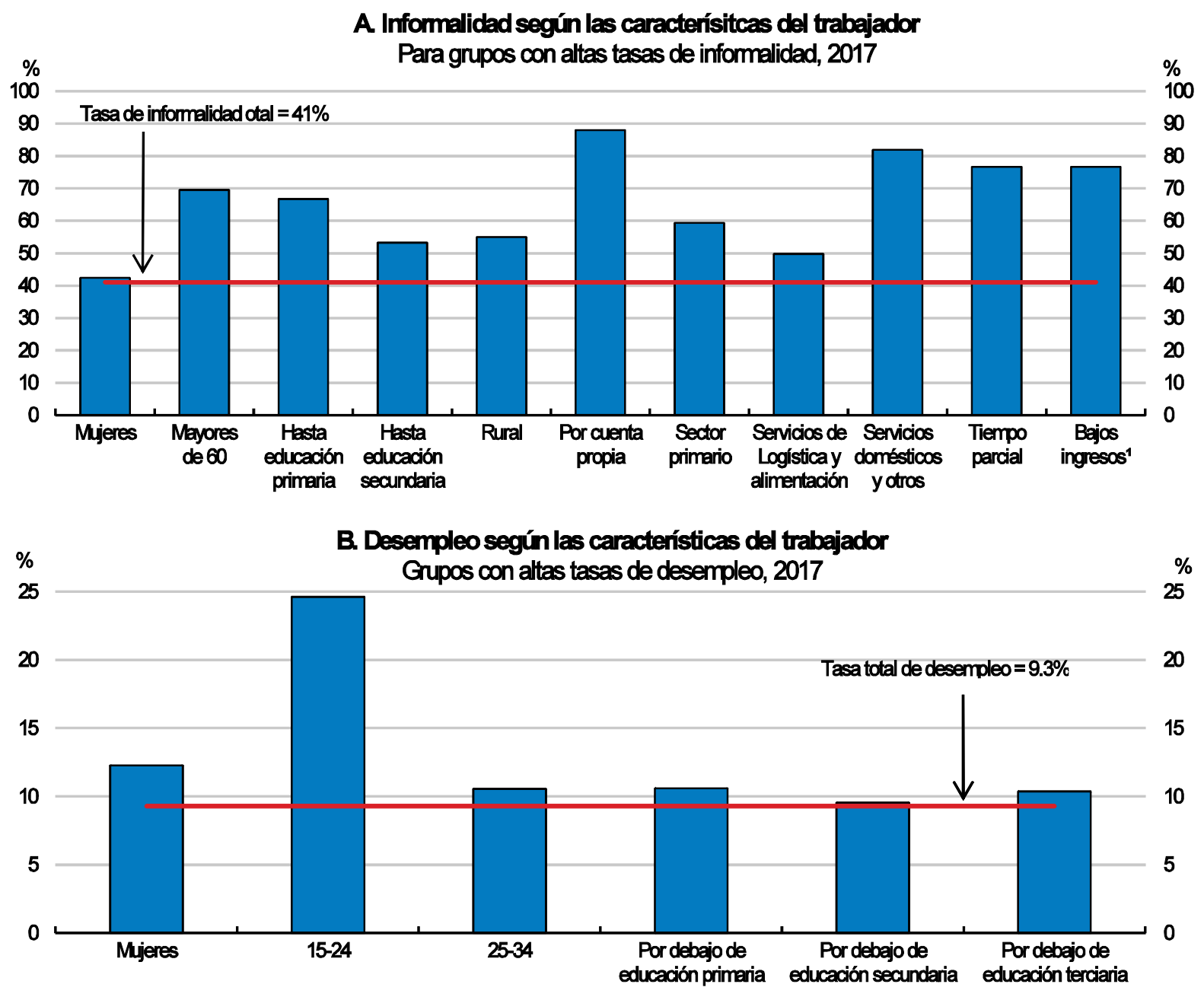

1. Panel A: La categoría de bajos ingresos se refiere a trabajadores con ganancias por hora por debajo del salario mínimo más bajo.

Fuente: INEC, Encuesta Continua de Empleo. 


\section{Recuardo 1. Impacto potencial de las reformas estructurales}

La cuantificación del impacto de las reformas estructurales sobre el PIB proporciona información sobre el tamaño potencial de los beneficios, y es un insumo útil para las decisiones de priorización. En el Cuadro 1 se resumen las estimaciones relevantes de los efectos de las reformas estructurales. Si bien las diferencias en cuanto a medición y metodología dificultan la comparación directa entre las distintas áreas de la reforma y los efectos no son aditivos, estas estimaciones proporcionan una indicación del efecto considerable que pueden tener las mejoras en el mercado laboral, la educación, el mercado de productos, los casos de insolvencia y la infraestructura del transporte.

Por ejemplo, en investigaciones recientes de la OCDE se estiman los efectos de las reformas sobre los niveles de PIB per cápita usando simulaciones basadas en relaciones históricas y entre países, entre las reformas y el crecimiento en los países de la OCDE y aquellos que no pertenecen a la OCDE (Égert, 2017). En conjunto, la propuesta para la Regulación del Mercado de Productos (RMP) y las medidas para casos de insolvencia podrían aumentar el PIB per cápita en un 5,1\% en el largo plazo. Estos beneficios son considerables a pesar de que incluso si se implementaran todas estas reformas al mercado de productos, la rigurosidad de las regulaciones que existen en Costa Rica se continuaría estando significativamente por encima del promedio de la OCDE, y estaría en un nivel similar al de Grecia o Eslovenia y levemente mejor que Colombia. Del mismo modo, si el tiempo que transcurre para resolver casos de se redujera de los 3 años que toma actualmente a 2,5 años, se impulsaría el PIB per cápita en 5,4\%. Sin embargo, es importante notar que la magnitud de la estimación para la insolvencia no es directamente comparable a los resultados para RMP debido a diferencias metodológicas. En particular, las estimaciones de RMP se basan en efectos promedio de tiempo (within), mientras que los de insolvencia usan efectos transversales para países (between). Esto tiene implica una gran diferencia para los resultados: por ejemplo, usar las estimaciones para RMP basadas en efectos entre países resulta en estimaciones mucho más grandes, en el rango de un incremento para el PIB per cápita de $24 \%$. También debería advertirse que las medidas de mejora a menudo son indicadores sustitivo. Por ejemplo, incrementar la red vial es un indicador sustitutivo para la calidad de la infraestructura en Lanau (2017), y además, el incremento de la red vial solo traerá beneficios si las decisiones de inversión se basan en la elección y priorización competentes de los proyectos mediante un análisis de costo-beneficio.

Existen otras áreas importantes de política que aún no se han cuantificado para Costa Rica, aunque las estimaciones hechas para otros países ofrecen una indicación general del impacto potencial de las reformas. Por ejemplo, para México, se estima que la asignación incorrecta de recursos es mucho más alta entre las empresas informales y cada peso mexicano de capital y mano de obra que se asigna a una empresa informal valdría un $28 \%$ más si se asignara a una empresa formal. A pesar de que para Costa Rica no hay estimaciones disponibles, esto sugiere que la informalidad tiene un importante impacto negativo sobre la productividad agregada y el PIB (Busso et al., 2012). En conjunto, mejorar la asignación de recursos podría aumentar el PIB en México en un 125\%, y las 
empresas informales representarían 35 puntos porcentuales de este beneficio (FMI, 2017).

Del mismo modo, no están disponibles las estimaciones de los desajustes en cuanto a habilidades para Costa Rica, con base en los datos de la Evaluación de Competencias de Adultos de la OCDE. Sin embargo, eliminar los desajustes de habilidades en un país donde aproximadamente un tercio de los trabajadores están poco calificados o sobre-calificados para su trabajo (como en Italia) podría contribuir a aumentar los niveles de productividad en un 10\% (Adalet McGowan y Andrews, 2015).

Cuadro 1. Efecto potencial de reformas estructurales

\begin{tabular}{|c|c|c|c|}
\hline $\begin{array}{l}\text { Área de política } \\
\text { estructural }\end{array}$ & Descripción y magnitud de la mejora & Efecto estimado & Fuente \\
\hline \multicolumn{4}{|c|}{ Mercados laborales inclusivos } \\
\hline $\begin{array}{l}\text { Reducir brechas de } \\
\text { género en la } \\
\text { participación en el } \\
\text { mercado laboral. }\end{array}$ & $\begin{array}{l}\text { Eliminar brechas de género en la } \\
\text { participación y oportunidades en el } \\
\text { mercado laboral (por ejemplo, opciones } \\
\text { para convertirse en empresario(a) y } \\
\text { opciones de empleo) }\end{array}$ & $\begin{array}{l}\text { Brechas de género } \\
\text { en Costa Rica } \\
\text { resultan en una } \\
\text { pérdida de ingreso } \\
\text { de } 22 \% \text { a largo } \\
\text { plazo. }\end{array}$ & $\begin{array}{c}\text { Cuberes y } \\
\text { Teignier (2016) }\end{array}$ \\
\hline \multicolumn{4}{|c|}{ Educación y competencias } \\
\hline $\begin{array}{l}\text { Mejorar el nivel de } \\
\text { las competencias }\end{array}$ & $\begin{array}{c}\text { Lograr competencias básicas } \\
\text { universales (por ejemplo, matrícula } \\
\text { universal en secundaria para personas } \\
\text { de } 15 \text { años y notas de PISA de } 4200 \\
\text { más). } \\
\text { Regulación del Mercado de }\end{array}$ & $\begin{array}{l}\text { Incremento del } \\
\text { crecimiento del PIB } \\
\text { de } 0,65 \text { puntos } \\
\text { porcentuales al año. }\end{array}$ & OECD(2015b) \\
\hline $\begin{array}{l}\text { Mejorar la } \\
\text { gobernanza de las } \\
\text { empresas del } \\
\text { Estado. } \\
\text { Improve the } \\
\text { governance of } \\
\text { state-owned } \\
\text { enterprises (SOEs) }\end{array}$ & $\begin{array}{c}\text { Las empresas del Estado no tienen } \\
\text { acceso a financiamiento que no esté } \\
\text { disponible para empresas privadas. } \\
\text { Establecer una unidad coordinadora de } \\
\text { la propiedad estatal en el Ministerio de } \\
\text { la Presidencia para administrar la } \\
\text { propiedad estatal de las empresas } \\
\text { públicas. }\end{array}$ & $\begin{array}{c}\text { Aumento a largo } \\
\text { plazo de } 1,1 \% \text { en el } \\
\text { nivel de PIB per } \\
\text { cápita.1 }\end{array}$ & $\begin{array}{l}\text { Égert (2017); } \\
\text { Égert y Gal } \\
\text { (2017) }\end{array}$ \\
\hline $\begin{array}{l}\text { Simplificar el } \\
\text { sistema de } \\
\text { permisos y licencias }\end{array}$ & $\begin{array}{l}\text { Establecer ventanillas únicas a nivel } \\
\text { local con la información disponible en } \\
\text { línea. } \\
\text { Establish one-stop shops implemented } \\
\text { at the local level with information } \\
\text { available online. }\end{array}$ & $\begin{array}{l}\text { Incremento de } 1,6 \% \\
\text { a largo plazo en el } \\
\text { nivel del PIB per } \\
\text { cápita.1 }\end{array}$ & $\begin{array}{l}\text { Égert (2017); } \\
\text { Égert y Gal } \\
\text { (2017) }\end{array}$ \\
\hline $\begin{array}{l}\text { Reducir las barreras } \\
\text { administrativas para } \\
\text { las empresas }\end{array}$ & $\begin{array}{l}\text { Procedimientos que actualmente son } \\
\text { hechas por el empresario (como el } \\
\text { registro con la seguridad social) se } \\
\text { hacen en una ventanilla única. El } \\
\text { número de días que toma registrar una } \\
\text { empresa se reducen a 220, y el } \\
\text { número de entidades que debe } \\
\text { contactarse se reduce a } 1 .\end{array}$ & $\begin{array}{l}\text { Incremento de } 0,9 \% \\
\text { a largo plazo en el } \\
\text { nivel del PIB per } \\
\text { cápita.1 }\end{array}$ & $\begin{array}{l}\text { Égert (2017); } \\
\text { Égert y Gal } \\
\text { (2017) }\end{array}$ \\
\hline
\end{tabular}


nivel de informalidad que ya es alto y va en crecimiento, obstaculiza la movilidad de los trabajadores, la asignación de recursos que contribuya a aumentar la productividad, y el acceso de los trabajadores a trabajos de calidad (López-Calva y Lustig, 2010; Busso et al., 2012; Hoeller et al., 2012; Hsieh, 2015 OCDE, 2016a, OCDE e BID, 2016). Por ejemplo, mejorar la asignación de recursos podría contribuir a aumentar el PIB en México en un $125 \%$, y las empresas informales representarían 35 puntos porcentuales de este beneficio (FMI, 2017, recuadro 1). Aunque es probable que los beneficios estimados sean menores para Costa Rica dado que su sector informal es más pequeño que el de México (Figura 5, Panel C), estos beneficios siguen siendo significativos.

La participación total en el mercado laboral de personas de 15-64 años en Costa Rica fue de 65\% en 2016, que es menor que el promedio de 71,7\% de la OCDE (Cuadro 2). Esta menor participación y las mayores tasas de desempleo se reflejan en la tasa de empleo, que fue del 58,7\% para las personas de 15 a 64 años en comparación con el promedio en los países de la OCDE del 67,0\%. Además, a pesar del aumento con el tiempo, la participación de las mujeres en edad laboral en el mercado laboral (50,4\% en 2016) es más baja que en todos los países de la OCDE, excepto en México y Turquía (Figura 7). En 2016, solo el 44,3\% de las mujeres costarricenses en edad laboral tenían empleo, en comparación con el 59,4\% en los países de la OCDE. También persiste una gran desigualdad de género, ya que la participación masculina $(79,2 \%)$ y las tasas de empleo $(72,8 \%)$ son mucho más altas y la tasa de desempleo entre los hombres es menor $(8,1 \%$ versus $12,2 \%$ para las mujeres) (Cuadro 2). Estas desigualdades existen a pesar de que se presenta un mejor rendimiento escolar de las niñas, niveles de educación ligeramente más altos entre las mujeres en edad laboral y una brecha salarial de género que es menor que en cualquier país de la OCDE (1,8\% del salario promedio masculino en 2016) (Carrillo et al., 2014; OCDE, 2016b; OCDE, 2017c). Los roles tradicionales de género continúan siendo importantes y las responsabilidades de cuido son una de las barreras principales que limitan la mayor participación de las mujeres, particularmente de las mujeres de bajos ingresos (Figura 8). En general, muchas mujeres no usan ni desarrollan sus habilidades plenamente, lo que no solo agrava las desigualdades socioeconómicas, sino que también limita la productividad agregada y el crecimiento del ingreso (Ruhm y Waldfogel, 2011; Mateo-Díaz y Rodríguez Chamussy, 2013; Gal y Theising, 2015). Se estima que la pérdida de ingresos a largo plazo debido a las desigualdades de género en cuanto a la participación y oportunidades laborales en términos de opciones laborales y empresariales es de 22\% en Costa Rica, en comparación con un promedio de 15,4\% para los países de la OCDE (Cuberes y Teignier, 2016 ; Recuadro 1).

Cuadro 2. Resultados en el mercado laboral son inferiores al promedio de la OCDE

\begin{tabular}{lcccccc}
\hline & $\begin{array}{c}\text { Costa } \\
\text { Rica }\end{array}$ & $\begin{array}{c}\text { OECD } \\
\text { average }\end{array}$ & $\begin{array}{c}\text { Costa } \\
\text { Rica }\end{array}$ & $\begin{array}{c}\text { OECD } \\
\text { average }\end{array}$ & $\begin{array}{c}\text { Costa } \\
\text { Rica }\end{array}$ & $\begin{array}{c}\text { OECD } \\
\text { average }\end{array}$ \\
\hline Total & 58.7 & 67.0 & 65.0 & 71.7 & 9.7 & 6.5 \\
Hombres & 72.8 & 74.8 & 79.2 & 80.0 & 8.1 & 6.4 \\
Mujeres & 44.3 & 59.4 & 50.4 & 63.6 & 12.2 & 6.6 \\
\hline
\end{tabular}

Nota: Los datos refieren a la población en edad de trabajar (15-64 años). El año de referencia es 2016.

Fuente: OCDE, base de datos de estadísticas de la fuerza de trabajo. 
$\mathrm{Al}$ igual que en muchos países de la OCDE, el desempleo y la inactividad entre los trabajadores jóvenes son altos. En 2007, el desempleo entre las personas de 15-24 años estaba por debajo del promedio de la OCDE (10,8\% versus 12,1\%), pero ha aumentado significativamente y ahora está por encima del promedio de la OCDE (23,1\% versus 12,9\% en 2016). Alrededor de una cuarta parte de los jóvenes de 18-24 años no tienen empleo, educación ni capacitación (jóvenes que ni estudian, ni reciben algún tipo de formación, ni trabajan, conocidos como NINIS) en comparación con un promedio de la OCDE de 15,3\%, con tasas más altas entre mujeres (33,3\% versus un promedio de la OCDE de 16,4\%) y de familias de bajos ingresos (Estado de la Nación, 2016). Esto es particularmente problemático para Costa Rica dado que su población es relativamente joven, lo que significa que las dificultades de empleo entre los jóvenes serán especialmente perjudiciales para los niveles futuros de habilidades, la productividad y la cohesión social (Bell y Blanchflower, 2011).

La alta tasa de desempleo, particularmente entre los jóvenes, junto con la insuficiencia de habilidades, hace destacar que el sistema educativo no está brindando a las personas las habilidades requeridas por el mercado laboral, ni las herramientas necesarias para adaptarse al cambio estructural y tecnológico. Además, las dificultades a las que se enfrentan los trabajadores desplazados para reincorporarse al mercado laboral ponen de relieve la necesidad de mejorar las políticas activas de este mercado, así como las oportunidades de educación y capacitación de por vida.

Figura 7. La participación femenina en el mercado laboral está por debajo de la mayoría de países de la OCDE y de América Latina

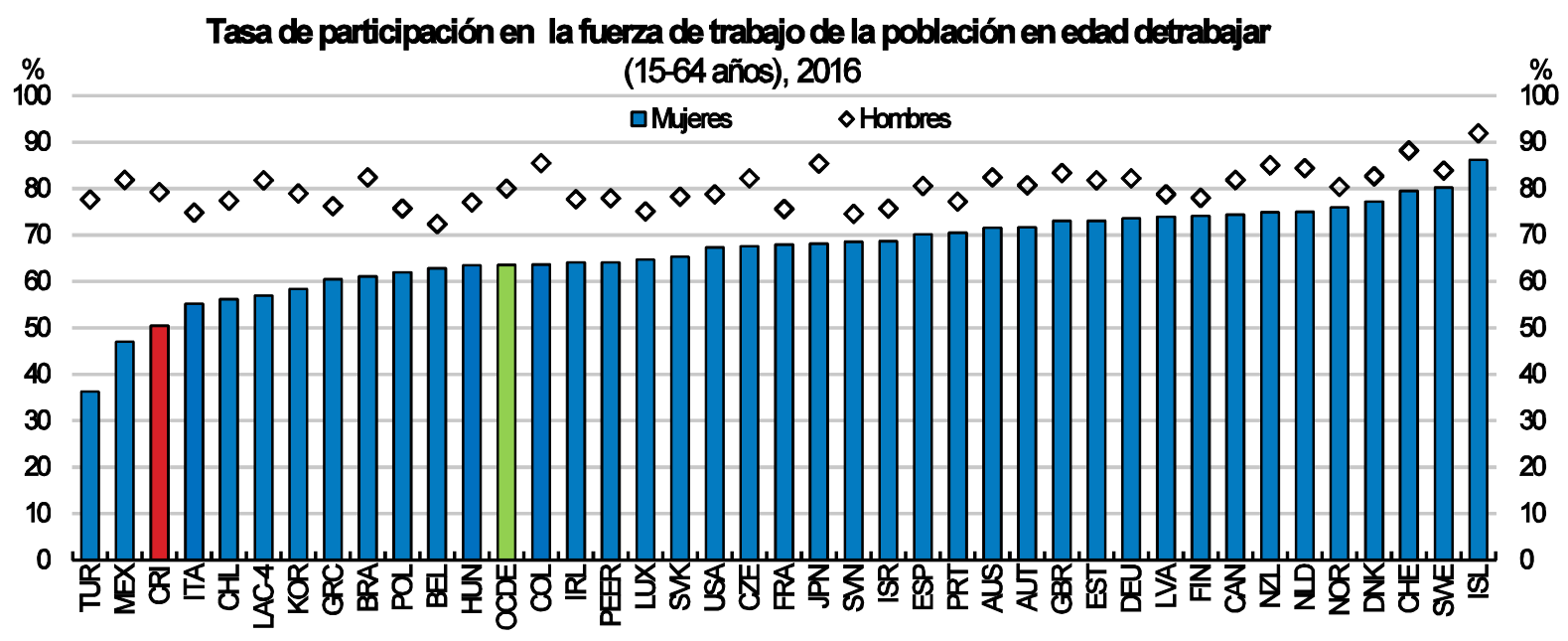

Nota: Los datos para Brasil se refieren a 2015. LAC-4 es el promedio sin ponderar de Brasil, Colombia, Chile y México. PEER hace referencia al promedio sin ponderar de los 10 países OCDE, no latinoamericanos, con el PIB per cápita más bajo: Republic Checa, Estonia, Grecia, Hungría, Letonia, Polonia, Portugal, República Eslovaca, Eslovenia y Turquía.

Fuente: OCDE, base de datos de estadísticas de la Fuerza de Trabajo. 
Figura 8. Las responsabilidades familiares son una barrera para la participación de la mujer en el mercado laboral A. Tasa de perticipación femenina en la fuerza
de trabajo, por quintil de inigreso, $24-35$ años

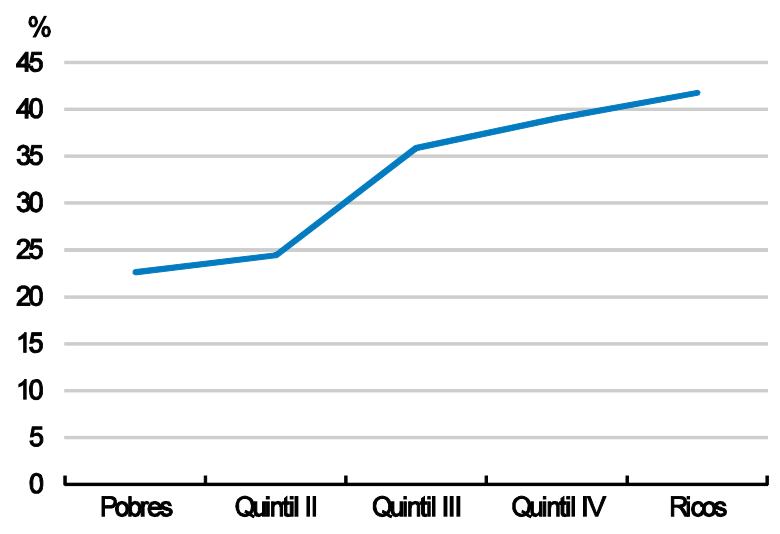

Fuente: INEC, Encuesta Nacional de Hogares 2014.

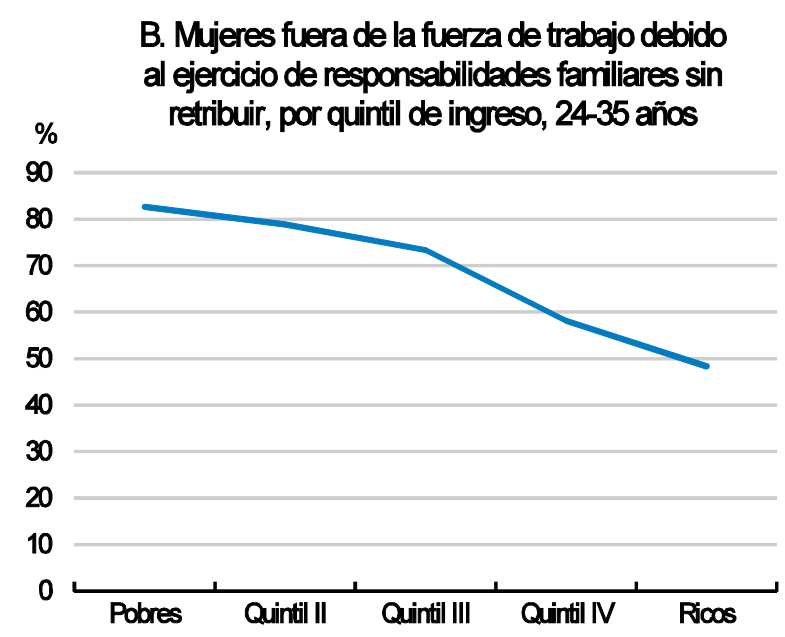

B. Mujeres fuera de la fuerza de trabajo debido Bercicio de responsabilidades familiares sin

\section{Fomento del empleo formal}

La OCDE recomienda la adopción de una estrategia integral para enfrentar la informalidad en Costa Rica, incluyendo acciones para reducir los costos laborales no salariales, simplificar la estructura del salario mínimo, fortalecer los mecanismos para asegurar el cumplimiento de las leyes, reducir los obstáculos al emprendimiento y mejorar la educación y la capacitación (OCDE, 2016b; OCDE, 2017b). En otros países de América Latina, las políticas destinadas a fomentar la formalización han logrado un éxito relativo (OCDE, 2017f, Recuadro 2).

En respuesta a dicha recomendación, el gobierno planea lanzar una Estrategia Nacional para la Transición a la Economía Formal en febrero de 2018, con el objetivo general de reducir la informalidad en 10 puntos porcentuales para el 2025, con respecto al promedio de 42,6\% de 2012-2016. De acuerdo con las recomendaciones de la OCDE, esto incluye la adopción de políticas destinadas a mejorar la educación y la capacitación, mejorar la seguridad social, reducir las cargas regulatorias y simplificar los trámites tributarios. El diseño y la solución son responsabilidad de un consejo técnico tripartito respaldado por una secretaría técnica que proporciona los informes semestrales de progreso y la estrategia se evaluará después de 18 meses.

Aunque la estrategia aún se encuentra en las primeras etapas, es un paso positivo. Para abordar el próximo desafío de convertir la estrategia de alto nivel en medidas viables, con líneas claras de rendición de cuentas, plazos y criterios de evaluación, las autoridades tienen la intención de establecer planes detallados de acción para cada una de las áreas principales de la estrategia. Incorporar la estrategia y los planes de acción asociados en el Plan Nacional de Desarrollo 2018-2022 lo consolidaría como un área prioritaria en el futuro. Además, es importante que el consejo técnico cuente con mecanismos de orientación para influir en el trabajo de las distintas entidades competentes que participan en la implementación de la estrategia. La experiencia de otros consejos tripartitos en Costa Rica es que estos tienen un papel secundario en la formulación de políticas (OCDE, 2017b), y para ser implementado exitosamente, el consejo deberá contar con las 
herramientas adecuadas para afrontar el alto grado de fragmentación del sector público. El Consejo Nacional de Facilitación del Comercio que se creó recientemente, podría ser un ejemplo útil de un consejo con miembros tanto del sector público y como privado que tenga autoridad para tomar decisiones vinculantes para las entidades gubernamentales correspondientes. Un desafío adicional es que algunas de las acciones clave (por ejemplo, la reducción de las contribuciones a la seguridad social por parte de las empresas nuevas y pequeñas, que se analizan a continuación) requerirán reformas legislativas y, por lo tanto, es muy incierto si estos cambios se producirán y cuándo.

Las reformas al pago de impuestos y las contribuciones a la seguridad social han sido el punto central de atención de los esfuerzos necesarios para reducir la informalidad en otros países de América Latina, y una de las principales características de la estrategia costarricense es la modificación de las contribuciones a la seguridad social (Recuadro 2). Las contribuciones a la seguridad social representan una alta proporción de los ingresos fiscales en Costa Rica: 34\% de los ingresos fiscales totales en comparación con un promedio de 16,6\% entre los países de LAC -5 y 26,1\% entre los países de la OCDE, y representan un gran obstáculo para la formalidad (Ramírez Alfaro, 2010; OIT, 2014; OCDE, 2017b; OCDE, 2017g). La tasa total de contribuciones a la seguridad social en Costa Rica es del 36,5\% del salario bruto, donde 26,33 puntos porcentuales son cubiertos por los patronos y 9,34 puntos porcentuales son pagados por los empleados (OCDE, 2017g). La gran proporción pagadera por los patronos hace que los costos laborales no salariales de Costa Rica se ubiquen en el rango superior de las clasificaciones de los países de la OCDE (Figura 9); a diferencia de estos países, el estado también paga una pequeña parte de las contribuciones a la seguridad social $(0,82 \%$ del salario bruto) (OCDE, 2017g). Reconociendo la necesidad de contener los costos laborales no salariales, actualmente se está analizando una propuesta para realizar mayores transferencias estatales anuales, ajustadas a la inflación, al fondo contributivo de pensiones.

Inusualmente entre los países de la OCDE, una parte significativa de las contribuciones a la seguridad social no se usan con fines de seguridad social. Del total de la tasa de contribución, 28 puntos porcentuales cubren la seguridad social (pensiones de vejez, atención médica y seguro de desempleo). Las contribuciones restantes se utilizan para otros fines, como para financiar a los bancos públicos y los programas contra la pobreza. La tasa de pago también es particularmente alta con respecto a los ingresos para los trabajadores de bajos y medianos ingresos, porque la contribución básica mínima es la misma independientemente de las horas de trabajo o las ganancias, lo que resulta en cuñas fiscales particularmente altas en la parte inferior de la distribución de ingresos y desalienta la formalidad (OECD, 2017b; OECD, 2017g; Araújo and Guichard, 2018). 
Figura 9. Los altos costos laborales no salariales desincentivan la formalidad

Porcentaje de ingresos brutos para una persona soltera que percibe el salario mínimo, $2013^{1}$

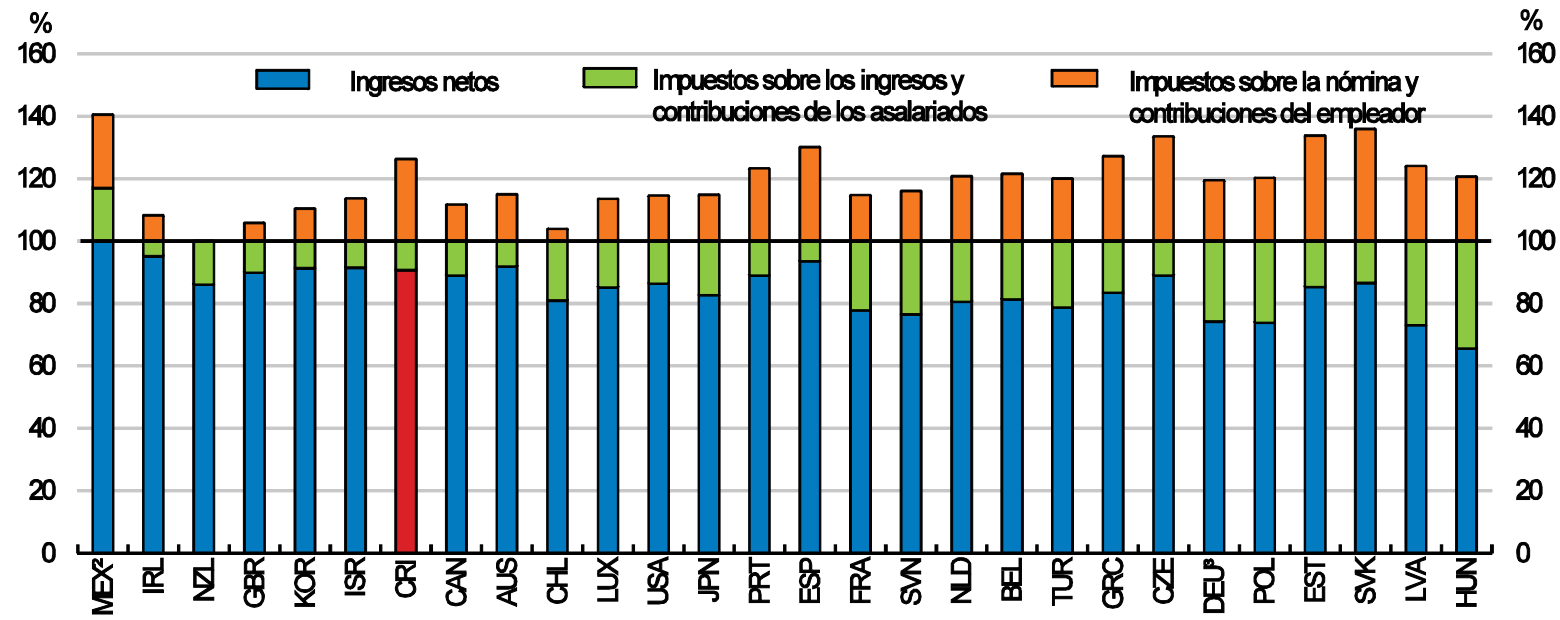

1. La carga fiscal ha sido calculada para un trabajador empleado a tiempo completo, en un hogar unipersonal, que recibe el salario mínimo, con el tipo impositivo normal (adulto). El concepto de tiempo completo hace referencia al número de horas que usualmente definen la jornada a tiempo completo en cada país. Las contribuciones sociales del empleador y empleado también incluyen cualquier pago obligatorio a seguros privados de salud, pensiones, etc.

2. Para México, los ingresos de los salarios bajos tienen impuestos sobre el ingreso negativos debido a que reciben un suplemento salarial en forma de crédito impositivo.

3. Para Alemania, los niveles de salario mínimo refieren a 2015.

Fuente: OCDE (2017b).

El mal estado de las finanzas públicas no permite actualmente una reducción significativa en las tasas de contribución (ver Araújo and Guichard, 2018). Sin embargo, el gobierno está investigando opciones para aumentar la cobertura en ciertos sectores en los que hay altos niveles de informalidad. La tasa mínima de contribución básica para quienes trabajan en servicio doméstico se redujo desde julio de 2017, y se estableció un sistema para contabilizar las contribuciones de varios empleadores. Además, un plan piloto para los cosechadores de café que implica una tasa reducida de contribución a la seguridad social del 15\% para cubrir el seguro de salud durante la temporada de cosecha empezará a implementarse en 2018. También se está considerando un plan especial para pasantes. El borrador de la Estrategia de Transición incluye planes para implementar planes similares para al menos dos grupos más de trabajadores (que aún no se han definido).

El gobierno también propuso un proyecto de ley para reducir la tasa de contribución de los empleadores de empresas nuevas y pequeñas durante los primeros cuatro años de operación, de aproximadamente el 25\% de la nómina bruta a entre el 13,33\% y el 15,33\%. Se espera lograr un acuerdo con la Caja Costarricense del Seguro Social en 2018 para permitir que las contribuciones sociales se reduzcan a entre 18,83\% y 20,83\%. Además, en noviembre de 2015 se propuso un proyecto de ley (No. 19.805) para que la tasa se reduzca 5,05 puntos porcentuales adicionales. La evidencia de otros países sugiere que este esquema podría contribuir a una mayor formalización y parece que la propuesta está bien diseñada (Comisión Europea y OCDE, 2015, OCDE, 2017b, OCDE, 2017f). Por ejemplo, limitar las tasas reducidas a cuatro años debería contribuir a minimizar el impacto fiscal y mitigar el riesgo de que esta política, que depende del tamaño de las 
empresas, actúe como un elemento disuasivo para el crecimiento empresarial (Braguinsky et al., 2011; Garicano et al., 2016). Sin embargo, será importante considerar los costos y beneficios, garantizando que la política contribuya efectivamente a la formalización, que las consecuencias fiscales sean manejables y que no haya consecuencias no deseada importantes. También existen planes para complementar estas medidas con trámites fiscales simplificados, incluyendo la integración de los sistemas de pago de impuestos y seguridad social. En esta etapa, se desconoce si estas reformas continuarán y si lo hacen, cuándo ocurrirán.

\section{Recuadro 2. Ejemplos de políticas para reducir los niveles de informalidad}

El nivel de informalidad ha disminuido en varios países de América Latina debido a una combinación de crecimiento económico e intervenciones de políticas específicas. Por ejemplo, la evidencia sugiere que las políticas para reducir los costos del empleo formal en Brasil contribuyeron a reducir la tasa de informalidad de más del 60\% en 2000 a menos del 50\% en los últimos años (Filho y Veloso, 2016; OCDE, 2017f). En particular, la ley SIMPLES de 1996, que introdujo un sistema integrado de pago de impuestos y contribuciones para micro y pequeñas empresas, facilitó el registro de empresas y redujo la tasa impositiva para las microempresas, y contribuyó a la formalización de casi medio millón de microempresas en cinco años. Una ley más reciente de 2008 dirigida a firmas de propietarios únicos también permitió reducir las contribuciones a la seguridad social y facilitó un aumento en la formalización entre los trabajadores independientes, aunque parece que esto tuvo algunos efectos indeseables y algunas empresas han sustituido empleados regulares por proveedores independientes. Los mecanismos más estrictos para asegurar el cumplimiento de la ley, incluyendo un sistema de pago por desempeño para los inspectores, también han ayudado (OCDE, 2013; OCDE, 2017f).

En México, se introdujeron dos esquemas en 2014 para ofrecer incentivos a las pequeñas empresas para que se formalicen. Estos incluían obligaciones fiscales y de seguridad social reducidas durante los primeros diez años de funcionamiento. Las medidas también incluyeron incentivos para ayudar a las nuevas empresas formales a expandirse a través del acceso al financiamiento y la capacitación con apoyo gubernamental, y una serie de herramientas electrónicas para simplificar el cumplimiento del pago de impuestos. La evidencia sugiere que esto ha conducido a que 1,5 millones de empresas informales se integren al sistema tributario. Además, una ley integral de reforma laboral en 2012 incluyó iniciativas para estimular el empleo formal, incluyendo iniciativas para estimular el empleo formal, reduciendo la incertidumbre y los costos para las empresas, por ejemplo, limitando el costo por despido de trabajadores (OCDE, 2015c, OCDE 2017f).

La reforma fiscal de 2013 en Colombia redujo las contribuciones de planilla de los empleadores en 13,5 puntos porcentuales, lo cual se estima que generó 213.000 empleos formales en el corto plazo y redujo la tasa de informalidad entre 1,2 y 2,2 puntos porcentuales (Fernández y Villar, 2016; y Medina, 2017; OCDE, 2017h; OCDE, 2017i). 
Cambiar la composición de la carga tributaria para que dependa menos de las contribuciones a la seguridad social e incluya fuentes menos distorsionadoras, incluyendo los ingresos personales, corporativos y los impuestos al valor agregado, sería una estrategia de mayor alcance para reducir los obstáculos a la formalidad. Sin embargo, los cambios deberían estar condicionados a la estabilización de la situación fiscal, ya que incluso un cambio que sea neutral en términos de los ingresos implicaría, en principio, un mayor nivel de incertidumbre en el corto plazo.

Como parte de este cambio, la OCDE también recomienda que las contribuciones sean utilizadas exclusivamente para fines de seguridad social, y que el financiamiento para otras instituciones y programas se traslade gradualmente a fuentes que son más progresivas y / o menos distorsionadoras (OCDE, 2016b, OCDE, 2017b). Podría analizarse más detenidamente la modificación de la tasa contributiva mínima para todos los trabajadores, en particular si el plan para las personas que trabajan en servicios domésticos es exitoso. Por ejemplo, la base contributiva mínima podría variar según el horario de trabajo, o las contribuciones podrían ser proporcionales a los ingresos recibidos por trabajos de tiempo parcial (OCDE, 2017b). Estos cambios serán particularmente importantes dada la naturaleza cambiante del trabajo que se está produciendo a nivel mundial, incluyendo el aumento de la cantidad de trabajadores que tienen empleos de tiempo parcial, ocasionales y con varios empleadores. Además, actualmente los trabajadores deben contribuir durante al menos 15 años para recibir una pensión reducida o 25 años para recibir una pensión completa, lo cual desalienta a aquellos que probablemente no alcanzarán los 15 años de contribuciones, a obtener un empleo formal. La cantidad mínima de años para calificar para recibir una pensión podrían reducirse o eliminarse, y con el fin de evitar montos de pensión muy bajos, las pensiones no contributivas podrían eliminarse progresivamente a medida que aumentan los ingresos contributivos para las pensiones (OCDE, 2017b).

A continuación se analizan otras medidas que también fomentarán la formalidad, entre ellas: mejorar la educación y la capacitación, lograr que los mecanismos que aseguren el cumplimiento de la ley sean más estrictos, facilitar el registro de las empresas, reducir los costos de cumplimiento para las empresas, y simplificar la estructura del salario mínimo.

\section{Simplificación de la estructura del salario mínimo}

El salario mínimo de Costa Rica es establecido por el Consejo Nacional de Salarios, una entidad tripartida, y varía por nivel de habilidad, ocupación y nivel de educación. El número de categorías de salario mínimo ha disminuido significativamente, de 520 en 1987 a 23 en la actualidad. La reducción más reciente, de 25 a 23 categorías se efectuó en enero de 2018. Además, se están realizando estudios de mercado con la intención de gradualmente llegar a una estructura con 10 categorías a finales de 2019. Sin embargo, debido a que el objetivo principal de los salarios mínimos es reducir la pobreza entre los trabajadores que tienen un poder de negociación más débil, es inusual que la diferenciación se haga en función de la ocupación y los niveles de habilidad. Si bien las prácticas de salario mínimo en los países de la OCDE varían, en general, en la mayoría de los países existe un salario mínimo legal único o un salario mínimo que difiere dependiendo del grupo de edad (tomando en cuenta que los jóvenes tienen menos experiencia por lo que el salario mínimo representa un mayor obstáculo para el empleo) y / o de la región (que toma en cuenta las diferencias en el costo de vida y las condiciones del mercado laboral local) (Recuadro 3). Además, el salario mínimo para los trabajadores no calificados asciende al $70 \%$ de la mediana del salario por trabajos de tiempo completo 
en Costa Rica, que es más alto que en todos los países de la OCDE excepto Turquía (Figura 10).

Figura 10. El salario mínimo en Costa Rica es alto

Salario mínimo como porcentaje del salario mediano de trabajadores a tiempo completo, 2016

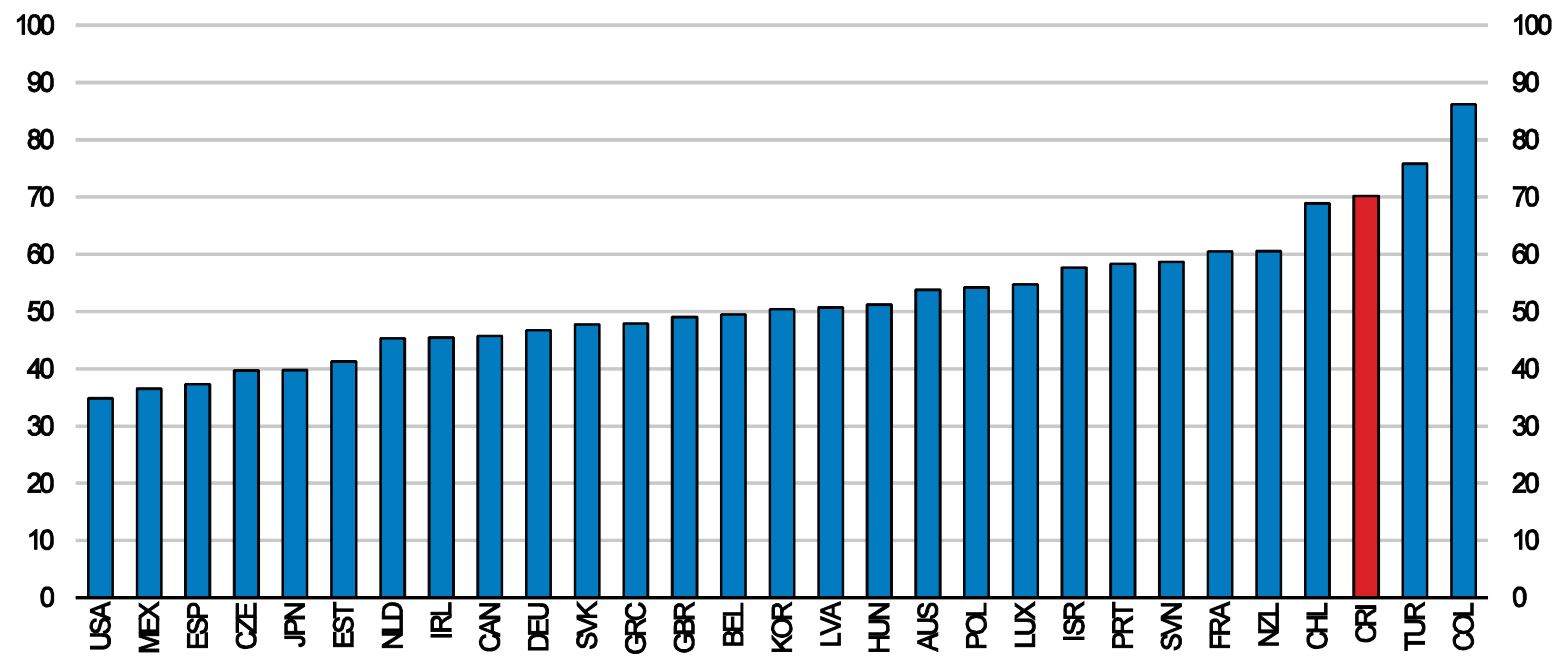

Nota: En el caso de Costa Rica, los cálculos utilizan el salario mínimo para trabajadores no cualificados. Fuente: OCDE, base de datos de estadísticas de la Fuerza de Trabajo.

La estructura compleja del salario mínimo en Costa Rica impone una carga administrativa pesada a las empresas y contribuye a que los niveles de cumplimiento sean bajos. Alrededor de un tercio de los trabajadores reciben un salario inferior al salario mínimo correspondiente, y aproximadamente una cuarta parte de los trabajadores reciben un salario por debajo del mínimo más bajo (Estado de la Nación 2014, OCDE, 2017b). Además, quienes ganan menos que el salario mínimo son de manera desproporcionada jóvenes, trabajadores a tiempo parcial, trabajadores de áreas rurales, inmigrantes y trabajadores de los sectores de la agricultura, la construcción y los servicios domésticos (OCDE, 2017b). Como resultado, la estructura actual del salario mínimo no es muy efectiva para proteger a los trabajadores en condición de desventaja; además, los salarios mínimos pueden obstaculizar el empleo formal, especialmente entre los trabajadores de bajos ingresos, si el límite inferior se establece en un nivel alto, como ocurre en Costa Rica (Recuadro 3). Se estima que para Costa Rica, un aumento del $10 \%$ en el salario mínimo reduciría el empleo formal en aproximadamente un $1 \%$ y las horas de trabajo en un 6\% (Gindling y Terrell, 2007). Esto pone de relieve la existencia de disyuntivas entre la protección de quienes desempeñan empleos relativamente estables del sector formal y el alivio de la pobreza entre los trabajadores más vulnerables.

También existen disyuntivas en la diferenciación de las categorías de salario mínimo con base en los niveles de ocupación, habilidad y calificación. El objetivo de este sistema es alentar a las personas a adquirir habilidades. Sin embargo, es poco probable que esto sea necesario ya que la alta y creciente existencia de primas en el ingreso para quienes cuentan con mayores habilidades en Costa Rica indica que el mercado ya recompensa las habilidades (González Pandiella y Gabriel, 2017). Además, es probable que el efecto 
potencial sobre la adquisición de habilidades sea excedido por el costo de desaliento a la formalidad y la limitación de la movilidad de los trabajadores.

Aunque los esfuerzos actuales para reducir la cantidad de categorías salariales son positivos, se recomienda adoptar en Costa Rica un régimen basado en un salario mínimo único, más modesto, o establecer una menor cantidad de salarios mínimos que difieran según el grupo de edad y / o la ubicación. La diferenciación con base en estos criterios debería fundamentarse en el análisis de las condiciones económicas regionales y el impacto del salario mínimo sobre las oportunidades de empleo formal y sobre las decisiones de los jóvenes en materia educativa. Pero por ejemplo, podría implicar un salario mínimo más alto en San José, tomando en cuenta los costos de vida más altos, y una tasa más baja para los trabajadores jóvenes para reconocer que el salario mínimo es un gran obstáculo para el empleo de las personas con menos experiencia. Esto también debería ir acompañado de mecanismos más estrictos para garantizar el cumplimiento de la ley más estricta (que se tratará más adelante). Además, las reformas al salario mínimo podrían complementarse con medidas para incrementar el diálogo social, debido a que en Costa Rica el salario mínimo depende en gran medida de disposiciones legales, y debido al papel secundario actual de los órganos tripartitos en la formulación de políticas. Por ejemplo, podría reconsiderarse la propuesta de 2003 para la creación de un Consejo Económico y Social (OCDE, 2017b). 
Recuardo 3. Establecimiento de los salarios mínimos en los países de la OCDE

El objetivo principal de los salarios mínimos es reducir la pobreza mejorando la situación de los trabajadores con menor poder de negociación en el mercado laboral. En la mayoría de los países de la OCDE existen salarios mínimos legales y en los pocos países (principalmente nórdicos) que no cuentan con un mínimo legal, una gran parte de la fuerza laboral está cubierta por convenciones colectivas sectoriales que incluyen pisos para los salarios mínimos. Sin embargo, el nivel del salario mínimo, los marcos institucionales para establecer los salarios mínimos, la proporción de trabajadores que ganan el salario mínimo y el nivel de cumplimiento varían según los países. Además, en algunos países los salarios mínimos se utilizan junto con negociaciones colectivas, mientras que en otros, como Costa Rica, son el principal marco institucional para aumentar el poder de negociación salarial de los trabajadores más vulnerables.

Si bien las prácticas en los países varían marcadamente, la OCDE (2015d) identifica algunos principios clave de política para los salarios mínimos:

1. Mejorar la cobertura y los mecanismos para asegurar el cumplimiento de la legislación sobre salarios mínimos, especialmente en países donde la negociación colectiva es débil o está disminuyendo.

2. Garantizar que los salarios mínimos se revisen regularmente, sobre la base de información y asesoramiento actualizados e imparciales, que analicen detalladamente las condiciones actuales del mercado laboral y las opiniones de los actores sociales.

3. Cuando sea necesario, permitir que los salarios mínimos varíen según el grupo de edad (reflejando las diferencias en cuanto a productividad u obstáculos al empleo) y / o la región (reflejando las diferencias en las condiciones económicas), tomando en cuenta que las estructuras simples del salario mínimo tienen más probabilidades de lograr un alto cumplimiento de la ley.

4. Lograr que los salarios mínimos representen los ingresos suficientes para que las personas sobrevivan, mientras se evita dejar sin trabajo a quienes están poco calificados, analizando cuidadosamente sus interacciones con el sistema de beneficios impositivos.

5. Usar los salarios mínimos como una herramienta para aumentar los salarios que se ubican en la parte inferior de la escala salarial, pero acompañarlos con otras medidas impositivas y de beneficios para luchar de manera eficaz contra la pobreza dentro y fuera del trabajo.

En la actualidad hay un debate sobre el impacto del salario mínimo en el empleo. En general, la evidencia empírica sugiere que el impacto negativo de aumentos en el salario mínimo sobre el empleo tiende a ser pequeño, pero los efectos son mayores para los grupos más vulnerables, como la juventud o las personas que se quedan sin empleo durante periodos prolongados, o si el nivel base del salario mínimo es alto (Broecke et al., 2017). Para las economías emergentes, la evidencia sugiere que los salarios mínimos tienen solo un pequeño efecto negativo sobre el empleo y la informalidad, pero en los países donde los salarios mínimos se fijan a un nivel alto, los efectos laborales negativos son más evidentes 
(OIT, 2013; Broecke et al. 2017). El análisis específico de Costa Rica sugiere que un aumento del $10 \%$ en el valor real del salario mínimo reduciría el empleo formal en el sector privado en aproximadamente un 1\% y la jornada laboral en un 6\% (Gindling y Terrell, 2007). Dado que las condiciones del mercado laboral son ahora menos favorables que cuando se llevó a cabo ese análisis, es posible que ese efecto sea ahora mayor. Además, a pesar de que en Costa Rica existen múltiples salarios mínimos, el mayor impacto sobre los salarios y el empleo de los trabajadores formales se encuentra en el extremo inferior de la distribución (Gindling y Terrell, 2007). Esto sugiere que existen disyuntivas importantes entre el apoyo que se brinda a quienes tienen empleos relativamente estables del sector formal y el alivio de la pobreza entre las familias trabajadoras que están luchando para salir adelante (OCDE, 2017b).

Al establecer los niveles del salario mínimo, también suele haber una disyuntiva entre lograr la simplicidad (lo cual fomenta el cumplimiento) y permitir que los salarios mínimos varíen según la región y / o los subgrupos. Alrededor de la mitad de los países de la OCDE tienen salarios mínimos más bajos para los jóvenes; esto puede justificarse porque quienes ingresan al mercado suelen tener una productividad inferior a la de los trabajadores con más experiencia, y puede ayudar a facilitar la transición de los jóvenes hacia la fuerza laboral. Las diferencias regionales para reflejar la variación en las condiciones económicas también son bastante comunes. En algunos países también existen tasas más bajas para pasantes y trabajadores con discapacidades; y en otros también se establece una diferencia del mínimo por sector / ocupación o nivel de tiempo en servicio, pero esto no es común (OCDE, 2015d).

\section{Fortalecimiento de los mecanismos para asegurar el cumplimiento de los reglamentos laborales}

Para combatir los altos niveles de informalidad y mejorar el cumplimiento del pago del salario mínimo es necesario que haya capacidad para controlar, investigar y sancionar las infracciones. La OCDE destacó la necesidad de fortalecer los servicios de inspección laboral en Costa Rica, ya que los inspectores carecen de los recursos básicos y cuentan con escasa información por lo que con frecuencia se limitan a inspeccionar únicamente a las empresas grandes (OCDE, 2017b).

Para abordar estos problemas, en Costa Rica se ha realizado una serie de cambios en la inspección laboral y se planea incorporar otras mejoras nuevas. En 2016, la Dirección Nacional de Inspección del Trabajo (DNI) cambió su enfoque de inspección, otorgando a los inspectores un mayor margen para realizar evaluaciones cualitativas, concentrándose en infracciones graves y haciendo un mejor uso de la información para enfocarse en las inspecciones del lugar de trabajo. Además, su presupuesto se incrementó en un 20\% y su personal en un $40 \%$, lo que resultó en un aumento significativo en la cantidad de trabajadores que son cubiertos por las inspecciones (de aproximadamente 175.700 en el 2014 y 146.100 en el 2015, a aproximadamente 200.600 en el 2016). Sin embargo, no queda claro si esto resultó en una mayor cantidad de infracciones identificadas, o si aumentó el efecto disuasorio. La Estrategia Nacional para la Transición hacia una Economía Formal incluye acciones adicionales, difundiendo al menos una campaña de información sobre las obligaciones de regulación laboral de los empleadores y los planes 
para formular una propuesta que busca mejorar aún más la dotación de recursos de la DNI.

Un problema adicional es que una vez que los incumplimientos de las regulaciones del mercado laboral se envían a los tribunales laborales, el proceso puede ser costoso y lento, lo que desalienta a las personas a denunciar dichos incumplimientos (Gindling y Trejos, 2010; OCDE 2017b). La reciente Ley de Reforma Procesal Laboral, que entró en vigencia en julio del 2017, tiene como objetivo agilizar el proceso judicial y reducir el costo para las personas: ahora las decisiones deben emitirse dentro de un plazo máximo de seis meses, simplificando la estructura de los tribunales laborales, creando unidades de resolución alternativa de conflictos por todo el país para que den servicios de arbritraje, y ofreciendo asistencia legal específica. La propuesta actual de otorgar a los inspectores laborales el derecho a imponer sanciones directamente a los empleadores, sin pasar por los tribunales laborales, también ayudaría a acelerar el trámite y aumentar los efectos disuasorios (proyecto de ley 19.130). En el futuro, las autoridades deberán garantizar que las sanciones impuestas por incumplimiento de las normas laborales sean lo suficientemente altas como para ser disuasivas (OCDE, 2016b).

\section{Facilitación del mercado laboral y la integración social de los inmigrantes}

A diferencia de otros países de América Central, en Costa Rica se experimenta una inmigración neta en la que las personas inmigrantes representan aproximadamente el 11\% de la población adulta (OCDE, 2017b). La mayoría de los migrantes provienen de Nicaragua, están en edad laboral y tienen niveles educativos promedio más bajos que la población nacional. Los migrantes están sobrerepresentados en ocupaciones y sectores poco calificados con altas tasas de informalidad, como son la construcción, los servicios domésticos, la hostelería y servicios de alimentación, y la agricultura (OCDE, 2017b).

La Ley General de Migración y Extranjería del 2010 y la Política Migratoria Integral posterior, ofrecen un marco riguroso para la migración, pero los desafíos de implementación persisten (OCDE, 2017b). El aprovechamiento de las disposiciones para que los inmigrantes con estatus irregular adquieran la residencia legal ha sido menor de lo esperado. Los inmigrantes que desean adquirir estatus legal deben abandonar el país, pagar una multa en la frontera y permanecer fuera del país por un período de tiempo equivalente al tiempo que pasaron de forma irregular en Costa Rica. Sin embargo, estos requisitos se levantaron hasta finales del 2017 para los trabajadores de la agricultura, la construcción y los servicios domésticos, quienes podían adquirir un permiso laboral presentando prueba de su contrato laboral. Este bajo aprovechamiento de la disposición refleja altas tasas de informalidad que impiden que los migrantes irregulares presenten contratos laborales formales, y que estos sean disuadidos por el requisito de salir del país, los largos tiempos requeridos para hacer los trámites, y los altos cargos por presentar la solicitud. Se están realizando esfuerzos para reducir el tiempo para realizar los trámites, por ejemplo, se espera iniciar trabajos para un nuevo sistema informático en el 2018. Este sistema nuevo también incluirá enlaces a los servicios gubernamentales correspondientes que se ofrecen a los migrantes, que deberían mejorar la baja cobertura en comparación con los que se ofrecen a las personas nacionales para programas tales como las transferencias monetarias condicionadas destinadas a fomentar la participación en la educación (OCDE / FUNDEVI, 2017). Dado que el 60\% de los recolectores de café son inmigrantes, principalmente de Nicaragua y Panamá, el plan especial de seguro de salud descrito anteriormente, que debe empezar a implementarse en la temporada de cosecha del 2018, también contribuirá a la integración y el bienestar de los inmigrantes. Sin embargo, si la prioridad de la regularización es identificar a los inmigrantes que están en 
el país y garantizar su protección contra la explotación, la OCDE recomienda que se considere una regularización única que no tenga el requisito de presentar un contrato laboral formal (OCDE, 2017b).

En adelante, la política migratoria podría responder mejor a las necesidades del mercado laboral. Si bien la Ley de Migración es integral y considera que la migración es un motor de desarrollo, esta carece de una visión estratégica. Sería necesario emprender un análisis continuado de la oferta y la demanda del mercado laboral para fundamentar mejor la política de migración, e investigar las medidas para atraer a migrantes calificados en áreas en las que hay escasez de mano de obra (OCDE, 2017b).

\section{Mejoras en la calidad y la eficiencia del sistema educativo}

Ofrecer educación de calidad para todas las personas es una excelente estrategia para impulsar la inclusión y la productividad (OCDE, 2012a). En Costa Rica existe un firme compromiso con la educación, y el gasto público como porcentaje del PIB es más alto que en todos los países de la OCDE; este ha aumentado significativamente, del 5\% del PIB en el 2006 al 7,9\% en el 2017 (OCDE, 2017c; Figura 11, Panel A). Sin embargo, este el alto nivel de gasto no se ha traducido en buenos resultados. Aunque las tasas de matrícula han aumentado en todos los ámbitos, permanecen por debajo del promedio de la OCDE en todas las áreas excepto en la educación primaria (OCDE, 2017c). Más de la mitad de los jóvenes de 25 a 34 años no han terminado la educación secundaria, en comparación con el promedio de la OCDE del 17\% (OCDE, 2017c). Las tasas de repetición y deserción escolar han disminuido en los últimos años, pero continúan siendo elevadas: a la edad de 15 años, casi un tercio de los costarricenses ha repetido al menos un grado y el $30 \%$ ha abandonado la escuela. Aproximadamente un tercio de los que continúan estudiando carecen de competencias fundamentales, y los jóvenes de 15 años de Costa Rica se desempeñan a alrededor de dos años por debajo de sus pares de los países de la OCDE, según el Programa Internacional para la Evaluación de Estudiantes (PISA) (Figura 11, Panel B). 
Figura 11. Los bajos resultados y las desigualdades persisten en la educación a pesar de los altos niveles de gasto

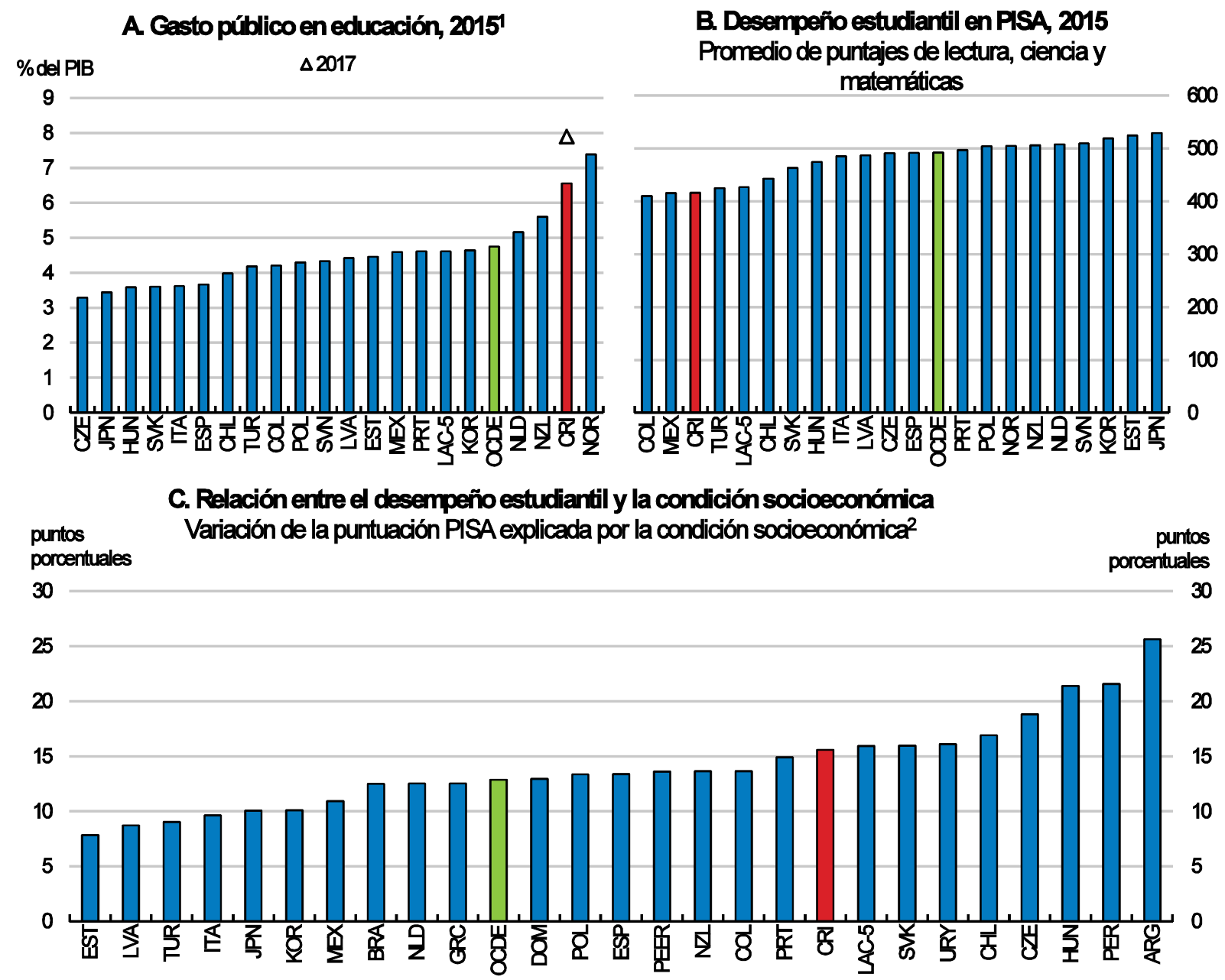

1. Gasto en educación primaria, secundaria, post-secundaria y terciaria. El año de referencia es 2015 o último año disponible.

2. La variación es medida como el cambio promedio en las puntuaciones PISA asociadas con un cambio de una unidad en el índice PISA de estatus económico, social y cultural. Para la OCDE, el dato corresponde al promedio sin ponderar de sus países miembros. Para LAC-5, el dato corresponde al promedio sin ponderar de Argentina, Brasil, Colombia, Chile y México. Para Argentina, los datos hacen referencia únicamente a la Ciudad Autónoma de Buenos Aires.

Nota: Para la OCDE, el dato corresponde al promedio sin ponderar de sus países miembros. Para LAC-5, el dato corresponde al promedio sin ponderar de Argentina, Brasil, Colombia, Chile y México. PEER hace referencia al promedio sin ponderar de los 10 países OCDE, no latinoamericanos, con el PIB per cápita más bajo: Republica Checa, Estonia, Grecia, Hungría, Letonia, Polonia, Portugal, República Eslovaca, Eslovenia y Turquía.

Fuente: OCDE, Indicadores de financiación de la educación; OECD, base de datos PISA 2015; OECD (2016c), Ministerio de Hacienda.

En Costa Rica podrían lograrse mejores resultados con los recursos que invierte. Por ejemplo, Croacia tiene un nivel comparable de PIB per cápita y gasta una cantidad similar por estudiante, pero a los 15 años, los estudiantes croatas tienen el equivalente a 1,5 años escolares por encima de los de Costa Rica. Además, los países con un desarrollo acelerado en América Latina, como Perú, han logrado matricular simultáneamente a más niños y niñas y mejorar los resultados promedio del aprendizaje (OCDE, 2017c); además, 
los resultados no han aumentado de acuerdo con el gasto (Jiménez, 2014). Por ejemplo, una porción significativa (60\%) del rápido aumento del gasto en la última década se debió a incrementos en el gasto salarial, pero no existe evidencia de que, como resultado de esto, la calidad de la enseñanza haya mejorado (OCDE, 2017c). Al mismo tiempo, existe una escasez generalizada y severa de libros de texto y otros materiales de aprendizaje. Alrededor del 38\% de los estudiantes se encuentran en centros educativos en los que los materiales didácticos son escasos; esta es una de las mayores proporciones entre los países que participan en las pruebas del programa PISA (OCDE, 2017c).

Además, las desigualdades en términos de educación continúan siendo considerables. Los niños y niñas que provienen de familias desfavorecidas donde los padres tienen un bajo nivel educativo, los que viven fuera de la capital, o que pertenecen a grupos indígenas o migrantes, tienen menos probabilidades de matricularse para estudiar en todos los niveles y obtienen resultados educativos más bajos (OCDE, 2017c). Los resultados de las pruebas PISA se ven más influenciados por el nivel socioeconómico que en la mayoría de los países de la OCDE (Figura 11, Panel C). Esta desigualdad se manifiesta de manera más marcada en los niveles superiores de educación. Solo el 3,8\% de los jóvenes costarricenses que se ubican en el quintil de ingresos más bajo se matricula en educación terciaria, en comparación con el 57,8\% del quintil más adinerado, una de las mayores diferencias en la región latinoamericana (Figura 12).

Figura 12. Las brechas socioeconómicas en las tasas de matriculación en educación terciaria están entre las más grandes de América Latina

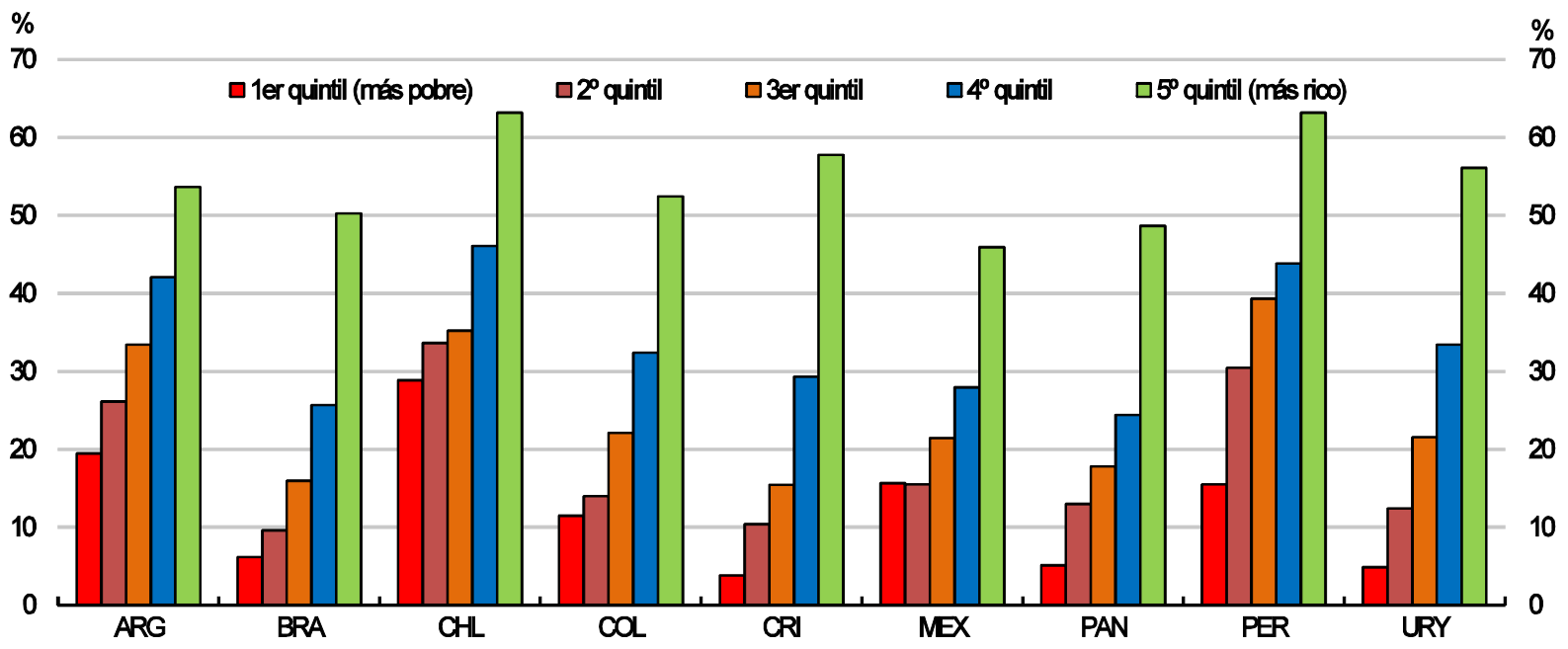

Nota: Para México, los datos se refieren a 2014.

Fuente: CEDLAS y el Banco Mundial, Tasas netas de Matriculación: Educación terciaria, Base de datos socioeconómica para América Latina y Caribe (SEDLAC).

La asignación de fondos plantea problemas en cuanto a la eficiencia y la equidad. Dar prioridad a los años formativos ayuda a superar las diferencias relacionadas con los antecedentes familiares y proporciona a la niñez las habilidades fundamentales necesarias para los logros que podrán alcanzar en años posteriores. Aunque es necesario que los países cuenten con un sistema de educación terciaria de alta calidad con recursos suficientes, el gasto público en educación terciaria tiende a ser regresivo (OCDE, 2007). En Costa Rica, la inversión en educación básica es relativamente baja, con un gasto acumulado a la edad de 15 años de alrededor de la mitad del promedio de los países de la 
OCDE. Si bien el gasto por alumno en educación preescolar (4 y 5 años) ha aumentado, continúa estando por debajo del gasto en otras economías emergentes en América Latina, y representa solo un tercio del gasto promedio de los países de la OCDE (OCDE, 2017c). En contraste, el gasto público por estudiante de educación terciaria es uno de los más altos entre los países de la OCDE y América Latina (OCDE, 2017c). Además, el gasto en educación primaria ha aumentado rápidamente, representando el 35\% del gasto adicional, aunque las tendencias demográficas hacen que la matrícula en educación haya disminuido, mientras que en educación secundaria la presión va en aumento.

Dirigir los recursos hacia los estudiantes más desfavorecidos también mejora la eficiencia y la equidad (OCDE, 2007). En Costa Rica existe una serie de iniciativas positivas en esta área, que incluyen una variedad de programas para promover el acceso a la educación mediante el suministro de alimentos, transporte, becas y transferencias monetarias condicionadas a través de los programas Avancemos y Puente al Desarrollo. Además, el programa Yo me apunto inició en 2015 y está dirigido a estudiantes en situación de desventaja y en riesgo de abandonar la educación (se trata más adelante). Sin embargo, se podrían lograr mayores avances en esta área a través de una focalización más sistemática. Por ejemplo, a diferencia de muchos países de la OCDE, no existen mecanismos sistemáticos para redistribuir recursos entre las escuelas en situación de desventaja a fin de garantizar que los estudiantes en riesgo reciban el apoyo necesario (OCDE, 2017c).

\section{Lograr que los resultados educativos se conviertan en el principal objetivo de la política, y reajustar la composición del gasto}

Existe una disposición constitucional para que el gasto en educación aumente al 8\% del PIB en el 2018. Siendo la educación una piedra angular del exitoso modelo social de Costa Rica, un objetivo de gasto educativo que está consagrado en la Constitución es único entre los países de la OCDE. Pero no existe un fundamento subyacente para este objetivo específico, que representa un mayor nivel de gasto que en cualquier país de la OCDE. Es necesario hacer un cambio en el enfoque, pasando de los aportes a los resultados, con el fin de garantizar que este alto nivel de inversión corresponda con buenos resultados (OCDE, 2016b, OCDE, 2017c). Se recomienda que los objetivos generales de rendimiento sean establecidos y respaldados mediante un régimen riguroso de evaluación. Se requiere establecer una orientación clara y verificable basada en el rendimiento para medir el éxito de las políticas educativas. Aunque se han realizado mejoras en la recopilación y manejo de datos (OCDE, 2017c), es necesario que haya información de mejor calidad sobre el rendimiento escolar y del alumno, que permita hacer una mejor evaluación de los resultados, dirigir los recursos donde más se necesitan y realizar mejoras fundamentadas en la evidencia (discutidas más adelante).

Equilibrar la composición del gasto para priorizando los años iniciales de formación sobre la educación terciaria también permitiría mejorar los resultados y resolver los problemas de desigualdad. En particular, los recursos deberían canalizarse hacia la educación y atención de la primera infancia y la educación secundaria para solucionar las deficiencias actuales y reflejar mejor los patrones demográficos. Esto podría lograrse a la vez que se atiende el crecimiento futuro previsto en la matrícula de educación terciaria, mediante reformas en los planes de financiación para las universidades (ver más abajo) (OCDE, 2016b). 


\section{Aumento en el acceso a la educación y atención de la primera infancia de calidad}

La educación y atención de la primera infancia (EAPI) de calidad contribuyen a reducir el impacto de los antecedentes socioeconómicos y mejorar la adquisición de habilidades, las perspectivas de empleo y las ganancias en el futuro (Cunha et al., 2006; OCDE, 2007; Almond y Currie, 2011; OCDE, 2016b). La expansión de los servicios de los programas de EAPI también facilitaría la participación femenina en el mercado laboral, particularmente dado el considerable obstáculo que las responsabilidades de cuido representan para las mujeres costarricenses (Figura 8).

A pesar de que se ha dado una significativa ampliación de la matrícula, los programas de EAPI continúan siendo subdesarrollados. En el año 2000, solo el 7\% de los niños y niñas de 4 años y el 83\% de los niños y niñas de 5 años se matricularon. Para el 2014, estas cifras habían aumentado al 63\% de los niños y niñas de 4 años y al $90 \%$ de los niños y niñas de 5 años. Sin embargo, las tasas de matrícula continúan siendo bajas según los estándares de la OCDE, particularmente entre la niñez de 3 años o menos. Solo el 6,5\% de los niños y niñas de 3 años están matriculados en los programas de EAPI, en comparación con más del $40 \%$ en Brasil, Chile y México, y el $70 \%$ en los países de la OCDE. Además, las tasas de matrícula son mucho más bajas para los niños y niñas que viven en áreas rurales y de familias de bajos ingresos, y estas disparidades están creciendo (Estado de la Nación, 2015, OCDE, 2016b, OCDE, 2017c). Además, es necesario mejorar la calidad, ya que muchos servicios se centran en la atención básica y la nutrición, con una limitada atención al desarrollo de habilidades (OCDE, 2017c).

Las autoridades costarricenses reconocen la importancia de ampliar los programas de EAPI. El actual Plan Nacional de Desarrollo incluye una meta para ampliar la cobertura del ciclo Interactivo II (4 años) de 63\% a 69,5\% entre el 2015 y 2018, dando prioridad a 75 distritos meta en los que la matrícula es baja y la tasa de pobreza es alta (MIDEPLAN, 2014). En el primer semestre del 2017, la cobertura de Interactivo II estaba en 66,1\%, y los datos preliminares sugieren que se han logrado nuevos avances en la segunda mitad del 2017. A pesar de que esta ampliación, incluyendo la focalización en las regiones desfavorecidas es positiva, es importante preparar un plan de ampliación más ambicioso con una mayor focalización de los recursos para alcanzar a los niños y niñas más desfavorecidos de manera más efectiva y reducir la brecha socioeconómica (OCDE, 2017c).

También se han adoptado medidas para mejorar la calidad. En el 2014, se introdujo un nuevo plan de estudios preescolar para alinear los programas durante los dos años de educación preescolar (Interactivo II y ciclos de Transición, que cubren a niños y niñas de 4 a 5 años). Su objetivo es preparar mejor a la niñez para la escuela primaria, adoptando un enfoque más integral del desarrollo y dando mayor énfasis al desarrollo de las habilidades de alfabetización temprana. Sin embargo, la implementación ha sido un desafío debido a la poca capacidad de los docentes, el tamaño de los grupos de clase y el compromiso limitado de los padres. Se necesita una mayor capacitación y apoyo para los docentes y los padres, para que estén en mejores condiciones de ayudar a los niños y niñas, en particular a los que están en situación de desventaja, a desarrollar las habilidades de alfabetización temprana y que logren pasar exitosamente a la escuela primaria (OCDE, 2017c). También se requiere hacer mayores esfuerzos en cuanto a la garantía y control de calidad. Aunque los servicios de atención están sujetos a un conjunto de estándares mínimos, los requisitos son limitados y el control no es el 
adecuado. Es necesario establecer y aplicar un conjunto más amplio de normas mínimas en todos los centros de atención (OCDE, 2017c).

Otra iniciativa importante reciente es el desarrollo y la implementación actual de una nueva política para la primera infancia, que va dirigida a apoyar el desarrollo integral de los niños y niñas de 0 a 8 años. Abarcando el período hasta el año 2021, esta iniciativa incluye planes para aumentar la provisión de centros de atención a nivel de las comunidades y crear un sistema general de gestión de la información para mejorar la formulación y la focalización de políticas (OCDE, 2017c). Además, el Consejo Superior de Educación recientemente estableció una política para hacer que completar la educación preescolar será un requisito para obtener matrícula en la escuela primara. Aunque la educación preescolar ya es obligatoria a partir de los 4 años y el derecho constitucional de acceso universal a la educación primaria de todas formas tendría prioridad, esta política es potencialmente útil para fomentar la matrícula en preescolar. Esta política se aplicará gradualmente a lo largo de 2 años y para apoyar su implementación, se están realizando acciones para identificar a todos los niños y niñas que no están matriculados en preescolar, y los niños y niñas en el sistema de cuido que están en edad preescolar también recibirán servicios educativos.

Un aumento de los fondos públicos asignado para los programas de EAPI facilitaría nuevas mejoras en cuanto al acceso y la calidad. Como se planteó anteriormente, esto debe lograrse reequilibrando el presupuesto actual, en lugar de aumentar los niveles de gasto público en educación que ya son altos. Si bien la educación preescolar actualmente se financia con cargo al presupuesto de educación, se le asignó solo el 9,3\% de los fondos en el 2016 (OCDE, 2017c). Por el lado de la atención, es difícil estimar con precisión el financiamiento público, pero parece que es bajo (OCDE, 2017c). La financiación del Fondo de Desarrollo y Asignaciones Familiares (FODESAF), que es la fuente principal, ascendió a aproximadamente el 0,2\% del PIB en el 2016, pero también existen otras fuentes, como las municipalidades y las organizaciones privadas y de la sociedad civil. Poner a todo el sector de los programas de EAPI bajo la dirección y presupuesto del Ministerio de Educación Pública (MEP) facilitaría la ampliación de los servicios y mejorar la calidad.

Establecer una entidad líder para todo el sector también permitiría mejorar la coordinación. A pesar de que Costa Rica no es el único país en el que varios ministerios y entidades participan en los programas de EAPI, es poco común no contar con alguna institución con responsabilidad general para implementar la política nacional. El liderazgo para la prestación de servicios de educación preescolar se concentra actualmente en el Ministerio de Educación Pública, pero no existe una entidad líder para los servicios de atención, en los cuales la dirección está dividida en tres ministerios / entidades gubernamentales principales: el Ministerio de Salud, el Patronato Nacional de la Infancia (PANI) y el Instituto Mixto de Ayuda Social (IMAS). Cada entidad gestiona sus propios recursos, establece sus propios estándares y objetivos y determina sus propios planes de expansión. En el 2014 se creó la Red Nacional de Cuido y Desarrollo Infantil (REDCUDI) para mejorar la coordinación entre los diferentes proveedores públicos y privados de servicios de atención; por medio de la Comisión Consultiva de la Red Nacional de Cuido y Desarrollo Infantil1 a cargo de las competencias interinstitucionales y de los varios tipos de servicios de cuidado infantil, y dirigidos a recomendar políticas generales y directrices estratégicas para el sistema de atención y desarrollo infantil. Esta es una reforma muy positiva, y REDCUDI está bien posicionada para ayudar a avanzar en la coordinación por el lado técnico. Sin embargo, aunque se están implementando procesos de articulación mejorados entre el MEP y REDCUDI con el fin de fortalecer a 
este último ente, actualmente carece de influencia política, capacidad institucional y autoridad para tener injerencia en el grado de transformación necesario en el sector (OCDE, 2017c). Conferir la responsabilidad de todo el sector al MEP ayudaría a fortalecer el liderazgo y a nombrar un claro defensor de la reforma.

Costa Rica reconoce el valor de mejorar la coordinación en educación, y más en general, en el sector social. Con el objetivo de mejorar la coordinación en el sector social, en mayo de 2016 se presentó a la Asamblea Legislativa un proyecto de ley (No. 19.960) para fortalecer el actual Ministerio de Desarrollo Humano e Inclusión Social, para darle los recursos y el personal que le permitan cumplir su mandato actual como el coordinador del sector. El Ministerio actuaría como la agencia que coordine los ministerios de Educación, Salud, Trabajo y Desarrollo Social, así como el PANI, con el fin de ofrecer servicios integrados. Esto podría facilitar el desarrollo de un enfoque holístico para el desarrollo de la niñez temprana, y para reducir más efectivamente las desigualdades al atacar múltiples barreras afrontadas por niños y niñas de entornos desfavorecidos.

En años recientes, Costa Rica ya ha avanzado hacia un enfoque más integral y más direccionado para los servicios sociales, por ejemplo, estableciendo la estrategia Puente al Desarrollo en 2015 (OCDE, 2017b). Liderado por el IMAS, este programa unificó alrededor de 30 programas separados en un único sistema. Esta estrategia tiene varios aspectos positivos. Por ejemplo, usa un sistema de información recientemente desarrollado para direccionar servicios a las familias que tienen las mayores necesidades. Esto es más efectivo para reducir las desigualdades y mejorar la eficiencia en el gasto que el sistema previo, en el que las familias tenían que identificarse y procurar las ayudas por sí mismas, lo que resultaba en programas que beneficiaban bastante a las familias de ingresos medios y altos (OCDE, 2016b). El programa también implica una participación más activa de los trabajadores sociales, con asistencia diseñada para las necesidades individuales de las familias, y provista condicionalmente a requisitos que sean relevantes para sus circunstancias, como la participación en programas de entrenamiento o la asistencia de los niños a clases. Los datos recolectados como parte de este programa ya se usan para mejorar la prestación del servicio. En el futuro, estos datos también serán útiles para la evaluación sistemática de estos programas. Como se resaltó en la Evaluación Económica de 2016 y en Araújo and Guichard (2018), la evaluación permitirá mejoras adicionales a los programas, y facilitará lograr mejoras en la eficiencia del gasto al identificar y permitir que los recursos se centren en las intervenciones más efectivas y al asegurar que los programas lleguen a los que más los necesitan.

Aunque algunas iniciativas ya se están implementando, también se requieren mayores esfuerzos para cubrir más efectivamente a los niños y niñas más desfavorecidos. El objetivo de la ampliación preescolar a 75 distritos en los que la matrícula es baja y existen altas tasas de pobreza, como parte del Plan Nacional de Desarrollo, es positivo. Además, la nueva política para la primera infancia incluye planes destinados a crear un sistema general de gestión de la información para mejorar la formulación y la focalización de políticas (OCDE, 2017c). Como un paso hacia el logro de este objetivo, se espera que en el primer semestre del 2018 esté lista una base de datos georreferenciada de centros e identificadores de niños y niñas. Sin embargo, la información disponible sobre la demanda actual y futura prospectiva para fundamentar la expansión continúa siendo limitada (OCDE, 2017c). También se están implementando iniciativas para ampliar el alcance, con el fin de identificar y matricular a los niños y niñas en edad preescolar que todavía no están en el sistema educativo. Por ejemplo, un censo puerta a puerta en Heredia permitió identificar a 160 niños y niñas en edad preescolar que no estaban en el sistema educativo, y de este modo 131 de ellos fueron matriculados. Como parte de un 
programa con UNICEF, los facilitadores de la primera infancia serán empleados en 43 distritos prioritarios para identificar a los niños y niñas que no están matriculados en educación preescolar.

Todavía hay espacio para continuar implementando el enfoque actual para ampliar la cobertura de la educación preescolar mediante de la red existente de escuelas primarias. Esta red llega a las partes más remotas del país y muchas escuelas primarias tienen capacidad adicional debido a la disminución de la cantidad de estudiantes. Una mayor atención a la prestación de servicios de los programas de EAPI a través de enfoques alternativos al modelo tradicional basado en los centros educativos, también podría permitir llegar a las comunidades más desfavorecidas. En el 2014, alrededor de 1.500 niños asistieron a servicios de atención comunitaria brindados en los hogares de "madres comunitarias" y más de 100.000 niños se beneficiaron del programa de visitas domiciliarias de los Centros de Educación y Nutrición Centros Infantiles de Atención Integral (CEN-CINAI). Sin embargo, a diferencia de otros países de América Latina, como Colombia, Bolivia y México, los programas que se implementan a nivel de las comunidades y familias no están bien desarrollados. Mejorar dichos programas podría ser una forma eficaz de lograr una cobertura más amplia, particularmente en áreas remotas, y también ayudar a fortalecer los entornos de aprendizaje en el hogar.

Las autoridades costarricenses están desarrollando un estudio de factibilidad para explorar arreglos alternativos para la prestación y el financiamiento de servicios de atención, así como las formas de administrarlos. Los servicios públicos de atención actualmente son gratuitos para toda la niñez. Como una forma de ampliar los servicios públicos de atención de una manera equitativa, también se podría considerar la introducción de un mecanismo de cobros con base en los ingresos. La mayoría de las mujeres que se ubican en primeros tres quintiles de ingresos, indican que las responsabilidades de cuido de familiares representan un obstáculo para el trabajo (Figura 8). Con frecuencia no tienen acceso a los servicios de atención pública, y es poco probable que puedan pagar servicios de atención privada. La introducción de un mecanismo de cobro con base en los ingresos, similares a los que existen en Francia o Noruega, podría permitir a los padres acceder a los servicios de atención a un menor costo y al mismo tiempo aumentar los ingresos no gubernamentales para la ampliación de los programas de EAPI, pero debería ser administrado con cuidado para asegurar que los cobros no estén basados en la capacidad de pago y no constituyan una barrera para el acceso (OCDE, 2017c). Además, se recomienda promover las alianzas con los gobiernos locales y los proveedores privados como un medio para mejorar el acceso y la calidad. La participación de las municipalidades en la financiación de los servicios de atención pública continúa siendo limitada. Los Centros de Cuido y Desarrollo Infantil (CECUDI) fueron creados en 2010 para incentivar la inversión local; mediante este programa, el costo de los centros es compartido entre el gobierno nacional y las municipalidades. Por ejemplo, en Curridabat, el gobierno nacional cubre los costos de construcción y la municipalidad proporciona el terreno y la gestión de los servicios, con donaciones de otros participantes locales. Si bien este es un modelo prometedor, reducir la complejidad administrativa facilitaría una mayor expansión de las asociaciones entre el gobierno central, las municipalidades y los proveedores privados, ya que las demoras en los trámites de aprobación y los procedimientos operativos actualmente representan un obstáculo (OCDE, 2017c). Además, es necesario contar con estándares mínimos claros y de cumplimiento obligatorio para garantizar que todos los servicios cumplan con los estándares de calidad, independientemente del proveedor (mencionado anteriormente). 


\section{Mejoras en la calidad de los docentes y los centros educativos}

Mejorar la calidad de los docentes y de quienes están a cargo de la educación es el desafío más importante para la educación básica en Costa Rica. En los últimos años se han dado pasos importantes para mejorar el nivel de capacitación requerido para ingresar a la docencia, y prácticamente todos los docentes ahora cuentan con un título de educación terciaria. Sin embargo, existen deficiencias en la formación, reclutamiento y apoyo de los docentes y las personas encargadas de la educación en Costa Rica, y no hay claridad en cuanto a las expectativas y la rendición de cuentas. Además, la escasa capacidad para evaluar el sistema escolar limita la formulación de políticas que podrían mejorar los resultados educativos y reducir las desigualdades, por ejemplo, dirigiendo la ayuda y los recursos hacia aquellas áreas en que más se necesitan (OCDE, 2017c).

Las evaluaciones de los docentes revelan lagunas significativas en el conocimiento de los docentes sobre las materias básicas, y la opinión de que muchos de los programas de formación docente inicial son de muy baja calidad es generalizada (OCDE, 2017c). La gran mayoría de los programas de formación docente no están acreditados y las universidades tienen autonomía total sobre los programas. Como parte de los esfuerzos para aumentar la calidad de la formación inicial de los docentes, se está analizando una propuesta para que la acreditación sea obligatoria para todos los programas de enseñanza en universidades privadas (Proyecto de ley 19.549). La OCDE también recomienda que se fortalezca el proceso inicial de selección de docentes y apoyar a los nuevos, mediante la introducción de un examen de ingreso, un período de prueba y un programa estructurado de inducción (OCDE, 2017c).

En Costa Rica tampoco existe un sistema de evaluación efectivo de los docentes existentes. En gran medida, las evaluaciones son un requisito administrativo, y prácticamente todos los docentes reciben calificaciones positivas (OCDE, 2017c). También hay carencia de apoyo continuo y oportunidades para el desarrollo profesional. La OCDE recomienda que se introduzcan mecanismos para alentar y apoyar a los docentes a aprender y desarrollarse, incluyendo el establecimiento de un marco para la evaluación y el desarrollo profesional (OCDE, 2016b, OCDE, 2017c).

Durante la última década, se ha emprendido en Costa Rica una serie de iniciativas con el fin de fortalecer los centros educativos y mejorar su calidad. Entre estas hay una iniciativa importante para modernizar el plan de estudios que se completará en el 2018. Este nuevo plan de estudios da énfasis al pensamiento crítico sobre el aprendizaje memorístico, y representa una gran promesa como medio para involucrar al estudiantado para que se conviertan en alumnos más activos y garantizar que adquieran habilidades más relevantes para la sociedad y el mercado laboral (OCDE, 2017c). Sin embargo, a pesar de la capacitación, muchos docentes no están preparados adecuadamente para impartir el nuevo plan de estudios; además, las debilidades en cuanto a las habilidades pedagógicas, y la escasez de materiales didácticos, como los libros de texto, son obstáculos importantes para la implementación en el aula.

Los esfuerzos adicionales que se han realizado para mejorar la calidad de los centros educativos incluyen el establecimiento de una unidad dedicada a la gestión y evaluación de la calidad dentro del MEP, la elaboración de directrices para la autoevaluación de los centros, y la reforma al sistema de supervisión académica. Sin embargo, las políticas y prácticas de evaluación de los centros de enseñanza aún se encuentran en una etapa incipiente. La OCDE recomienda fortalecer aún más la supervisión de los centros educativos, estableciendo estándares más claros para la evaluación de la calidad de estos y los criterios para dirigir los esfuerzos hacia los centros que más lo necesitan (OCDE, 
2017c). El establecimiento de indicadores comunes, la recopilación de datos compartidos y un sistema de información único mejorarían la rendición de cuentas y permitiría que los datos se usen para realizar mejoras. En Costa Rica debería considerarse la creación de una entidad de evaluación independiente, dedicada a promover políticas que se fundamenten más en evidencias y que estén más orientadas hacia el logro de resultados, así apoyar el desarrollo de una cultura de evaluación más rigurosa en todos los niveles del sistema.

La creciente consciencia en Costa Rica de que las escuelas cumplen una función central en mejorar los resultados educativos se refleja en la declaración El Centro Educativo de Calidad como Eje de la Educación Costarricense, de 2008, en medidas para mejorar las habilidades de liderazgo en las escuelas, y en la reforma de 2010 para redirigir la función de la supervisión a las escuelas de un control externo hacia un liderazgo interno. Los líderes en las escuelas siguen teniendo una función limitada como líderes de enseñanza (por ejemplo, estableciendo objetivos para la mejora, emprendiendo observación en la clase, y aumentando la motivación y el acompañamiento a los maestros). Por consiguiente, la OCDE ha recomendado que Costa Rica mejore la relevancia de los programas de desarrollo de liderazgo inicial y durante la enseñanza, y que establezca esquemas de aprendizaje entre pares. La creación de puestos de liderazgo en la enseñanza dentro de las escuelas, con responsabilidad clara en el desarrollo profesional de los maestros, mejoraría el conocimiento pedagógico y la calidad de la enseñanza (OCDE, 2017c).

Contar con mejor información sobre el rendimiento de los estudiantes y los centros educativos permitiría que los recursos y el apoyo sean destinados a los centros de enseñanza donde el rendimiento es bajo. Aunque en Costa Rica se han llevado a cabo evaluaciones nacionales que incluyen a una muestra pequeña de centros educativos desde el 2007, esto se ha hecho principalmente con el fin de informar a los hacedores de política si los estudiantes están cumpliendo con los objetivos nacionales de aprendizaje, y no tienen consecuencias para los centros educativos, los docentes o el estudiantado. Sería importante que en Costa Rica se considerara la aplicación del censo para la evaluación de los centros de enseñanza, de manera que el desempeño de los centros individuales pueda compararse con estándares nacionales y con otros centros similares, y para que el MEP cuente con datos de mejor calidad para fundamentar las políticas y la asignación de recursos (OCDE, 2017c). Cuando se comparan los resultados a nivel de los centros educativos, los resultados de desempeño podrían ponerse en contexto para poder hacer comparaciones justas. Por ejemplo, en Brasil y Colombia se utiliza un índice multidimensional que toma en cuenta el rendimiento del estudiante, el progreso escolar, la repetición de grado y factores relacionados con el entorno escolar (OCDE, 2016d).

\section{Reducción de la alta tasa de deserción}

Para solucionar el problema de la alta tasa de deserción se requiere la aplicación de un enfoque multifacético que incluya medidas para preparar a los docentes de manera que tengan la capacidad de impartir educación de alta calidad, y un plan de estudios relevante que mantenga al estudiantado participando activamente (como se discutió más arriba), en combinación con medidas más específicas para identificar y brindar apoyo adicional a estudiantes en riesgo. En Costa Rica ya se está avanzando en esta área, en particular a través del programa Yo me apunto, que se lanzó en el 2015. El programa pretende reducir la tasa de deserción escolar en 85 centros educativos de secundaria seleccionados mediante la detección y la intervención tempranas, empezando desde la educación primaria. Los centros educativos de secundarios que participan en el programa han reducido sus tasas de deserción de 14,4\% en 2013 a 9,2\% en 2017. Aunque este programa 
apenas empieza, tiene el potencial de crear las condiciones para el éxito académico en las comunidades más desfavorecidas (OCDE, 2016b, OCDE, 2017c). Por lo tanto, la OCDE recomienda que este programa sea evaluado de manera sistemática $\mathrm{y}$, si se determina que tiene éxito, se amplíe (OCDE, 2016b).

Al igual que muchos países, Costa Rica enfrenta el desafío de transformar el enfoque de su sistema de educación secundaria superior para que en lugar de preparar a una pequeña elite para la universidad, se concentre en la formación de un grupo más amplio de estudiantes, incluyendo a los que ingresarán al mercado laboral o buscarán otras opciones de formación. La creciente brecha en cuanto a habilidades, donde los trabajadores poco calificados se enfrentan a un mercado laboral cada vez más difícil, mientras que aumentan las bonificaciones para los trabajadores calificados, destaca la necesidad de que el sistema sea más inclusivo. La OCDE recomendó anteriormente el desarrollo de una opción de educación vocacional en estrecha relación con los empleadores.

Para desarrollar un sistema más inclusivo que satisfaga mejor las necesidades del mercado laboral, se dará un enfoque creciente a los centros de educación técnica. En Costa Rica, estos centros de educación técnica incluyen desde el sexto hasta el noveno grados, así como niveles de educación secundaria superior, y los alumnos estudian para obtener títulos técnicos y académicos (Bachillerato) simultáneamente. Poco más de una quinta parte de los que ingresan a la educación secundaria están cursando programas técnicos; esta cifra es mucho más baja que en los países de la OCDE, Sin embargo, esta opción ha venido creciendo y existen planes ambiciosos para una mayor expansión. Fuera del sistema de educación formal, el Instituto Nacional de Aprendizaje (INA) se financia a través de impuestos a los empleadores y ofrece cursos breves de educación y formación vocacional (EFP). Los programas del INA sirven como una vía alternativa hacia el mercado laboral para los estudiantes que han abandonado la educación secundaria, pero la falta de coordinación con el MEP hace que sea difícil para los estudiantes volver a ingresar al sistema de educación formal (OCDE, 2017c). Sin embargo, también se espera que el trabajo que se está desarrollando sobre el marco de cualificaciones haga posible que los estudiantes reciban créditos dentro del sistema de educación formal por sus calificaciones del INA. De acuerdo con la recomendación de la OCDE de desarrollar la formación profesional en estrecha colaboración con los empleadores (OCDE, 2016b), también se están desarrollando iniciativas conjuntas con los empleadores, y tanto el INA como el MEP están estableciendo programas que incluyen más experiencia práctica en el lugar de trabajo. En diciembre del 2016, el gobierno aprobó una nueva etapa de aprendizaje en la educación secundaria superior y, a principios del 2017, se empezó a implementar un programa piloto a pequeña escala con la participación de cuatro centros de educación técnica que preparan a los estudiantes en el sector automovilístico. Los estudiantes que optan por esta opción de pasantía deben haber completado los primeros años de educación secundaria, y dividirán su tiempo entre el aula y el lugar de trabajo. Después de completar el programa al final del $12^{\circ}$ grado, los estudiantes recibirán un diploma de habilidades técnicas de nivel medio y el Bachillerato de educación secundaria. Paralelamente, en la Asamblea Legislativa se está discutiendo una reforma para establecer una opción de pasantía que también regule la situación contractual de los estudiantes en el lugar de trabajo (proyecto de ley 19.378). Se recomienda que estos programas piloto sean monitoreados y evaluados, y que se sigan explorando opciones para fomentar la educación vocacional.

A pesar de estos esfuerzos, algunas características institucionales frenan el atractivo de los centros de educación técnica y la expansión del sistema de educación vocacional. En Costa Rica no existe el tipo de centros especializados de educación vocacional secundaria 
superior que se encuentran en muchos países, que pueden ser una manera para desarrollar habilidades técnicas, la participación de los patronos y las oportunidades de aprendizaje basadas en el trabajo, mientras los estudiantes posponen la elección de carrera hasta el nivel de secundaria superior. En lugar de esto, en Costa Rica la mayoría de los centros de educación técnica son prácticamente, en gran medida, instituciones académicas ya que abarcan del sexto al noveno grados, así como los grados superiores de educación secundaria, y todos los estudiantes de último año obtienen tanto el Bachillerato como un título técnico. Por el contrario, en muchos países se mantiene un plan integral de estudios durante la educación secundaria inferior y luego se introduce una opción vocacional en la educación secundaria superior. Para dar cabida a las diferentes opciones, los centros de educación secundaria inferior y superior están separados; esto tiene la ventaja de que el estudiantado puede posponer la escogencia de una opción de especialización vocacional hasta que llegan a la educación secundaria superior, facilitándoles escoger una mejor opción de estudios. También se pospone el momento en que los estudiantes deben viajar o vivir lejos de su hogar para emprender la educación secundaria superior especializada. Por lo tanto, la OCDE recomienda que en Costa Rica se considere avanzar gradualmente hacia la separación de centros educativos de educación secundaria superior e inferior (OCDE, 2017c). Esto permitiría el desarrollo de institutos técnicos especializados con la misión central de enseñar habilidades técnicas, e incluir el establecimiento de mayores vínculos con los empleadores y el mercado laboral. Esto también podría implicar migrar hacia los sistemas duales que existen en países como Austria, Alemania y Suiza, donde los estudiantes que han elegido la opción de pasantía no tienen el equivalente del Bachillerato de educación secundaria de Costa Rica, sino que normalmente tienen la opción de estudiar para exámenes que les permitan obtener el ingreso a la universidad posteriormente. Esto podría llevarse a cabo junto con las reformas al sistema actual para obtener el título de Bachillerato de educación secundaria (que se analiza a continuación).

Además de lograr que la educación vocacional se convierta en una opción más atractiva, la reforma al sistema de evaluación de la educación secundaria (Bachillerato) también podría contribuir a reducir la tasa de deserción escolar. El Bachillerato tiene un criterio de pase binario (el estudiante aprueba o reprueba), por lo que el tercio de los estudiantes que continúan estudiando hasta el último año pero no aprueban los exámenes de Bachillerato, no tienen nada que mostrar por sus esfuerzos, con lo cual para muchos el atractivo de los estudios secundarios superiores es limitado (OCDE, 2017c). La OCDE recomienda que el criterio actual de pase binario sea sustituido por un límite de aprobación para cada uno de los seis temas individuales, de modo que se reconozcan mejor los logros parciales y que se considere la adopción de un sistema de calificación más flexible, como se ha hecho en otros países como Australia y Nueva Zelanda (OCDE, 2017c).

\section{Abordaje de la escasez de habilidades}

El sistema educativo no se ha mantenido al día con la transformación estructural que se está llevando a cabo hacia sectores de alto contenido tecnológico y de habilidades, lo que ha provocado una escasez de habilidades a pesar de que los niveles de desempleo son altos. Los desajustes en cuanto a la falta de habilidades perjudican el crecimiento de la productividad; la falta de personal calificado es uno de los principales obstáculos mencionados por los empresarios para la innovación entre las empresas costarricenses, y la mayoría de los empleadores considera que el sistema educativo no satisface las necesidades de la economía (UCCAEP, 2011; Adalet McGowan y Andrews, 2015; MICITT, 2016). Las mejoras en las habilidades básicas aumentaría significativamente el crecimiento inclusivo, y las iniciativas como el nuevo plan de estudios y el desarrollo de 
la educación vocacional deberían preparar mejor a los estudiantes para la educación superior o el lugar de trabajo.

La OCDE también destaca la necesidad de adoptar reformas significativas en la educación terciaria (OCDE 2017c). Las universidades costarricenses tienen un alto nivel de autonomía y pocos incentivos para responder a las necesidades del mercado laboral. Si bien la autonomía universitaria es un principio respetado en todos los países de la OCDE, esta suele ir acompañada de rigurosos mecanismos rectores y para la rendición de cuentas, a fin de garantizar que las instituciones de educación terciaria cumplan con los estándares básicos de calidad y sirvan a los propósitos de la sociedad. En Costa Rica, dichos mecanismos de rendición de cuentas son muy limitados, y no existe un órgano de coordinación permanente ni un plan a largo plazo para dirigir el sector hacia objetivos comunes (OECD, 2017c).

El gasto público en educación terciaria como proporción del PIB prácticamente se ha duplicado desde el año 2000 y al día de hoy representa el 1,5\% del PIB (OCDE, 2017c). La gran mayoría de los fondos (alrededor del 90\%) para las universidades públicas proviene del Fondo Especial para la Educación Superior (FEES) del gobierno. A pesar de su tamaño, no cuenta con su propio marco rector, de monitoreo y evaluación, y crea incentivos para aumentar los espacios en los cursos que son menos costosos de impartir, resultando en un sesgo hacia las ciencias sociales. La cantidad reducida de graduados y posgraduados en ciencia, tecnología, ingeniería y matemáticas (STEM, por sus siglas en inglés) en todas las carreras plantea un obstáculo significativo a la aspiración de Costa Rica de desarrollar una economía basada en el uso intensivo de la tecnología y del conocimiento (OCDE, 2016b; OCDE, 2017c). Se recomienda establecer en Costa Rica mecanismos de financiación a fin de mejorar la relevancia para el mercado laboral y los resultados educativos; por ejemplo, el financiamiento basado en el desempeño, en virtud del cual una parte del financiamiento está condicionada al cumplimiento de objetivos tales como la cantidad de graduados en campos específicos o los resultados de los graduados en términos de sus ingresos (OCDE, 2016b, OCDE, 2017j). Aunque las autoridades reconocen el problema, las propuestas para reformar el sistema del FEES se han topado con una resistencia considerable por parte de los interesados y, hasta la fecha, no se ha avanzado.

Las universidades públicas subsidian de manera importante la matrícula y otorgan becas para que los estudiantes cuyos resultados académicos son suficientemente buenos como para ingresar a una universidad pública tengan pocos obstáculos financieros, permitiendo que los jóvenes que provienen de entornos menos favorecidos asistan a la universidad. Sin embargo, más de la mitad de los estudiantes costarricenses se matriculan en instituciones privadas que están excluidas del sistema de subsidios públicos cuantiosos (OCDE, 2017c). Estas disposiciones de financiamiento son insostenibles ya que el gasto en educación terciaria prácticamente se ha duplicado como una parte del PIB desde el año 2000 y se prevé un mayor crecimiento en la matrícula, lo que contribuirá al desarrollo económico continuo de Costa Rica. Estas disposiciones también son inequitativas ya que la mayoría de los estudiantes que se benefician de las universidades públicas provienen de entornos más adinerados. En 2015, 3,8\% de los jóvenes del quintil más bajo de ingresos se matriculó en educación terciaria (Figura 12). Aunque la mayoría $(70,1 \%)$ de estos jóvenes de bajos ingresos se matricularon en universidades públicas, esto significa que solo el 2,7\% de los jóvenes del quintil de ingresos más bajos asistirían a una universidad pública. En comparación, mientras que solo el $41,8 \%$ de los estudiantes del quintil de ingresos más altos que se matricularon en educación terciaria lo hizo en universidades públicas, la mayor tasa de matrícula $(57,8 \%)$ en este grupo implica que casi un cuarto de 
los estudiantes de familias de altos ingresos se beneficiarían de universidades públicas. Los estudiantes que pueden permitirse asistir a un centro privado de educación secundaria tienen el doble de probabilidades de ingresar a una universidad pública, que aquellos que asisten a un centro público de educación secundaria. Por el contrario, en las universidades privadas los estudiantes casi no tienen acceso a becas, aunque tienen que pagar costos más altos, resultando en que solo un 1,1\% de los jóvenes del quintil más bajo de ingresos se matriculan en educación terciaria privada, en comparación con un tercio de los del quintil más alto.

Es necesario desarrollar un nuevo sistema de financiamiento y apoyo estudiantil para la educación terciaria, para permitir que haya una distribución de los costos más eficaz y equitativa entre el gobierno y los estudiantes que se benefician de la educación terciaria (OCDE, 2017c). Este nuevo acuerdo debe tener como objetivo el apoyo financiero a los estudiantes con base en la necesidad y su capacidad de beneficiarse, incluyendo un aumento regulado pero sustancial de los costos en las universidades públicas (OCDE, 2017c). Se recomienda que las becas y los préstamos respaldados por el gobierno se ofrezcan a los estudiantes que cursan programas de calidad en universidades públicas o privadas, reemplazando las disposiciones actuales que benefician principalmente a los estudiantes de universidades públicas mediante la subvención de matrículas y becas (OCDE, 2017c).

\section{Fortalecimiento de la competencia}

La escasa competencia en Costa Rica frena el proceso de convergencia hacia los niveles de ingresos de los países de mayores ingresos. Las regulaciones que restringen la competencia pueden obstaculizar las mejoras en términos de eficiencia, innovación y asignación de recursos para aumentar la productividad, y contribuir al aumento de la desigualdad al subir los precios al consumidor y hacer más amplia la distribución de los salarios (Nicoletti y Scarpetta, 2003; Aghion y Griffith, 2005; Conway et al., 2006; Song et al., 2015; Denk, 2016; Ennis et al., 2017). La competencia desempeña un papel clave al permitir que los recursos fluyan hacia sus usos más productivos. Las estimaciones sugieren que una asignación de recursos más eficiente podría aumentar la productividad multifactorial (PMF) de Costa Rica en más del 50\%, que es similar a la que existe en otros países latinoamericanos, pero más alta que en los países más desarrollados, como los EE. UU. (Alfaro Ureña y Garita, 2018).

En Costa Rica, las regulaciones del mercado de productos son más restrictivas que en cualquier país de la OCDE, excepto en Turquía, y también se comparan desfavorablemente con otros países de América Latina, incluyendo Chile, Colombia y México (Figura 13). Los controles estatales son particularmente restrictivos, y existe una enorme participación del gobierno en los sectores de redes (como el suministro de electricidad y el transporte marítimo y terrestre) y en el control de precios, y mala gobernanza de las empresas estatales (Figura 14, Panel A). Los obstáculos al emprendedurismo en Costa Rica también son importantes debido al sistema para la obtención de licencias y permisos, las cargas administrativas a las pequeñas empresas, las exenciones antimonopolio y las restricciones en los sectores de las redes (Figura 14, Panel B). 
Figura 13. Las regulaciones del mercado de productos son restrictivas

Puntuación global del Indicador de Regulación del Mercado de Productos, escala de 0 a 6, de menos a más restrictiva

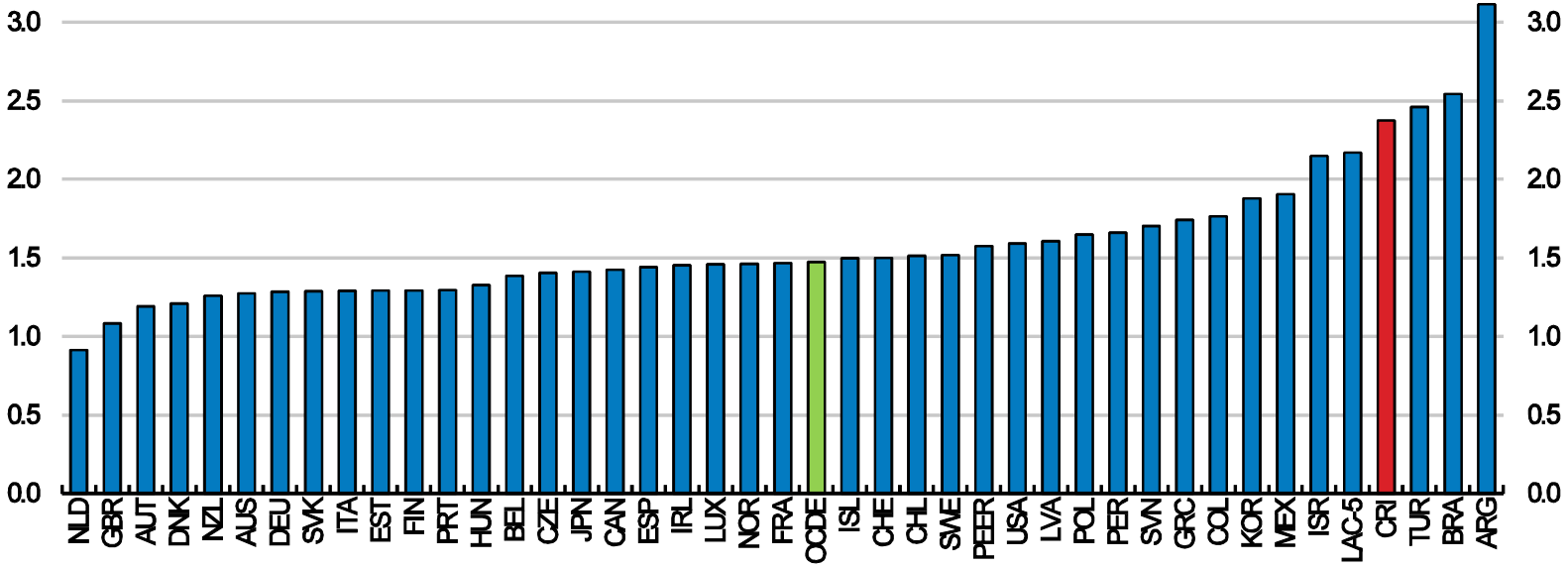

Nota: Los datos se refieren a 2013. Para la OCDE, el dato corresponde al promedio sin ponderar de los países miembros de la OCDE. Para LAC-5, el dato corresponde al promedio sin ponderar de Argentina, Brasil, Colombia, Chile y México. PEER hace referencia al promedio sin ponderar de los 10 países OCDE, no latinoamericanos, con el PIB per cápita más bajo: Republic Checa, Estonia, Grecia, Hungría, Letonia, Polonia, Portugal, República Eslovaca, Eslovenia y Turquía.

Fuente: OCDE-Grupo del Banco Mundial, Base de datos de Regulación del Mercado de Productos para todos los países LAC excepto Brasil, Chile and México; OCDE, Base de datos de Regulación del Mercado de Productos.

\section{Otorgar a la autoridad para la competencia más independencia y recursos}

Los problemas en la implementación obstaculizan la efectividad de la política para la competencia en Costa Rica. La principal entidad para asegurar el cumplimiento de las leyes, la Comisión para Promover la Competencia (COPROCOM) es una entidad del Ministerio de Economía, Industria y Comercio] (MEIC) y no cuenta con independencia administrativa y presupuestaria. El personal de la Unidad Técnica de Apoyo son empleados del MEIC y de COPROCOM no tiene personalidad jurídica propia y depende de la Fiscalía General para defender sus decisiones ante los tribunales. La COPROCOM tampoco tiene los recursos suficientes: la Unidad Técnica de Apoyo no cuenta con suficiente personal y su presupuesto es bajo en comparación con el de otras entidades de regulación económica en Costa Rica y otros organismos similares para promover la competencia en la región (OCDE, 2016b). Además, los Comisionados trabajan a tiempo parcial por un salario insignificante y tienen un trabajo principal en otro lugar, lo que plantea posibles conflictos de intereses.

En Costa Rica se reconocen estos problemas, y en la Asamblea Legislativa se está analizando un proyecto de ley (No. 19.996) para abordarlos, que podría adoptarse en el 2018. Mediante este proyecto de ley se crearía un nuevo Consejo Nacional de Competencia (CONACOM) respaldado por una Secretaría General de Competencia. El CONACOM será un organismo de "máxima desconcentración" adscrito al MEIC pero con independencia funcional, administrativa y financiera, así como con personalidad jurídica propia (OCDE, 2016e). La reforma propuesta también incluye medidas para mejorar el proceso de nombramiento de la junta directiva de la autoridad de la 
competencia, reducir los conflictos de intereses, aumentar el nivel de recursos y mejorar la flexibilidad para la selección del personal y el establecimiento de condiciones laborales y pago. De acuerdo con las recomendaciones de la Evaluación Económica 2016, el proyecto de ley también le otorga a CONACOM autoridad para realizar estudios de mercado y crear un programa de clemencia para proteger a los denunciantes. También establece un nuevo sistema de sanciones, mediante el cual las multas son determinadas dependiendo del nivel de severidad de la infracción. Sin embargo, es posible que las sanciones no sean lo suficientemente altas como para que tengan un efecto disuasivo suficiente en algunas industrias (OCDE, 2016e). Este proyecto de ley debe adoptarse e implementarse con prioridad.

\section{Evaluación y eliminación de las exenciones antimonopolio injustificadas}

Muchos sectores en Costa Rica están exentos de la ley de competencia y, aunque no está claro qué porción de la economía representa esto, una estimación aproximada sugiere que puede ser un tercio de la economía (OCDE, 2016e). Estos sectores incluyen electricidad, transporte y distribución de combustible, destilación de alcohol, azúcar, arroz, servicios profesionales y transporte marítimo. Como varios de estos sectores son proveedores inmediatos (upstream), el porcentaje de la economía que se ve afectada indirectamente por estas exenciones es mucho mayor, lo cual tiene repercusiones en los incentivos para mejorar la productividad de los sectores de procesamiento posterior (downstream), disminuye la competitividad internacional y reduce la resiliencia económica (Bourlès et al., 2013; Monteiro et al., 2017).

En la mayoría de los casos, parece que no existe una justificación económica para las exenciones, y en varios casos, especialmente con respecto al arroz, COPROCOM ha argumentado reiteradamente que se deben eliminar las exenciones existentes. La OCDE recomienda que se eliminen en Costa Rica todas las exenciones injustificadas (OCDE, 2016b, OCDE, 2016e). Esto podría aumentar el PIB per cápita en un 0,08\% (Recuadro 1).

En respuesta a esto, en Costa Rica se están realizando revisiones a fondo de 25 sectores exentos de la ley de competencia entre el 2017 y 2020 (en el Cuadro 3 se presenta un cronograma de revisión). A enero de 2018 se han completado dos estudios pero aún no se habían aprobado y publicado. Tres estudios adicionales están en proceso y se espera que se completen en el primer trimestre de 2018. Aunque estas revisiones son un primer paso positivo, es probable que eliminar las exenciones se convierta en un proceso controversial y prolongado. Por ejemplo, las negociaciones comerciales internacionales fueron el catalizador para la liberalización del sector de telecomunicaciones costarricense, e incluso entonces, las reformas solo fueron aprobadas después de un referéndum muy estrecho (OCDE, 2016b). Por lo tanto, se recomienda que los siguientes pasos se planifiquen detalladamente, indicando cómo se usarán estos estudios para estimular las acciones concretas. También es necesario reconsiderar el cronograma de revisión, y los sectores que son proveedores grandes y o inmediatos (como la electricidad) deben revisarse antes. 
Figura 14. Los controles del Estado y barreras al emprendimiento limitan la competencia
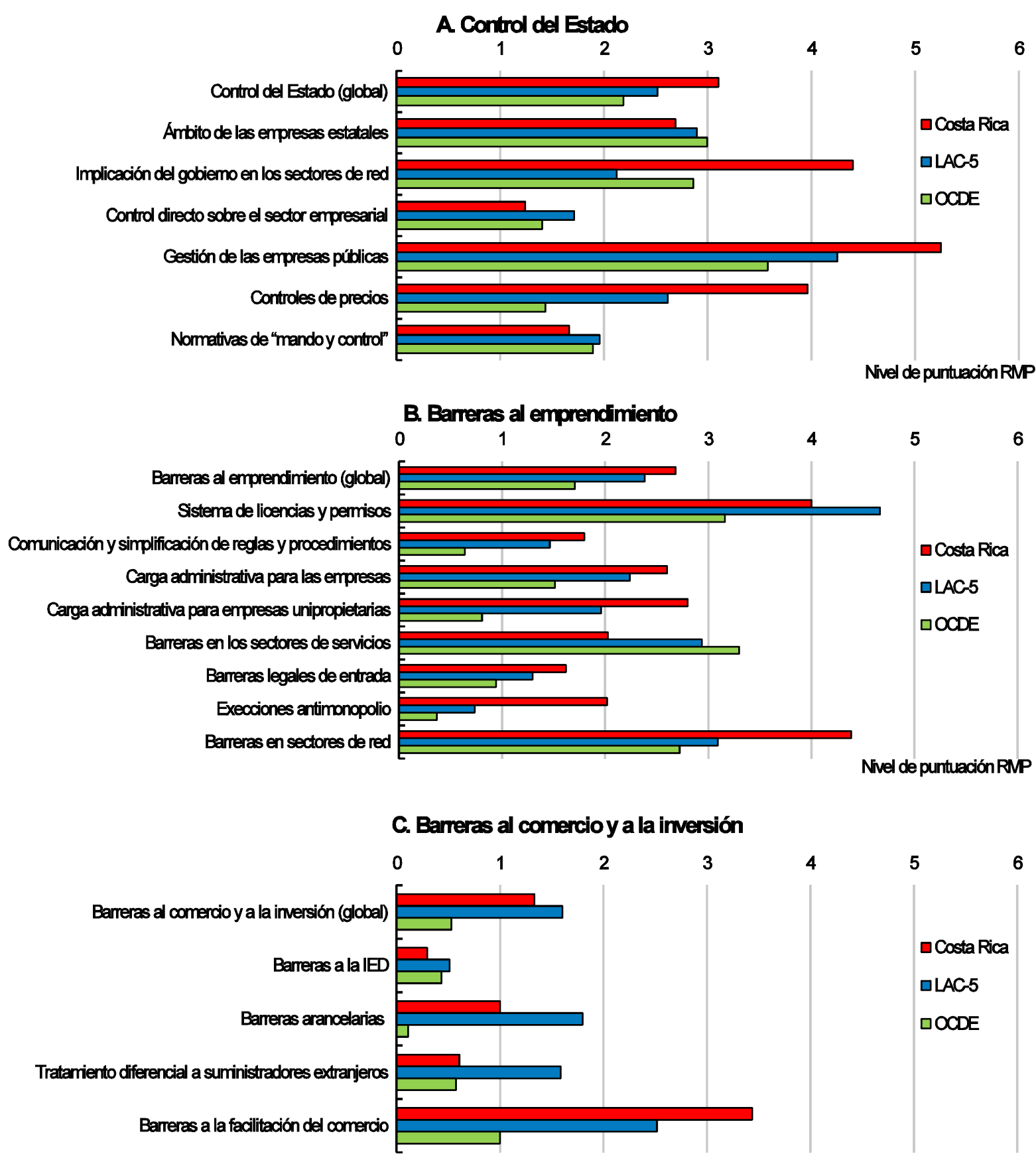

Nivel de puntuación RMP

Nota: Los datos se refieren a 2013. Para la OCDE, el dato corresponde al promedio sin ponderar de los países miembros de la OCDE. Para LAC-5, el dato corresponde al promedio sin ponderar de Argentina, Brasil, Colombia, Chile y México.

Fuente: OCDE-Grupo del Banco Mundial, Base de datos de Regulación del Mercado de Productos para todos los países LAC excepto Brasil, Chile and México; OCDE, Base de datos de Regulación del Mercado de Productos. 
Cuadro 3. Costa Rica está revisando sectores exentos de la ley de competencia

Cronograma para revisiones sectoriales a profundidad

\begin{tabular}{|c|c|c|c|}
\hline Sector & $\begin{array}{l}\text { Año de la } \\
\text { revisión }\end{array}$ & Sector & $\begin{array}{l}\text { Año de la } \\
\text { revisión }\end{array}$ \\
\hline 1. Alcohol & $2017-2018$ & 14. Concesiones de obra pública & 2019 \\
\hline $\begin{array}{l}\text { 2. Asociaciones } \\
\text { profesionales }\end{array}$ & $2017-2018$ & 15. Sector cafetalero & 2019 \\
\hline 3. Servicios de notariado & $2017-2018$ & 16. Acueductos y alcantarillados & 2019 \\
\hline 4. Inspección de vehículos & 2017-2018 & 17. Loterías y bingos & 2019 \\
\hline 5. Gasolineras & 2017-2018 & $\begin{array}{l}\text { 18. Importación y producción de } \\
\text { combustibles. }\end{array}$ & 2019 \\
\hline 6. Servicios postales & 2017-2018 & 19. Transporte de combustibles & 2020 \\
\hline 7. Puertos & 2018 & 20. Gas licuado & 2020 \\
\hline 8. Servicios de estiba & 2018 & 21. Generación de electricidad & 2020 \\
\hline 9. Transporte marítimo & 2018 & 22. Distribución de electricidad & 2020 \\
\hline $\begin{array}{l}\text { 10. Transporte aéreo } \\
\text { internacional }\end{array}$ & 2018 & 23. Sector azucarero & 2020 \\
\hline 11. Transporte en autobús & 2018 & 24. Sector arrocero & 2020 \\
\hline 12. Transporte ferroviario & 2018 & 25. Servicios de seguridad social & 2020 \\
\hline 13. Transporte en taxi & 2018 & & \\
\hline
\end{tabular}

\section{Mejorar la gobernanza de las empresas estatales}

En la economía costarricense existe un alto grado de control estatal (Figura 14, Panel A), que restringe la competencia y conduce a ineficiencias operacionales y de asignación de recursos, disminuyendo la productividad (Hsieh y Klenow, 2009). Las empresas estatales desempeñan un papel dominante en muchos sectores clave, como la electricidad, la infraestructura de transporte, la banca, los seguros y los productos derivados del petróleo (OCDE, 2016b, OCDE, 2017k, OCDE, 2017l). Incluso en los sectores liberalizados, como en las telecomunicaciones y los seguros, aún hay predominancia de las empresas estatales. Varios de estos sectores serán sometidos a revisión como parte de los estudios detallados del sector mencionados anteriormente, brindando la oportunidad de evaluar no solo si la participación del estado está justificada, sino también si la participación del estado (incluyendo la presencia de empresas estatales) es apropiada.

La gobernanza de las empresas estatales también representa un problema. La mayoría de las empresas estatales fueron creadas por leyes específicas, y como consecuencia, se observa una falta de uniformidad en los informes y las regulaciones operacionales. Mejorar su gobernanza podría tener un impacto considerable en el crecimiento, impulsando el PIB per cápita en 1,1\% en el largo plazo (Recuadro 1). Casos recientes de alto perfil que involucran a dos bancos públicos (el cese de las actividades de intermediación de Bancrédito y las investigaciones sobre las prácticas comerciales del Banco de Costa Rica) también han servido para concientizar al público sobre la importancia de la buena gobernanza.

Con el fin de hacer mejoras a la gobernanza, la OCDE formuló una serie de recomendaciones que permiten alinear las prácticas con las Directrices de la OCDE sobre el Gobierno Corporativo de las Empresas Públicas (OCDE, 2015e, OCDE, 2016b, OCDE, 2017m). En respuesta, el gobierno lanzó un plan de acción para empresas estatales en julio del 2017, que se estaría empezando a implementar a finales del 2018, y 
que incluye acciones para establecer una unidad coordinadora de la propiedad estatal, desarrollar una política de propiedad, mejorar la composición de las juntas directivas de las empresas estatales, mejorar su gobierno corporativo, promover la adopción de normas internacionales sobre información financiera y mejorar el monitoreo y la divulgación del desempeño de las empresas estatales.

Ya se han puesto en marcha varias acciones. En octubre del 2017 se creó una unidad de asuntos relacionados con la propiedad, como entidad legal. También se preparó un borrador para un decreto que busca alinear los procesos para el nombramiento de los miembros de la junta con las Directrices de la OCDE estableciendo una política de nominación clara y transparente para los miembros de la junta y los directores ejecutivos de las empresas estatales. Las autoridades esperan tener en operación la unidad coordinadora y haber definido el proceso de nombramientos antes de que tenga lugar la próxima ronda de nombramientos de la junta, después de que la nueva administración asuma el cargo en mayo del 2018. También se están haciendo esfuerzos para abordar temas pendientes planteados por la OCDE. Por ejemplo, se han expresado preocupaciones de que la unidad coordinadora de la propiedad no solo será responsable de las empresas estatales, sino también de otras entidades autónomas como la Autoridad Reguladora de los Servicios Públicos (ARESEP) (OCDE, 2017m). Para abordar estos aspectos, en sus primeros dos años de operación, la unidad coordinadora solo será responsable de las empresas estatales y después de este tiempo, se creará una división separada para supervisar a las otras entidades autónomas. El nivel de recursos de la unidad coordinadora de la la propiedad también se ha planteado como un posible problema, ya que parece que la cantidad de personal que se planea tener es pequeña en comparación con la que tienen otras entidades coordinadoras de la propiedad en los países de la OCDE y con respecto a la cantidad de empresas estatales que tendrá que supervisar (OCDE, 2017m). El Ministerio de la Presidencia planea evaluar el nivel de personal después de dos años, y hacer los ajustes necesarios.

Un problema adicional es que muchas empresas estatales se establecen bajo su propia legislación, y en algunos casos, es posible que estas leyes deban modificarse para evitar conflictos con el borrador del decreto. Si bien las autoridades planean abordar este problema mediante medidas administrativas inicialmente, la reforma legal traería una mayor estabilidad. También se espera que se presente a la Asamblea Legislativa un proyecto de Ley de Gobernanza Corporativa durante 2018. Sin embargo, este proyecto de ley se está redactando actualmente y su contenido aún no está claro (OCDE, 2017m), pero en general busca dar cohesión a la política pública en gobierno corporativo y complementar acciones administrativas que ya están siendo implementadas.

Además, el Plan de Acción no aborda los aspectos relacionados con la necesidad de ofrecer igualdad de oportunidades. Con frecuencia, las empresas estatales disfrutan de flujos de ingresos garantizados por el gobierno. Por ejemplo, el banco público Bancrédito había dependido tradicionalmente de monopolios avalados por el estado para la recaudación de los impuestos de salida del aeropuerto y la gestión de un fondo de desarrollo estatal (OCDE, 2017m). Los bancos públicos también tienen la ventaja sobre los bancos privados de que cuentan con una garantía total del gobierno sobre los depósitos. Por otro lado, los bancos públicos deben hacer transferencias parafiscales de sus ingresos netos (discutido en Araújo and Guichard, 2018). Estas transferencias no pasan como parte presupuesto nacional y se envían directamente a entidades gubernamentales, como el Instituto Nacional de Fomento Cooperativo (INFOCOOP), la Comisión Nacional de Préstamos para Educación (CONAPE), la Comisión Nacional de 
Prevención de Riesgos y Atención de Emergencias (CNE), y el Régimen de Invalidez, Vejez y Muerte (IVM) (OCDE, 2017n).

La apertura a la entrada para las nuevas empresas de tecnología en los servicios financieros (FinTech) y la creación de un espacio regulatorio seguro (regulatory sandbox), sería una forma de impulsar la competencia y reducir los altos costos de la intermediación financiera. La innovación impulsada por la tecnología en los servicios financieros tiene el potencial de aumentar la competencia en el sector financiero, mejorar el acceso al crédito, impulsar la inclusión financiera y reducir el costo de las transacciones transfronterizas. Por ello, varios gobiernos han implementado, o están considerando implementar opciones de marcos regulatorios para estas empresas. Al proveer mayor certeza para empresas que innovan y dar especio para la experimentación, estos marcos regulatorios buscan facilitar el desarrollo de FinTech al tiempo que se asegura la protección del consumidor y la estabilidad financiera. En el Reino Unido se abrió un espacio regulatorio seguro en mayo del 2016 para permitir que existiera un terreno de prueba para los nuevos servicios de FinTech, permitiendo la innovación en igualdad de condiciones para todos los participantes, a la vez que se limita las consecuencias de un eventual fallo. Desde entonces, otros gobiernos han creado espacios regulatorios limitados, como en Singapur y Hong Kong. México recientemente aprobó un proyecto de ley para crear un marco regulatorio para FinTech y la Comisión Europea también está considerando opciones de regulación.

En Costa Rica, para fomentar la competencia en el sector financiero, donde prevalecen altos costos de transacción, el Banco Central ha actualizado su Reglamento del Sistema de Pagos, de modo que las empresas FinTech puedan registrarse y usar el Sistema Nacional de Pagos Electrónicos, que es administrado por el Banco Central y ampliamente utilizado por la población. Con base en este paso positivo, para seguir facilitando el desarrollo de FinTech las autoridades costarricenses deberían explorar opciones e implementar un marco regulatorio apropiado.

\section{Reducción de las barreras al emprendedurismo y simplificación de los trámites regulatorios}

Los grandes obstáculos que existen en Costa Rica para el emprendedurismo se reflejan en el bajo nivel de dinamismo de los negocios y las altas tasas de informalidad. Las regulaciones al mercado de productos son particularmente estrictas debido al sistema de licencias y permisos y a las altas cargas administrativas para las pequeñas empresas (Figura 14, Panel B). La reducción de la carga administrativa para las empresas podría aumentar el PIB per cápita en un 1,6\%, y la agilización del sistema para la obtención de licencias y permisos podría sumar un $0,9 \%$ (Recuadro 1 ).

De acuerdo con los indicadores de Doing Business del Banco Mundial, el indicador de distancia a la frontera para Costa Rica es 81,7 de 100, que es más bajo que en todos los países de la OCDE. De acuerdo con este indicador, toma 22,5 días para iniciar un negocio, aproximadamente 2,7 veces más que en el promedio de los países de la OCDE, cuesta aproximadamente 2,2 veces más, e involucra 9 trámites. En Costa Rica se introdujo una plataforma en línea para el registro de empresas en el 2012, que redujo significativamente la cantidad de tiempo necesario. Sin embargo, todavía toma mucho más tiempo iniciar un negocio que en otros países de la región (Banco Mundial, 2017). Además, un mapeo de los procesos necesarios por parte de las autoridades costarricenses sugiere que el tiempo necesario para que una empresa pueda entrar operación (que incluye no solo el registro de empresas, sino también la obtención de los permisos 
necesarios de construcción, ambientales y de otro tipo), con frecuencia es mucho más largo, con una duración de aproximadamente seis meses en un escenario optimista, que involucra 17 trámites y 14 entidades públicas.

El Gobierno está trabajando para reducir estos costos de cumplir con la legislación. La mayoría de los 22,5 días que toma iniciar un negocio según el indicador del Banco Mundial corresponde a la emisión de una licencia de negocio por parte de la municipalidad local. Por ello, el Ministerio de Economía, Industria y Comercio (MEIC) está trabajando con varias municipalidades para reducir el tiempo y el papeleo involucrado en el proceso, incluyendo establecer ventanillas únicas en la región Brunca, Pacífico Central y Chorotega. Además, el MEIC y la Promotora de Comercio Exterior de Costa Rica (PROCOMER) iniciaron un proyecto conjunto en 2016 para extender estas iniciativas regionales para simplificar y digitalizar los trámites empresariales, no solo en la fase de registro de la empresa, sino también para obtener licencias y permisos (como los de construcción, salud y ambientales). La plataforma digital ya se ha extendido a empresas dentro de las zonas de libre comercio, y actualmente se le está extendiendo a todas las firmas. El proyecto busca reducir el tiempo actual de establecimiento, de entre 5 a 18 meses, a solamente tres meses para empresas manufactureras, de seis meses a 30-45 días para empresas de servicios y de 1,5-2 años a seis meses para empresas del sector agroindustrial. Los aspectos que se propone mejorar incluyen la reducción del tiempo para el registro de empleados extranjeros, obtener permisos ambientales y de salubridad, someterse a inspecciones aduaneras y obtener aprobaciones de Zonas Francas.

Estos son pasos positivos, y si el proyecto actual se implementa con éxito, podría sentar las bases para hacer aún más mejoras en el futuro. Actualmente, el proyecto implica mejorar los trámites dentro del marco legal actual, lo cual puede limitar las mejoras posibles. En segundo lugar, algunos de los trámites, como la obtención de una patente comercial y permisos ambientales, son responsabilidad de las municipalidades locales. Dado que las municipalidades tienen un alto grado de autonomía, mejorar estos procesos requerirá la consulta y coordinación con cada municipalidad por separado. A pesar de estas limitaciones, las autoridades deberían continuar con estas buenas iniciativas, con el fin de establecer ventanillas únicas implementadas a nivel local, que tengan objetivos claros y medibles contra los que el desempeño, incluyendo el desempeño de la municipalidad, pueda ser comparado. Como un ejemplo de lo que se podría obtener, el número de trámites que un empresario debe enfrentar para iniciar un negocio podría reducirse de nueve a uno si estas tareas se implementaran mediante una ventanilla única, como en el caso de los países con mejor desempeño en el Doing Business, como Nueva Zelanda.

También se están haciendo otros esfuerzos para reducir la burocracia. Las regulaciones relacionadas con el registro de productos alimenticios y cosméticos de bajo riesgo se simplificaron en el 2016. Además, se introdujo un sistema nuevo de solicitud en línea para permisos de agua (OCDE, 2017d). Un nuevo método para la aprobación de agroquímicos entró en vigencia en el 2017, mediante el cual se espera reducir el tiempo de aprobación de cuatro años a tan solo seis meses, aunque es demasiado pronto para evaluar su impacto. Las autoridades deben continuar haciendo esfuerzos permanentemente para reducir las cargas regulatorias.

Desde el 2012, la Ley para la Protección al Ciudadano del Exceso de Requisitos y Trámites Administrativos (Ley 8220) permite la aplicación de la regla del "silencio positivo". Si los permisos y las licencias no se emiten dentro del límite de tiempo legal, la actividad se considera aprobada. Sin embargo, el "silencio positivo" cubre solo los 
permisos, licencias y autorizaciones, y excluye aquellos trámites relacionados con la salud, la sanidad animal, y aspectos fitosanitarios y ambientales. También existe la obligación de que los interesados soliciten el "silencio positivo", que implica la presentación de una solicitud que confirma que toda la documentación necesaria se ha presentado y el tiempo de respuesta legal ha transcurrido. La administración tiene tres días para certificar que se otorga el "silencio positivo" o presentar las razones por las que no se aplica. Estas exclusiones y requisitos pueden estar limitando su uso y efectividad. Desafortunadamente, no existe información sobre la frecuencia con la que se aplica el "silencio positivo" en los casos en los que vence el límite de tiempo legal. Se recomienda recolectar esta información con el fin de evaluar la efectividad de la regla del "silencio positivo" en la práctica.

\section{Mejoras en el régimen de insolvencia para facilitar el cierre de empresas inviables}

En el otro extremo del ciclo de vida de las empresas, facilitar el cierre de empresas inviables (o empresas zombi) libera los recursos para que estos fluyan hacia usos más productivos. De acuerdo con los indicadores de la OCDE sobre las características de diseño de los regímenes de insolvencia, Costa Rica se desempeña por encima del promedio de los países de la OCDE. Esto se debe en gran medida a que en Costa Rica se han alcanzado estándares de mejores prácticas para las herramientas de reestructuración, mientras que podrían mejorarse los sistemas para la prevención y la agilización de los trámites (Adalet McGowan et al., 2017). Sin embargo, las mediciones de resultados del indicador de resolución de insolvencia del Doing Business del Banco Mundial, que está basado en un caso de estudio estilizado y se centra más en la implementación que los indicadores de la OCDE, son mucho menos positivas. De acuerdo con la medida del Banco Mundial, el puntaje de distancia a la frontera de Costa Rica es 34,4, que es más bajo que el de todos los países de la OCDE excepto Turquía y significativamente por debajo del promedio de la OCDE de 74,8. Esto refleja una tasa de recuperación en Costa Rica (31 centavos por dólar) es mucho más baja que en los países de la OCDE (75 centavos) y que en países como Colombia (72 centavos). El tiempo estimado de resolución de tres años también es mucho en comparación con el promedio de la OCDE (1,8 años) y países comparables como Colombia (1,7 años) (Banco Mundial, 2017).

Reconociendo estos problemas, se está llevando a cabo una revisión importante del régimen de insolvencia. Actualmente, el marco regulatorio para la insolvencia se encuentra disperso en varios textos de la legislación. Se espera que un proyecto de ley que ofrece un marco regulatorio unificado para la insolvencia esté listo en poco tiempo. El marco seguirá las recomendaciones del Banco Mundial y el modelo utilizado en otros países, como en México, España y Uruguay. Presentará una fase de reestructuración basada en soluciones acordadas con los acreedores, brindando la oportunidad para que las empresas puedan negociar su ruta hacia la viabilidad, y en caso de que el negocio no sea viable, establece una fase de liquidación. Su objetivo es acelerar esta fase, que a menudo dura tres años o más, para reducirla a menos de un año. Por ejemplo, los procesos se simplificarán mediante la limitación la capacidad de los acreedores para apelar las valoraciones de activos y la creación de sanciones financieras para apelaciones relativamente triviales. Además, desde febrero del 2018, todos los casos de insolvencia serán atendidos en un tribunal especializado. 


\section{Continuación de los esfuerzos para aumentar el perfil y la coordinación de las políticas relacionadas con la productividad}

Para mejorar la productividad y el crecimiento inclusivo se requiere adoptar medidas que abarquen muchas áreas diferentes de políticas, lo que representa un desafío particular para Costa Rica dado el alto grado de fragmentación del sector público (Cornick y Trejos, 2016). El Consejo Presidencial sobre Competitividad, Innovación y Talento Humano, diseñado a partir de las comisiones sobre productividad que existen en países de la OCDE como Chile y México, se estableció para mejorar el perfil de las políticas relacionadas con la productividad y coordinar y alinear los esfuerzos de política.

Si bien este Consejo ha tomado medidas positivas para mejorar el desarrollo y la coordinación de políticas, su eficacia podría mejorarse si asumiera un papel más estratégico, si sus tres subconsejos se fusionaran, y si la unidad técnica se fortaleciera (OCDE, 2016b, OCDE, 2017e). Para abordar estos problemas, se ha creado un comité técnico encargado de establecer una agenda de prioridades para el trabajo del Consejo. Además, se está analizando un proyecto de ley para institucionalizar el Consejo a fin de garantizar que perdure, unificar sus tres subcomités, fortalecer la secretaría técnica y agregar una oficina de asesoramiento estratégico (proyecto de ley 20.331). Aunque este es un avance positivo, aún no está claro si esta ley se promulgará y cuándo se implementarán los cambios.

\section{Promoción de la innovación, la difusión tecnológica y la integración a las cadenas globales de valor}

La estrategia económica impulsada por la IED y la exportación que comenzó en Costa Rica en la década de 1980 ha contribuido a una transformación estructural de una economía basada en la agricultura a otra con una estructura más diversificada integrada a cadenas globales de valor (CGV), que ha permitido una expansión sostenida de la producción desde mediados de la década de 1980 (Rodríguez-Clare et al., 2001; Alfaro Ureña y Vindas, 2015). Este patrón cambiante de la producción se refleja en las ventajas comparativas del país, que, al igual que en los países con economías avanzadas de la OCDE, muestra una canasta exportadora cada vez más especializada y sofisticada (OCDE, 2017o, Figura 15, Panel A). Con base en las experiencias existentes en cuanto a la producción y los patrones de especialización, Costa Rica podría beneficiarse de un conjunto de oportunidades de sofisticación en una serie de sectores industriales de tecnología media y alta (Araújo, Linares y Chalaux, 2018a, Figura 15, Panel B). La industria de los servicios también ha comenzado a ganar protagonismo, ya que se ha experimentado un aumento en la actividad económica de las industrias que requieren altos niveles de conocimiento (OCDE, 2017e). También ha habido un aumento en las exportaciones de servicios, reflejando un incremento en el sector turístico y en los servicios que requieren altos niveles de conocimiento (servicios profesionales y comerciales, y servicios de telecomunicaciones, computación e información) (Figura 16). Esta diversificación y transformación contribuirán a la resiliencia económica y estimularán la productividad y la convergencia de Costa Rica hacia el nivel que disfrutan los países de altos ingresos. Si bien el país enfrenta el desafío de distribuir los beneficios de esta transformación de manera más amplia, tiene el potencial para mejorar el bienestar de la población mediante la creación de empleos formales mejor remunerados.

Los flujos importantes de inversión extranjera directa a Costa Rica se han visto facilitadas por un régimen de IED favorable (Figura 17). Si bien las barreras regulatorias a la IED 
son más bajas que el promedio de la OCDE, las restricciones continúan siendo rigurosas en algunos sectores, incluyendo algunos sectores clave de los sectores de redes, como el suministro de electricidad y el transporte marítimo y terrestre (OCDE, 2016b, OCDE, 2017p). Además, en Costa Rica se restringe el comercio en muchos sectores de servicios más que en otros países, con restricciones particularmente rigurosas en el transporte de carga por carretera, manejo de carga y almacenamiento, y servicios de almacenamiento (Figura 18). Si estas restricciones se flexibilizan, los costos de logística podrían reducirse y facilitar el comercio y la integración a cadenas globales de valor (CGV).

Figura 15. Costa Rica se está especializando en productos complejos
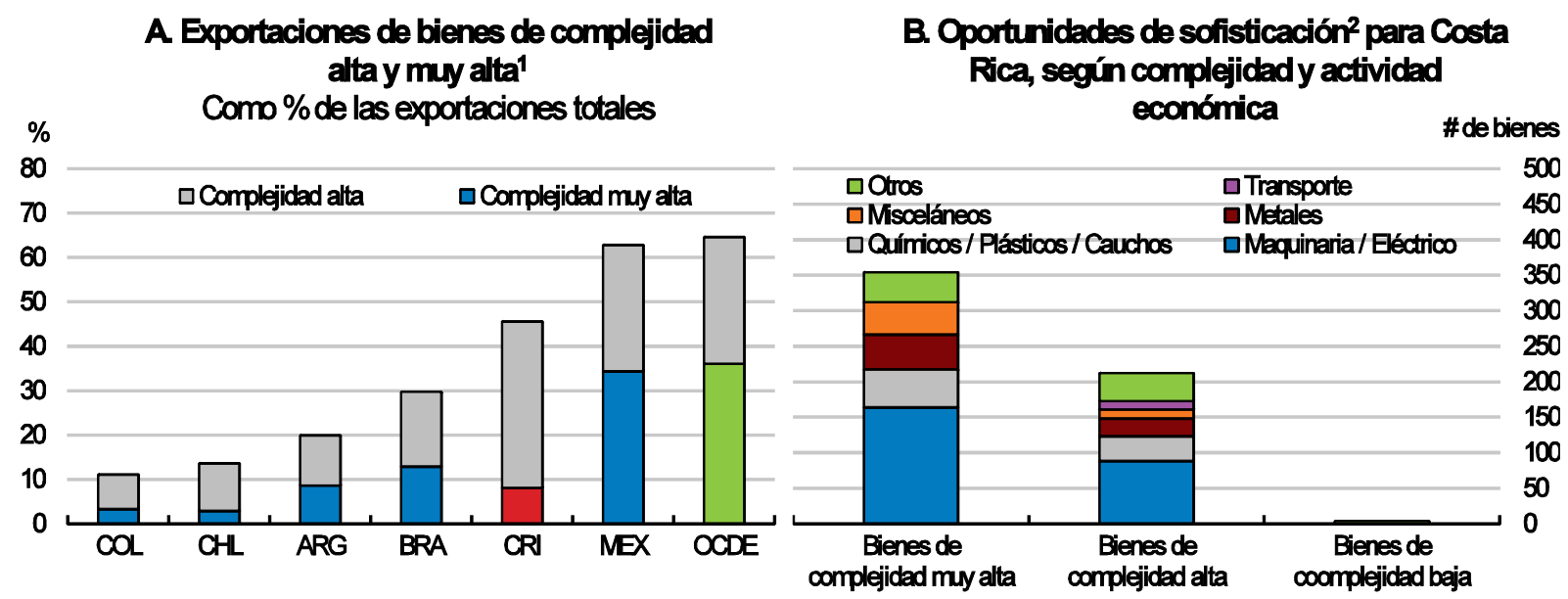

1. Los bienes de complejidad "alta" y "muy alta" son aquellos con puntuaciones de complejidad en los cuartiles tercero y cuarto de la distribución del conjunto total de bienes intercambiados en el mundo. Éstas se calculan en base al Índice de Complejidad de Producto (ICP) que es una medida relativa de la intensidad de conocimiento incorporado en un bien. Un ejemplo de un bien en el cuarto cuartil (mayor complejidad) es "dicloruro de etileno", el cual ocupó el décimo lugar en 2015 entre 4214 bienes enumerados en la clasificación del Sistema Armonizado de 6 dígitos. Un bien en el primer cuartil (menor complejidad) es la "Pasta de cacao total o parcialmente desgrasada" situada en el puesto 4201 in 2015.

2. Las oportunidades de sofisticación, conducentes a elevar la complejidad de la canasta exportadora, hace referencia a aquellos bienes que actualmente se exportan sin una ventaja comparativa, tienen un nivel de complejidad (ICP) más alto que el índice de complejidad del país, y están más cerca del patrón de especialización del país.

Fuente: Panel A: Araújo, Chalaux and Haugh (2018); Panel B: Araújo, Linares and Chalaux (2018).

A pesar del cambio hacia bienes y servicios que utilizan el conocimiento de forma más intensiva, Costa Rica no tiene una buena puntuación en cuanto a la contribución de la innovación y las medidas de resultados. Por el lado de los insumos, el gasto en I + D como porcentaje del PIB está a la par de otros países latinoamericanos que tienen un nivel similar de desarrollo, pero se ha estancado en los últimos años y está muy por debajo del promedio de los países de la OCDE (Figura 19). La contribución del sector privado es débil, y hay una buena parte de I + D financiada por el gobierno que va en aumento (Figura 20), con una transferencia limitada de conocimientos a las empresas. Costa Rica también está muy por debajo del promedio de los países de la OCDE en términos de la participación de los investigadores en el empleo total (Figura 19). La inversión en otras formas clave de activos intangibles para la innovación, como las TICs y el gasto en software, parece más alta que en otros países de América Latina (como porcentaje del PIB), pero continúa siendo varias veces menor que en los países de la OCDE. En cuanto a 
los resultados, Costa Rica tiene bajo rendimiento en la mayoría de los indicadores del conocimiento y la producción tecnológica. La actividad de publicaciones es inferior a la de varios países comparables de la región y está muy por debajo del promedio de la OCDE. Los indicadores de producción intelectual, como patentes y diseños industriales, muestran que Costa Rica tiene un desempeño bastante por debajo de otros países de ALC y de la OCDE. Costa Rica se clasifica mejor que la mayoría de los países de América Latina en términos de registro de marcas por persona, pero aún está muy por debajo del promedio de la OCDE (OCDE, 2017e).

Figura 16. Los servicios intensivos en conocimiento cada vez son una parte más importante de la economía

\section{A. Los servicios suponen una proporción cada vez mayor de las exportaciones de Costa Rica}

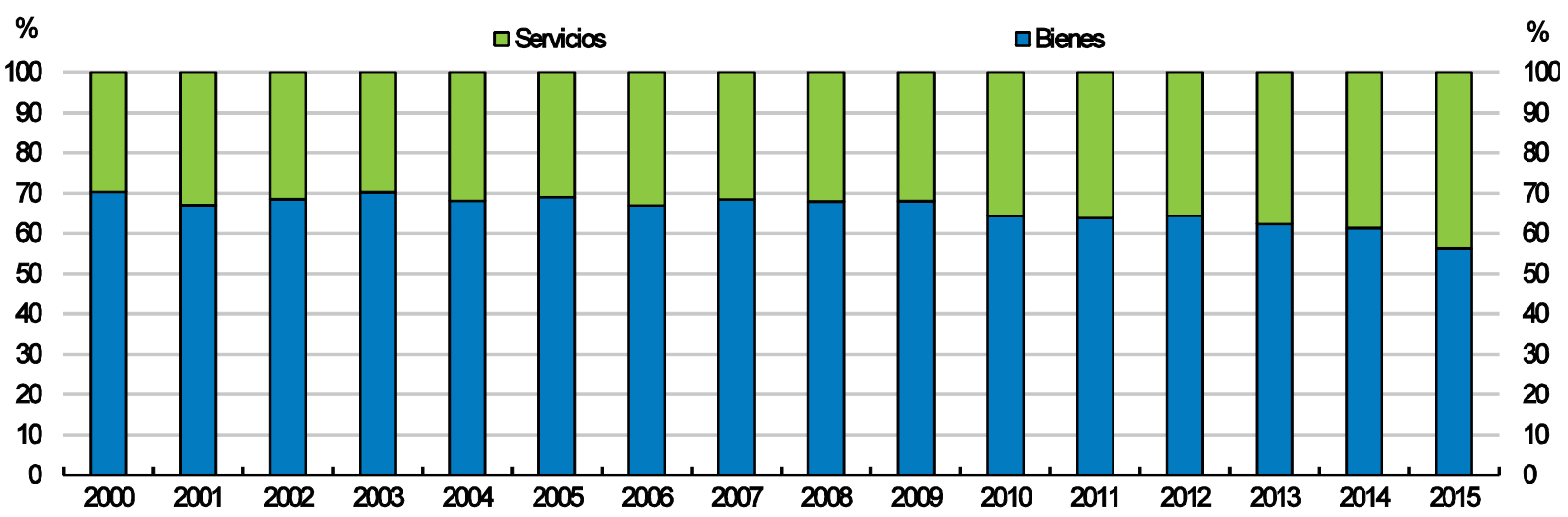

B. La composición de las exportaciones de servicios se ha hecho más intensiva en

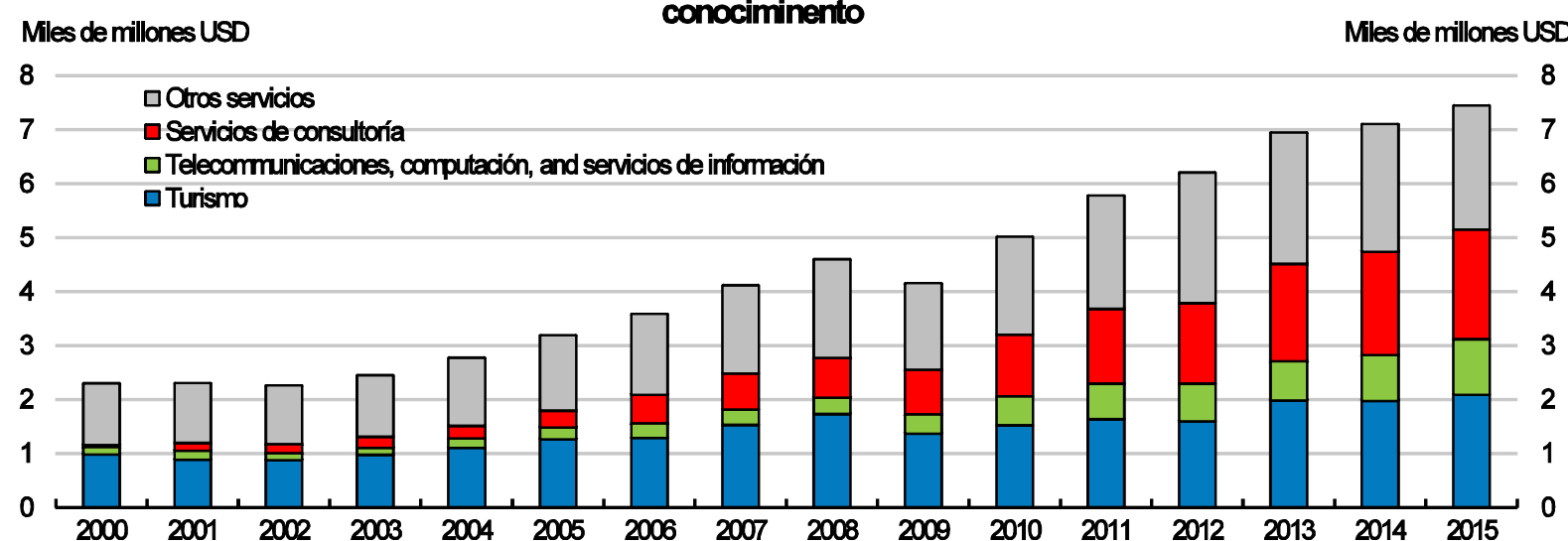

Fuente: OCDE, conjunto de datos Bilateral Trade in Goods by Industry and End-use (BTDIxE), ISIC Rev.4; OCDE, conjunto de datos EBOPS 2010 - Trade in services by partner country.

Además, el uso de la innovación y la tecnología se concentra entre las empresas que operan en las zonas francas (ZF). Estas empresas de alta productividad coexisten con empresas nacionales de baja productividad (incluyendo las informales). Existe una integración limitada de las empresas locales a las cadenas de suministro de las empresas multinacionales debido a un desajuste entre lo que demandan las empresas extranjeras y las competencias del sector empresarial local (OCDE, 2017e). Como resultado, los proveedores locales proporcionan solo el $24 \%$ de los insumos a las empresas 
multinacionales en Costa Rica, que consisten principalmente en actividades de bajo valor agregado, como los servicios de empaque y limpieza (OCDE, 2017e). Sin embargo, hay evidencia de que existen "spillovers" positivos de la IED en las empresas nacionales. En el sector manufacturero, las empresas que proveen a compañías de propiedad extranjera tienen, en promedio, el $8 \%$ más de productividad laboral que las empresas con características similares que no tienen relaciones comerciales con empresas de propiedad extranjera, y en el sector de los servicios, esas empresas tienen una productividad laboral mayor al 6,4\% (Sandoval et al., 2018). Además, existe un sector de servicios cada vez más dinámico, con sofisticados servicios comerciales y de informática que representan el 45\% del sector total (OCDE, 2017e).

Figura 17. Las restricciones regulatorias de IED son, en general, relativamente bajas Índice Global de Restricción Regulatoria de IED, escala de 0-1, de menor a mayor restricción, 2016

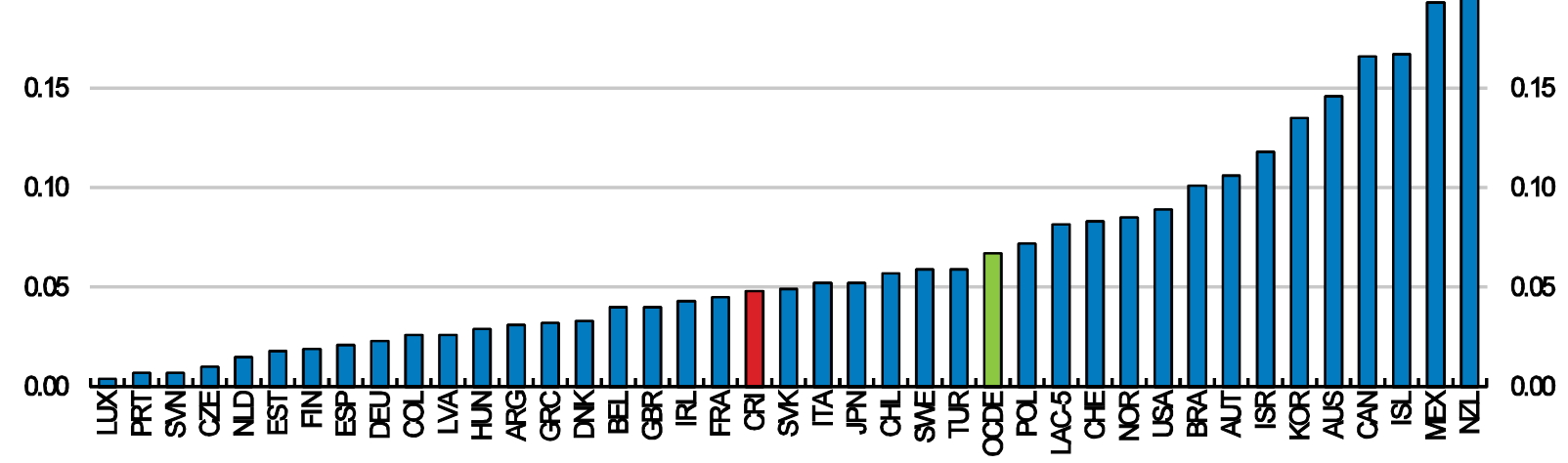

Nota: El Índice Global de Restricción Regulatoria de IED va de cero (régimen menos restrictivo) a uno (el más restrictivo); cuanto mayor sea el valor del índice, más obstáculos hay para el ingreso de IED. OCDE es el promedio sin ponderar de los países de la OCDE. LAC-5 es el promedio sin ponderar de Argentina, Brasil, Colombia, Chile and México.

Fuente: OCDE, base de datos Índice de Restricción Regulatoria de IED. 
Figura 18. Las restricciones al comercio de servicios son elevadas, sobres todo en el ámbito del transporte y la logística

\section{A. Incice globel de Restricción del Comercio de Servicios 2017}

Escala de 0-1 de menos a más restrictivo

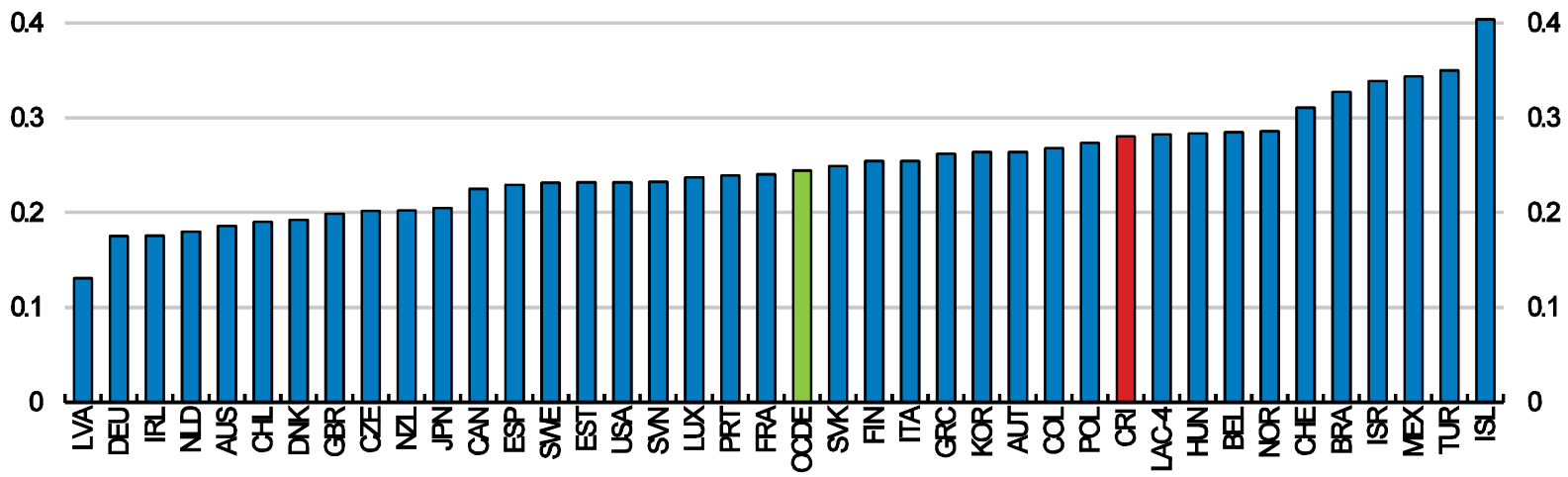

B Índice de Restricción del Comencio de Servicios, por sector

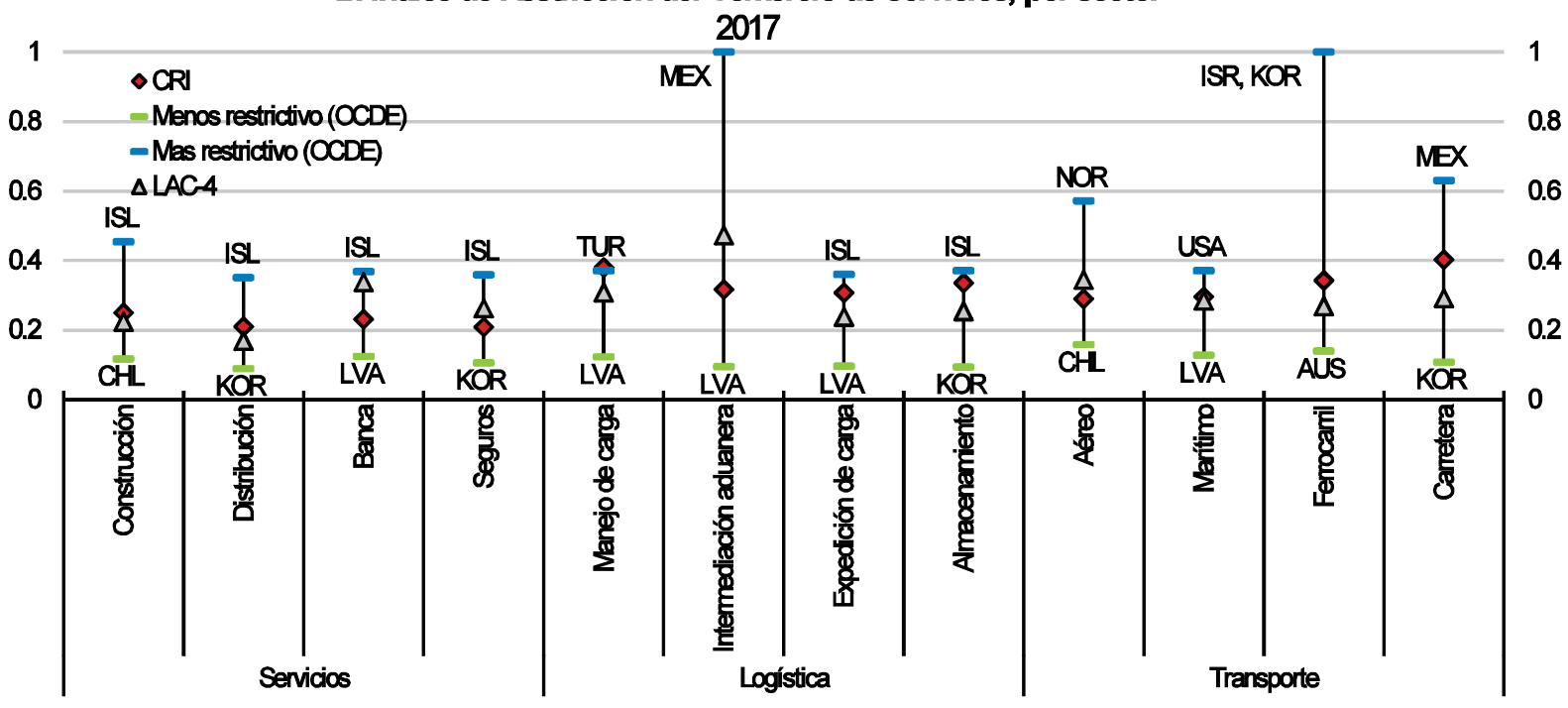

Nota: LAC-4 se refiere al promedio sin ponderar de Brasil, Chile, Colombia and México.

Fuente: OCDE, Índice de Restricción del Comercio de Servicios (IRCS). 
Figura 19. La inversión en capital basado en conocimiento está retrasado

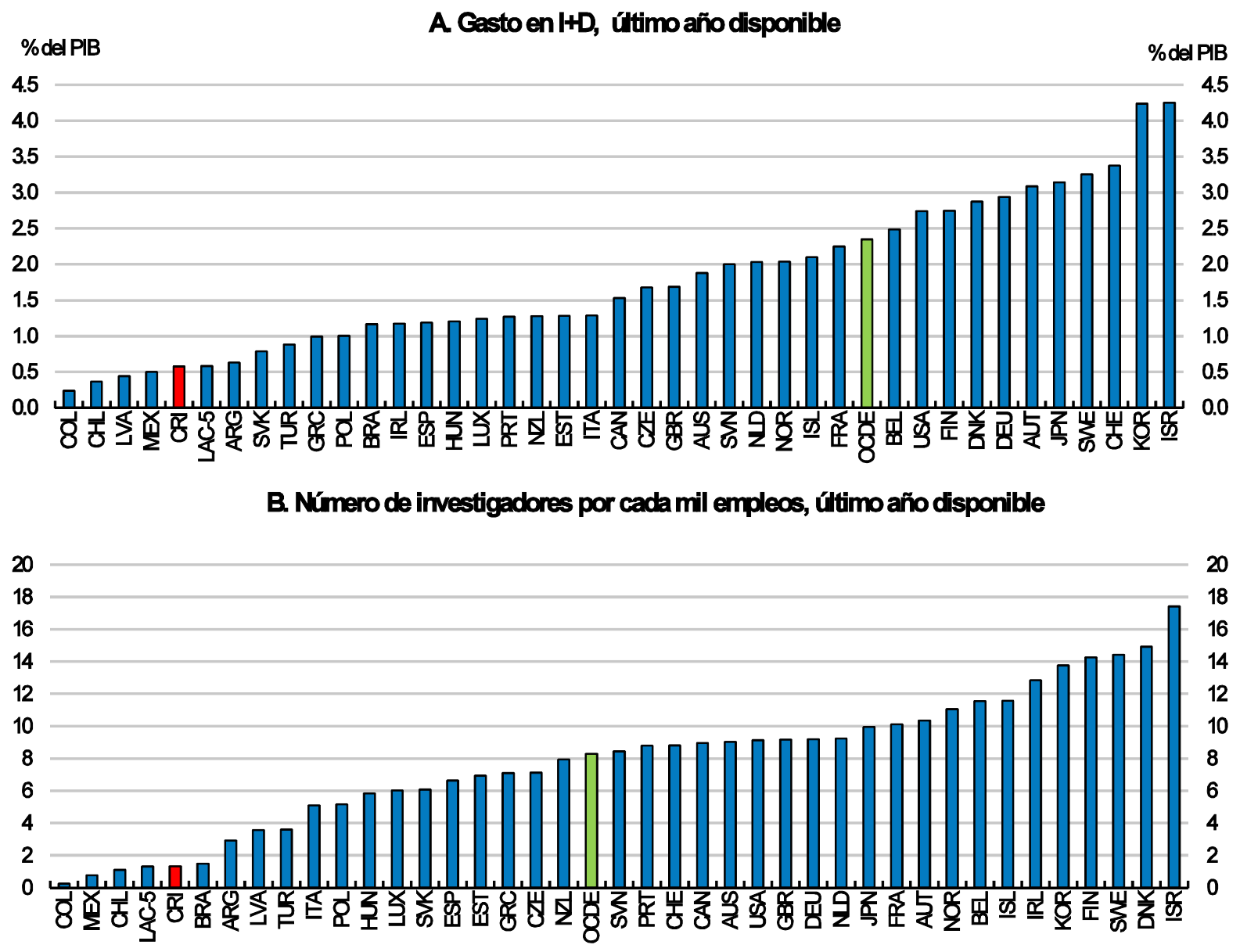

Nota: El gasto de I+D es medido como el gasto bruto interno en actividades de investigación y desarrollo. OCDE es el promedio sin ponderar de los países de la OCDE. LAC-5 es el promedio sin ponderar de Argentina, Brasil, Colombia, Chile and México.

Fuente: OCDE, base de datos de Indicadores Principales de Ciencia y Tecnología; UNESCO Institute for Statistics. 
Figura 20. Una gran y creciente proporción de I+D es financiada por el gobierno

Casto en I+D por fuente de financiación

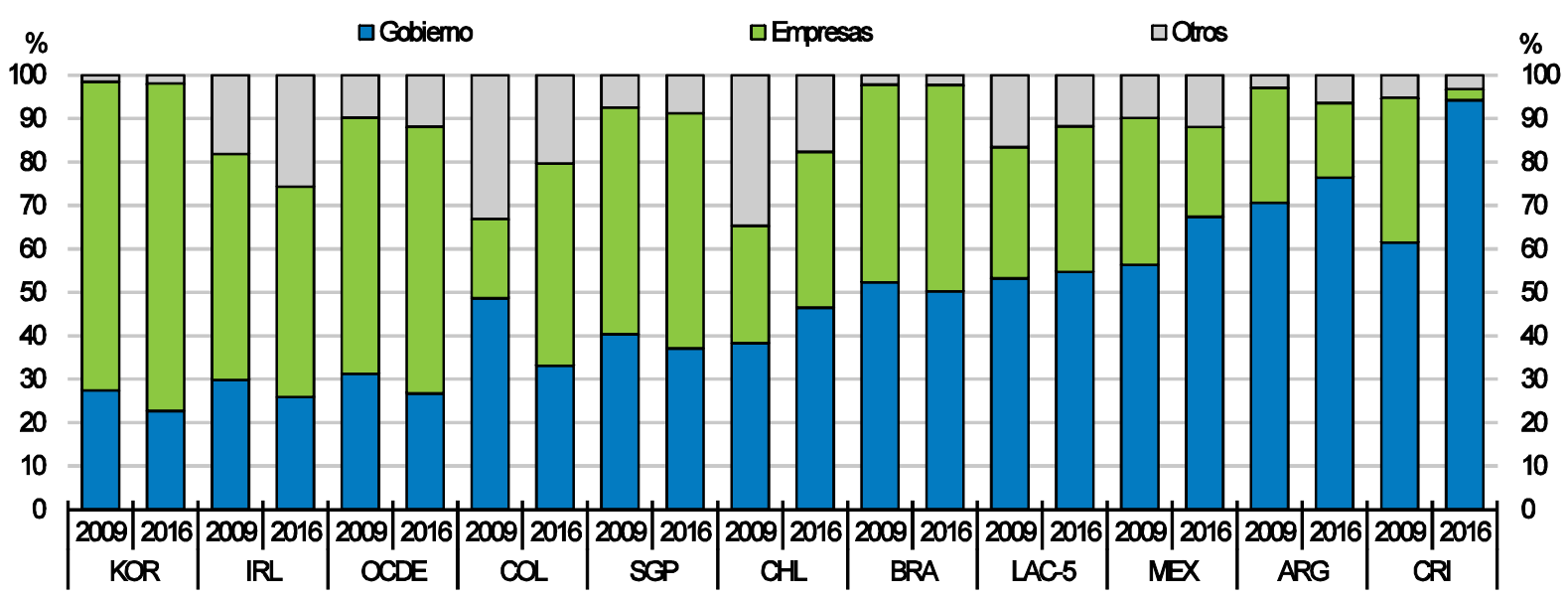

Nota: El gasto de I+D es medido como el gasto bruto interno en actividades de investigación y desarrollo. OCDE es el promedio sin ponderar de los países de la OCDE. LAC-5 es el promedio sin ponderar de Argentina, Brasil, Colombia, Chile and México.

Fuente: OCDE, Base de datos de Indicadores Principales de Ciencia y Tecnología y Red de Indicadores de Ciencia y Tecnología RICYT, Indicadores de Insumo.

\section{Fortalecimiento de la coordinación para mejorar los vínculos entre las empresas y la contribución de la investigación pública a la innovación}

La efectividad de la política de innovación costarricense se ve obstaculizada por la fragmentación en la ejecución de las políticas y los marcos institucionales, limitando la coherencia y dirección en la política de investigación e innovación del Ministerio de Ciencia, Tecnología y Telecomunicaciones (MICITT) y sus entidades (OCDE, 2017e). Esta fragmentación afecta ejecución de programas de asistencia empresarial, destinados a impulsar la innovación en las empresas locales y profundizar sus vínculos con las filiales extranjeras. Estos programas incluyen PROPYME, administrado por el MICITT para promover la innovación y el desarrollo tecnológico de las PyMEs a través de subvenciones, y Linkages (anteriormente Costa Rica Provee), administrado por PROCOMER para mejorar los vínculos entre empresas extranjeras y nacionales, contribuyendo a que se formen vínculos entre proveedores y compradores. La evaluación de políticas sugiere que estos programas ayudan a mejorar el desempeño del negocio, resultando en mayor empleo, rentabilidad y exportaciones, con efectos más importantes para las empresas inscritas en ambos programas (Monge González et al., 2010; MongeGonzález y Rodríguez-Álvarez, 2013).

Dados estos resultados positivos, la Evaluación Económica del 2016 recomendó la ampliación de PROPYME y Linkages, y hacer esfuerzos para mejorar su coordinación, así como el establecimiento de una única entidad a cargo de los servicios de asistencia empresarial relacionados (OCDE, 2016b). Un proyecto de ley (No. 19.822) para crear la Agencia Costarricense de Fomento Productivo, Innovación y Valor Agregado (FOMPRODUCE) con el fin de concentrar los fondos y las responsabilidades relacionadas con la innovación y el desarrollo empresarial en una sola entidad, coincide con esto. Sin embargo, esta propuesta se ha estancado, aunque el trabajo continúa abordando las preocupaciones de las partes interesadas y obteniendo apoyo para el proyecto de ley. 
El marco legal para los derechos de propiedad intelectual en Costa Rica cumple con las normas internacionales; sin embargo, su ejecución tiene debilidades, en particular con respecto a la piratería de derechos de autor y la falsificación de marcas, lo que puede desalentar la creación y difusión de conocimiento (OCDE, 2016b). Para abordar este problema, las autoridades costarricenses han tomado medidas para fortalecer el procesamiento judicial en casos de infracciones a los derechos de propiedad intelectual y mejorar las medidas de control fronterizo, como la Ley para Mejorar la Lucha contra el Contrabando (Ley 9328), aunque su impacto aún está por verse (OCDE, 2017p).

El alto nivel de autonomía universitaria es otro aspecto que evidencia la falta de un enfoque unificado y concertado en el ámbito de la investigación y la innovación. Como se discutió anteriormente en relación con las mejoras en la educación, la OCDE recomienda que Costa Rica adopte un enfoque más unificado para el financiamiento universitario y que reforme el sistema de financiamiento del FEES, mediante una mayor participación de fondos concursables para mejorar la calidad de la investigación e incentivar los vínculos con el sector empresarial (OCDE, 2016b, OCDE, 2017e). Hasta la fecha, esta recomendación no ha avanzado debido a la gran resistencia de las partes interesadas.

\section{Impulso a la integración regional a través de una mejor facilitación del comercio}

Costa Rica está bien integrada en las cadenas globales de valor (CGV) desde una perspectiva de participación hacia atrás, con un porcentaje de valor agregado en exportaciones brutas similar al de México (Figura 21, Panel A). Sin embargo, Costa Rica permanece por debajo de sus pares en lo que respecta a participación a CGV, esto es, el porcentaje de valor agregado costarricense dentro de las exportaciones de otros países es bajo (Figura 21, Panel B). La participación hacia atrás de Costa Rica está concentrada en industrias de tecnologías media-alta y alta (Figura 21, Panel D), mientras que su participación hacia adelante está concentrada en servicios (Figura 21, Panel F). La participación hacia atrás de Costa Rica tiende hacia los Estados Unidos de América (Figura 21, Panel C), mientras que su participación hacia adelante está orientada a Asia, con solo una pequeña parte de su participación en CGV relacionada con países latinoamericanos (Figura 21, Panel E). Esto refleja el resultado más general de que los vínculos intrarregionales en América Latina son débiles, en contraste con el importante papel de las cadenas de valor regionales en Asia, Europa y América del Norte. Por ejemplo, del valor agregado extranjero total utilizado para producir exportaciones en América Latina, solo el 9\% proviene de la región, en comparación con el 49\% en la UE y el $40 \%$ en el sudeste asiático (OCDE y BID, 2016). 
Figura 21. Costa Rica está bien integrada en las CGV desde la perspectiva de la participación hacia atrás

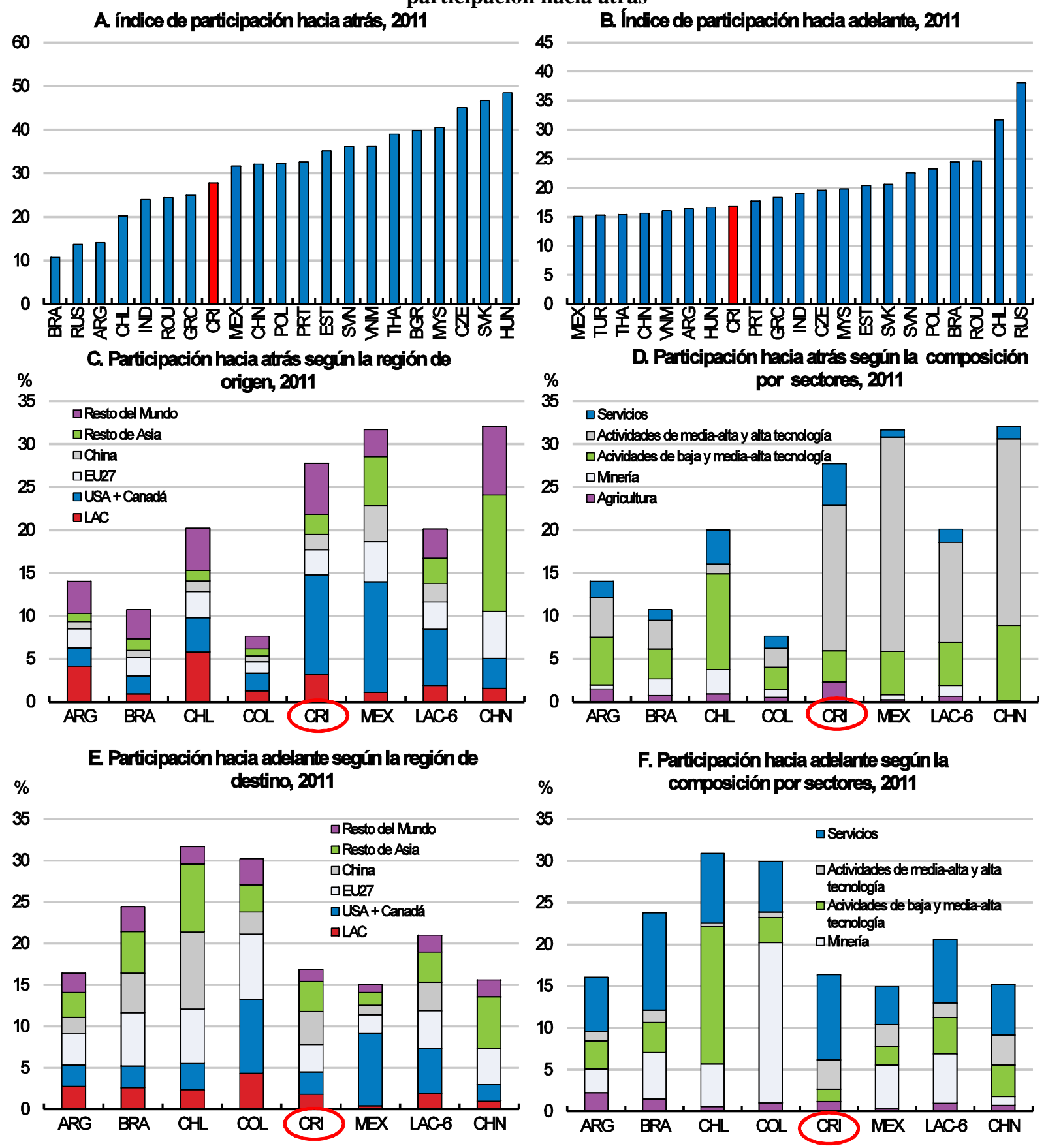

Nota: El índice de participación hacia atrás se define como la proporción of valor agregado extranjero contenido en las exportaciones brutas del país. La participación hacia adelante se define como la proporción del valor agregado interno incorporado en las exportaciones de países extranjeros. Por razones de comparabilidad la mayoría de países incluidos como pares son países no-OCDE, como Brasil, Argentina, Indonesia, Rumania, Vietnam, entre otros. Según la clasificación de la OCDE de actividades económicas según tecnología, las actividades de alta tecnología incluyen: maquinaria aeronáutica y espacial, productos farmacéuticos, productos informáticos, electrónicos y ópticos, instrumentos médicos y odontológicos; las actividades de media-alta tecnología se refieren a productos como vehículos de motor, maquinaria y equipo, sustancias y productos químicos, equipo eléctrico. LAC-6 se refiere a Argentina, Brasil, Chile, Colombia, México y Perú.

Fuente: OCDE-OMC, base de datos de Comercio en Valor Agregado. 
Reconociendo el potencial para impulsar el comercio intrarregional, en abril del 2017 se aprobó la Ley 9430 para crear un Consejo Nacional de Facilitación del Comercio (CONAFAC), y se espera que el Consejo esté en pleno funcionamiento en el 2018. El Consejo cuenta con 12 miembros: siete viceministros cuyas funciones se relacionan con el control fronterizo, y cinco representantes del sector privado. Las decisiones del CONAFAC son vinculantes para las entidades gubernamentales correspondientes. Su objetivo es reducir los costos de transacción y aumentar la seguridad de las operaciones comerciales transfronterizas. El CONAFAC es responsable de la implementación de acuerdos de libre comercio, así como de la modernización y mejora continua de todas las obras de infraestructuras relacionadas con el transporte transfronterizo de bienes y personas (no cubre servicios). Algunas de las iniciativas previstas incluyen la estandarización y la digitalización de los pasos fronterizos terrestres en América Central, ya que los retrasos en los pasos fronterizos contribuyen de manera significativa a la lentitud del transporte terrestre.

Según los Indicadores de Facilitación del Comercio de la OCDE, el desempeño de Costa Rica es superior al de otros países de la región, pero se mantiene por debajo del promedio de la OCDE. El CONAFAC tiene el potencial para mejorar el desempeño en varias dimensiones, por ejemplo, simplificar y armonizar los documentos, automatizar y agilizar los trámites fronterizos, y mejorar la coordinación de las entidades nacionales correspondientes. Los cambios relativamente modestos en estos aspectos podrían tener un impacto significativo en el crecimiento; por ejemplo, la comunicación de las regulaciones de manera accesible a nivel internacional podría impulsar el crecimiento del PIB per cápita en un 0,9\% (Recuadro 1).

\section{Abordaje de las brechas en la infraestructura de transporte}

En Costa Rica existen importantes brechas de infraestructura, particularmente en infraestructura de transporte, que obstaculizan la productividad y el crecimiento ambientalmente sostenibles, y afectan de manera negativa el bienestar de la población (Estado de la Nación, 2016, OCDE e IDB, 2016; OCDE, 2017d ). Costa Rica se ubica por debajo del promedio latinoamericano en cuanto a la calidad percibida de las carreteras, los puertos y los ferrocarriles, pero está por encima del promedio en los aeropuertos (Figura 21). Estas percepciones son respaldadas por evaluaciones técnicas, donde solo la mitad de las carreteras consideradas están en buenas condiciones (LANAMME, 2017). Las posibles ganancias que se obtendrían mediante la mejora de la calidad y cantidad de la red de carreteras son significativas. Las estimaciones sugieren que las tasas de crecimiento del PIB podrían aumentar en 0,14 puntos porcentuales si la calidad de las carreteras de Costa Rica aumentarse hasta el promedio que existe en los países latinoamericanos (Lanau, 2017; Recuadro 1).

La baja calidad de la infraestructura de transporte refleja una subejecución constante en el pasado, una planificación estratégica insuficiente y una gestión y ejecución de proyectos deficientes. El gasto en infraestructura ha sido inferior al promedio de los países de la OCDE, a pesar de que existen mayores necesidades. El gobierno es consciente de esta subejecución y en el Plan Nacional de Transporte 2011-35 se proyectan necesidades anuales de gasto en infraestructura de casi el 4\% del PIB hasta el 2035 (MOPT, 2011; OCDE, 2016b). Sin embargo, el gasto ha sido irregular ya que no existe un proceso presupuestario multianual, lo que hace que la inversión en infraestructura sea vulnerable a los recortes, especialmente en un contexto de un espacio fiscal restringido y un alto nivel 
de asignación obligatoria de fondos para fines específicos para otras áreas del gasto público (MOPT, 2011; OCDE, 2016b).

También existen debilidades en cuanto a la planificación estratégica y la gestión de proyectos, que se reflejó en los problemas bastante difundidos con el puente "Alfredo González Flores". El puente es parte de la carretera que conecta San José con la provincia de Alajuela, y es la ruta principal entre la capital y el Aeropuerto Internacional Juan Santamaría y por este transitan alrededor de 90.000 automóviles por día. Sin embargo, a pesar de su importancia y los intentos de tres gobiernos sucesivos para repararlo y ampliarlo desde el 2009, este trabajo apenas se completó en marzo del 2017.

Otro ejemplo es la necesidad de que exista un sistema de transporte masivo rápido para la Gran Área Metropolitana de San José (GMA), con el fin de reducir la congestión y la contaminación, promover la competencia entre empresas, y maximizar los beneficios de las economías de aglomeración (Ahrend, 2015; Atkin y Donaldson, 2015 ; Hsieh y Moretti, 2015). A pesar de que existen planes desde hace mucho tiempo, se ha avanzado poco. Más recientemente, la planificación involucró la creación de un comité compuesto por representantes de las 21 municipalidades de la GAM, el Ministerio de Vivienda y Asentamientos Humanos, el Ministerio de Obras Públicas (MOPT) y el Ministerio de Medio Ambiente y Energía (MINAE). Sin embargo, los ejercicios de planificación anteriores no han llevado a acciones concretas, y no está claro si la implementación del último plan tendrá más éxito que los intentos anteriores, destacándose una vez más los problemas derivados del alto grado de fragmentación institucional. 
Figura 22. La calidad percibida de la infraestructura de transporte es baja

Calidad percibida de la infraestructura de 1 (peor) a 7 (mejor)

A Cameteras

B. Puertos
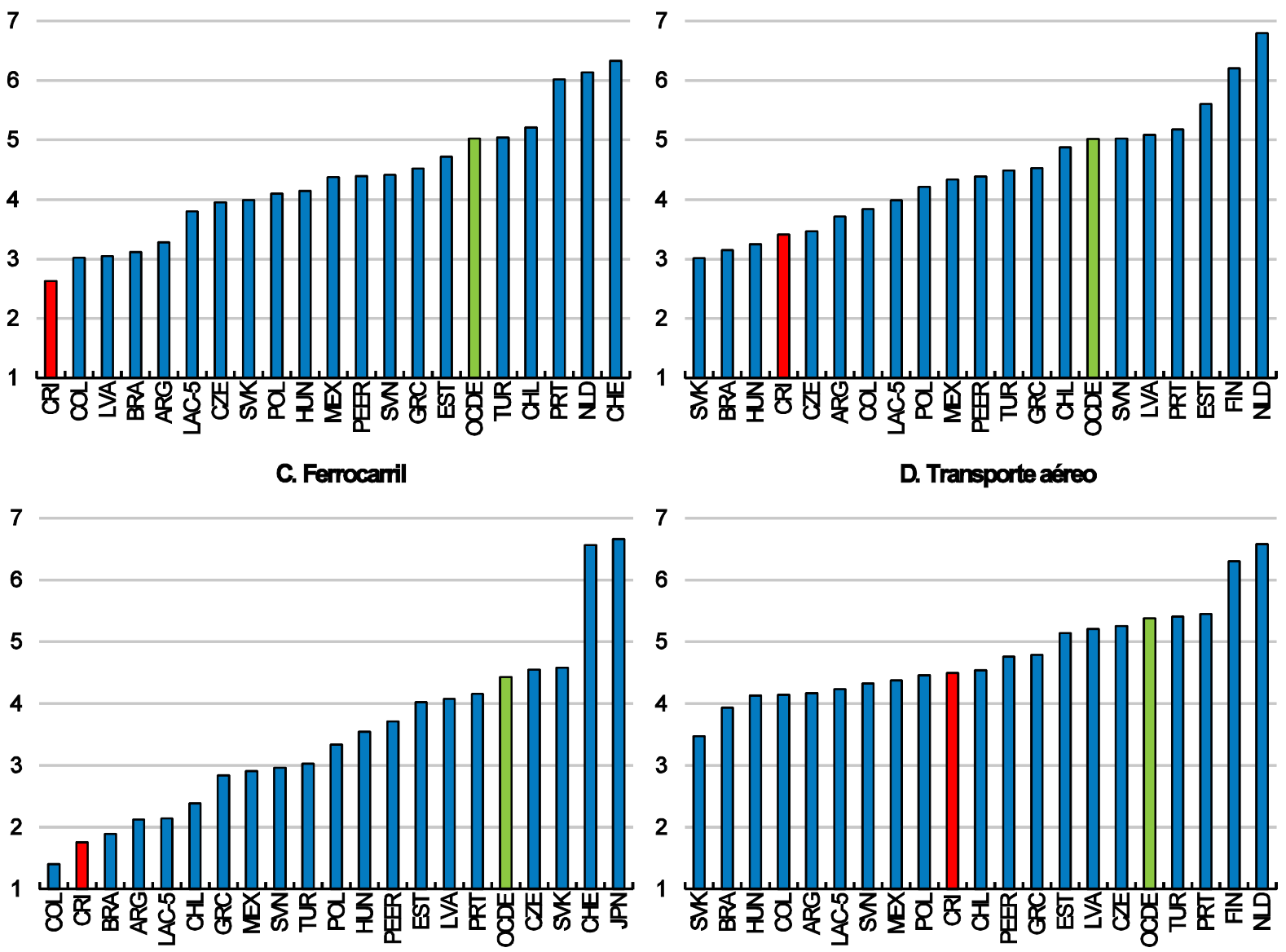

Nota: Para la OCDE, el dato corresponde al promedio sin ponderar de los países miembros de la OCDE. Para LAC-5, el dato corresponde al promedio sin ponderar de Argentina, Brasil, Colombia, Chile y México. PEER hace referencia al promedio sin ponderar de los 10 países OCDE, no latinoamericanos, con el PIB per cápita más bajo: Republica Checa, Estonia, Grecia, Hungría, Letonia, Polonia, Portugal, República Eslovaca, Eslovenia y Turquía. Los datos relativos a carreteras, puertos transporte aéreo hacen referencia a la edición 2017-2018 del Global Competitiveness Index. Los datos correspondientes al ferrocarril hacen referencia a la edición 2016-2017 en lugar de 2017-18 para poder incluir a Costa Rica.

Fuente: Foro Económico Mundial, The Global Competitiveness Index Historical Dataset 2007-2017.

\section{Simplificación del marco institucional para la inversión en infraestructura de transporte}

Los procesos para la planificación de la infraestructura de transporte están muy fragmentados, con la participación de distintos ministerios y entidades gubernamentales con competencias poco claras y superpuestos, lo cual resulta en una falta de coherencia y contribuye a retrasos en los proyectos (Pisu y Villalobos, 2016). La OCDE recomienda que se simplifique el marco institucional y legal de las entidades de obras públicas y que se adopte un enfoque más estratégico para la planificación a largo plazo, incluyendo la 
creación de una cartera de proyectos para aumentar la certidumbre en la ejecución (OCDE, 2016b).

Estos problemas se reconocen en Costa Rica y se han realizado algunos esfuerzos para mejorar la situación. Se aprobó una ley para facilitar el financiamiento y la inversión del Instituto Costarricense de Ferrocarriles (INCOFER), un paso necesario pero modesto para lograr el objetivo del gobierno de establecer un sistema de transporte masivo rápido para la GAM de San José. Además, en 2016 se propuso un proyecto de ley (No. 19.900) para fortalecer la gestión del Ministerio de Obras Públicas (MOPT) del sector, y crear un organismo de coordinación para la infraestructura vial (el Instituto Nacional de Infraestructura Vial), pero este carece de apoyo político. Sin embargo, incluso si se implementan estas medidas, los problemas de fragmentación seguirán siendo significativos.

Una condición necesaria para que un programa de infraestructura sea exitoso es la planificación estratégica apropiada que establece una visión a largo plazo y establece prioridades para la inversión (OCDE, 2017q). Aunque en Costa Rica se estableció el Plan Nacional de Transporte 2011-2035 en respuesta a la necesidad de desarrollar una visión estratégica de largo plazo y prioridades de inversión, este sirve principalmente como guía para las instituciones que participan en proyectos relacionados con la infraestructura de transporte y carece de mecanismos para asegurar el cumplimiento de ley (Pisu y Villalobos, 2016). Diferentes organismos autónomos son responsables de los numerosos aspectos relacionados con la infraestructura de transporte y no existen mecanismos para coordinar y alinear los incentivos. Por ejemplo, en el transporte por carretera, el Consejo Nacional de Vialidad (CONAVI) es responsable de extender y dar mantenimiento a la red vial nacional, las municipalidades están a cargo de las carreteras locales, mientras que el Consejo de Transporte Público (CTP) es responsable del transporte público (es decir, taxis, y autobuses). La falta de coordinación y la estricta división presupuestaria, y en algunos casos (sobre todo el transporte público) la ausencia de un rubro presupuestario, significa que no existe un mecanismo para hacer intercambios estratégicos entre diferentes modos de transporte, por ejemplo, decisiones tales como si se debe o no invertir en el transporte público como alternativa a la construcción de más carreteras.

La coordinación y la rendición de cuentas mejorarían enormemente si se aclararan las competencias de las diferentes organizaciones, y si se asignara la autoridad y el de la gestión de la infraestructura a una sola institución. Esta institución líder también podría estar a cargo de la planificación estratégica a largo plazo y el desarrollo de una cartera de proyectos clara, con selección de proyectos y priorización basada en las herramientas de las mejores prácticas, como los análisis de costo-beneficio (OCDE, 2016b, Pisu y Villalobos, 2016; OCDE, 2017q). Actualmente, no se toman en cuenta estos pasos, dando mayor énfasis a las concesiones y al financiamiento de proyectos, que, si bien son importantes, son consideraciones secundarias para la priorización sistemática. De hecho, para garantizar que se establezcan las prioridades de los proyectos de acuerdo con los criterios de costo-efectividad, los Principios de la OCDE para la Gobernanza Pública de las Alianzas Público-Privadas destacan que la mejor práctica implica separar las decisiones relacionadas con la selección de los proyectos, de aquellas que tienen que ver con la forma de entrega. Después de que haya tenido lugar el proceso de priorización, los proyectos seleccionados deben evaluarse caso por caso para identificar la forma de entrega más adecuada (por ejemplo, alianza público-privada o provisión pública directa) (OCDE, 2017q). 


\section{Reforma de los entornos institucionales para atraer más inversión del sector privado}

El Plan Nacional de Transporte de Costa Rica 2011-35 prevé que un tercio del gasto del $4 \%$ del PIB en infraestructura de transporte provendrá de la inversión del sector privado (MOPT, 2011). Sin embargo, Costa Rica tiene relativamente poca experiencia con las APP y la participación privada en proyectos de infraestructura ha sido baja y tensa. Desde que se aprobó la Ley General de Concesiones en 1998, que regula la participación del sector privado, únicamente cuatro proyectos de APP se han desarrollado, y estos sufrieron demoras de hasta 11 años antes de que comenzara la construcción (OCDE 2016b, Pisu y Villalobos, 2016; OCDE, 2017r).

Aunque hay varias razones legítimas para buscar la participación del sector privado en la inversión en infraestructura, las alianzas público-privadas a veces son usadas de forma inapropiada para disimular presiones sobre las finanzas públicas. En tales casos, las decisiones de inversión, al evitar arreglos alternativos apropiados de inversión, llevarán a resultados subóptimos. Esto resalta la importancia de separar las decisiones de invertir en un proyecto de las decisiones de cómo licitar y financiar la inversión. Además, el uso de alianzas público-privadas debería acompañarse de una evaluación transparente y formal de su impacto esperado a largo plazo sobre las finanzas públicas (Araújo y Sutherland, 2010; OCDE, 2012b). Un ejemplo notorio ocurrió en Hungría con varias alianzas público-privadas para autopistas que se registraron por fuera del presupuesto en 2005 y 2006, a pesar de que la alianza involucraba una empresa de propiedad estatal (Araújo y Sutherland).

La participación privada en infraestructura en Costa Rica se rige por un marco legal fragmentado (OCDE, 2017q). Dada la complejidad de las APP, las Directrices de la OCDE resaltan la importancia de una estructura de gobernanza sólida, donde los organismos relevantes conocen claramente sus competencias y sus responsabilidades (OCDE, 2012b). En respuesta a estas preocupaciones, Costa Rica está en el proceso de desarrollar un nuevo marco para iniciativas público-privadas. En el 2016, se formuló una política pública para las APP y se emitió un decreto para regular los proyectos de APP. Si bien es positivo, se necesita una mayor claridad sobre la forma en que se implementará este nuevo esquema dentro del marco institucional y legal actual (OCDE, 2017r). Por ejemplo, debe aclararse el papel de la nueva regulación con respecto a la legislación de concesiones ya existente (Ley 7762) que ha estado vigente desde 1998.

La OCDE también ha recomendado que el Consejo Nacional de Concesiones (CNC), que es responsable de promover y gestionar los proyectos de concesión, sea trasladado del Ministerio de Obras Públicas al Ministerio de Hacienda, que está mejor posicionado para asumir la responsabilidad de los pasivos contingentes, derivadas de la participación del sector privado (OCDE, 2016b). El arreglo actual también puede crear un sesgo en contra de la participación privada en la infraestructura porque el Ministerio de Obras Públicas también promueve proyectos de infraestructura financiados con fondos públicos que pueden estar en competencia directa con los de financiación privada (OCDE, 2016b). Esta recomendación no ha avanzado, pero se creó una unidad de APP dentro del Ministerio de Hacienda. En consonancia con las recomendaciones para alinear las prácticas con los Principios de la OCDE para la Gobernanza Pública de las Alianzas Público-Privadas, la unidad gestionará los asuntos de financiación pública relacionados con APP, incluyendo los pasivos contingentes asociados; también desarrolló una serie de líneas directrices y criterios de evaluación del proyecto, y se está impartiendo capacitación sobre su uso (OCDE, 2012; Pisu y Villalobos, 2016; OCDE, 2017r). Aunque 
es positivo que la unidad de APP esté implementando las pautas de mejores prácticas, la incorporación de otra entidad tiene el potencial de contribuir aún más a los problemas de coordinación institucional. Las APP traen consigo una serie de problemas, tales como seleccionar al mejor oferente; el diseño de contratos para distribuir los riesgos de manera efectiva, la mitigación de los atrasos y minimización de las renegociaciones costosas; la gestión y el seguimiento constantes de los contratos de APP; y la contabilización del impacto fiscal de las APP a través de la análisis e informes de los pasivos contingentes (Araújo y Sutherland, 2010). En la práctica, parece que las dos entidades están trabajando juntas: la unidad de APP se centra en los aspectos relacionados con el financiamiento público y el CNC está a cargo de la gestión de contratos y los aspectos técnicos. Sin embargo, se requieren esfuerzos adicionales para aclarar las funciones de las dos entidades y establecer mecanismos para alinear y coordinar su trabajo (OCDE, 2017r). De manera más general, se debería seguir monitoreando estos arreglos puesto que siguen sin ser probados en la práctica y ninguna APP ha ocurrido bajo el nuevo arreglo institucional y el nuevo marco regulatorio. 
Recuadro 4. Recomendaciones de políticas estructurales para impulsar la productividad y la inclusión

(Las recomendaciones principales incluidas en el Resumen Ejecutivo están en negrita)

Lograr que los mercados laborales sean más inclusivos

- Continuar simplificando la estructura del salario mínimo.

- Implementar un plan integral para reducir la informalidad, que incluya un mayor cumplimiento con las obligaciones del pago de contribuciones.

- Ampliar la oferta de servicios de atención infantil financiados con fondos públicos, incluyendo todo el gasto en educación y atención de la primera infancia dentro gasto en educación por obligación constitucional.

- Fortalecer los mecanismos para asegurar el cumplimiento de las regulaciones laborales al otorgarles a los inspectores el derecho de imponer sanciones directamente y asegurar que las sanciones sean lo suficientemente fuertes para que actúen como elementos de disuasión.

Mejoras en la calidad y la eficiencia del sistema educativo

- Establecer mejores resultados educativos como principal objetivo de política, en lugar de centrarse en el gasto, y desarrollar indicadores de rendimiento.

- Reequilibrar el gasto en educación para la primera infancia y la educación secundaria. Fortalecer el apoyo específico para estudiantes en riesgo y la capacitación de maestros.

- Establecer y hacer que se cumpla un conjunto completo de estándares mínimos para todos los centros de atención infantil.

- Fortalecer el sistema nacional de evaluación para proporcionar información a nivel del sistema, los centros educativos y el estudiantado.

- Monitorear los resultados del programa piloto de educación dual y analizar opciones para desarrollar una educación vocacional adicional, en estrecha colaboración con los empleadores.

- Reformar el sistema de evaluación de la educación secundaria (Bachillerato) para reconocer mejor los logros parciales y aumentar la flexibilidad.

- Aumentar la participación de fondos concursables para las universidades públicas, con base en medidas de desempeño tales como la relevancia de las calificaciones en el mercado laboral y resultados de las investigaciones. 


\section{Fortalecimiento de la competencia}

- Adoptar e implementar el proyecto de ley que fortalece la autoridad y la independencia de la comisión de competencia.

- Continuar implementando el plan de acción para mejorar la consistencia con las Directrices de la OCDE sobre Gobierno Corporativo de las Empresas Estatales.

- Continuar la realización de los 25 estudios sectoriales planificados para evaluar la exención de la competencia y eliminar las exenciones injustificadas.

- Abrir la entrada de empresas nuevas FinTech, con regulación apropiada.

- Establecer una ventanilla única para el registro y la tramitación de licencias comerciales. Introducir objetivos de rendimiento. Continuar trabajando para mejorar el régimen de insolvencia y la facilitación del comercio.

- Aprobar e implementar la propuesta de institucionalizar el Consejo Presidencial sobre Competitividad, Innovación y Talento Humano, unificar los tres subcomités y fortalecer la secretaría técnica.

- Crear una ventanilla única para los servicios de asistencia empresarial del gobierno.

Abordaje de las brechas en la infraestructura de transporte

- Mejorar la coordinación entre los diferentes organismos de obras públicas especificando claramente sus competencias y otorgando el control general a una sola entidad líder. Dar orden de prioridad a los proyectos con base en análisis costo-beneficio.

- Especificar claramente las competencias del Consejo Nacional de Concesiones (CNC) y la unidad de APP, e introducir mecanismos para alinear y coordinar el trabajo de las dos entidades.

Notas: 1. En esta comisión, de acuerdo con la ley 9220, participan los Ministros o Viceministros del Ministerio de Educación, Ministerio de Salud, Ministerio de Trabajo y Seguridad Social. También, participan jerarcas de instituciones como el PANI, INAMU, CCSS y la Secretaría Técnica de REDCUDI. 


\section{Referencias}

Adalet McGowan, M. y D. Andrews (2015), "Skill mismatch and public policy in OECD countries", OECD Economics Department Working Papers, No. 1210, OECD Publishing, París,

http://dx.doi.org/10.1787/5js1pzw9lnwk-en.

Adalet McGowan, M., D. Andrews y V. Millot (2017), "Insolvency regimes, zombie firms and capital reallocation", OECD Economics Department Working Papers, No. 1399, OECD Publishing, París, http://dx.doi.org/10.1787/5a16beda-en.

Aghion, P. y R. Griffith (2005), Competition and Growth: Reconciling Theory and Evidence, MIT Press, Cambridge MA.

Ahrend, R. et al. (2017), "What makes cities more productive? Evidence from five OECD countries on the role of urban governance”, Journal of Regional Science, Vol. 57/3, pp. 385-410.

Alfaro Ureña, A. y J. Garita (2018). “Misallocation and productivity in Costa Rica”, in OECD Economic Survey of Costa Rica 2018: Research findings on productivity, OECD Publishing, París, por publicarse.

Alfaro Ureña, A. and A. Vindas (2015), “Transformación estructural y productividad sectorial en Costa Rica”, Documento de Investigación, No. 07-2015, Departamento de Investigación Económica, Banco Central de Costa Rica, San José,

http://www.bccr.fi.cr/investigacioneseconomicas/crecimientoeconomico/Transformacestructuralyprod uctividadsectorialenCR.pdf.

Almond, D. y J. Currie (2011), “Human capital development before age five”, Handbook of Labor Economics, Vol. 4, Part B, pp. 1315-1486.

Araújo, S. and S. Guichard (2018), "Costa Rica: restablecer la sostenabilidad fiscal y establecer las bases para una política fiscal más inclusiva y favorable al crecimiento”, OECD Economics Department Working Paper, 1484, OECD Publishing, Paris.

Araújo, S., A. Linares y T. Chalaux (2018), “The road to development: Identifying upscaling opportunities for Costa Rica”, OECD Economics Department Working Paper, por publicarse.

Araújo, S., T. Chalaux y D. Haugh (2018), "Who’s in your export market? The changing pattern of world trade in the age of GVCs”, OECD Economics Department Working Paper, por publicarse.

Araújo, S. y D. Sutherland (2010), “Public-private partnerships and investment in infrastructure”, OECD Economics Department Working Papers, No. 803, OECD Publishing, París, http://dx.doi.org/10.1787/5km7jf6q8f0t-en.

Atkin, D. y D. Donaldson (2015), "Who's getting globalized? The size and implications of intra-national trade costs”, NBER Working Paper, No. 21439, National Bureau of Economic Research, Cambridge MA, http://dx.doi.org/10.3386/w21439.

Banco Central de Costa Rica (2016), Programa Macroeconómico 2017-2018, Banco Central de Costa Rica, San José, http://www.bccr.fi.cr/noticias/historico/2016/noticia_programa_2017_18.html. 
Banco Mundial (2017), “Doing Business 2018: Reforming to Create Jobs”, A World Bank Group Flagship Report, Banco Mundial, Washington D.C.

Bell, D.N.F. y D.G. Blanchflower (2011), "Young people and the Great Recession”, Oxford Review of Economic Policy, Vol. 27/2, pp. 241-267.

Bourlès, R. et al.(2013), "Do product market regulations in upstream sectors curb productivity growth? Panel data evidence from OECD countries", Review of Economics and Statistics, Vol. 95/5, pp. 17501768.

Braguinsky, S., L.G. Branstetter y A. Regateiro (2011), “The incredible shrinking Portuguese firm”, NBER Working Paper, No. 17265, http://www.nber.org/papers/w17265.

Broecke, S., A. Forti y M. Vandeweyer (2017), "The effect of minimum wages on employment in emerging economies: A survey and meta-analysis”, Oxford Development Studies, Vol. 45/3, pp. 366391.

Busso, M., M. Fazio y S. Levy (2012), “(In)formal and (un)productive: The productivity costs of excessive informality in Mexico”, IDB Working Paper Series, No. IDB-WP-341, BID, Washington DC,

https://publications.iadb.org/bitstream/handle/11319/4047/\%28In\%29Formal\%20and\%20\%28Un\%29 Productive\%3A\%20The\%20Productivity\%20Costs\%20of\%20Excessive\%20Informality\%20in\%20M exico.pdf?sequence $=1$.

Carrillo, P., N. Gandelman, y V. Robano (2014), "Sticky floors and glass ceilings in Latin America”, Journal of Economic Inequality, Vol. 12, pp. 339-361. http://dx.doi.org/10.1007/s10888-013-9258-3.

Comisión Europea y OECD (2015), Policy Brief on Informal Entrepreneurship, Publications Office of the European Union, Luxemburgo.

Conway, P., D. de Rosa, G. Nicoletti y F. Steiner (2006), "Regulation, competition and productivity convergence", OECD Economics Department Working Papers, No. 509, OECD Publishing, París, http://dx.doi.org/10.1787/431383770805.

Cornick, J. y A. Trejos (2016), "Building public capabilities for productive development policies: Costa Rican case studies”, IDB Working Paper, No. IDB-WP-686, BID. https://publications.iadb.org/handle/11319/8017.

Cuberes, D. y M. Teignier (2016), “Aggregate effects of gender gaps in the labor market: A quantitative estimate”, Journal of Human Capital, Vol. 10/1, pp.1-32.

Cunha, F. et al. (2006), "Interpreting the evidence on life cycle skill formation" in Hanushek, E. and F. Welch (eds.), Handbook of the Economics of Education, Elsevier B.V., Amsterdam.

Denk, O. (2016), "How do product market regulations affect workers?: Evidence from the network industries”, OECD Economics Department Working Papers, No. 1349, OECD Publishing, París, http://dx.doi.org/10.1787/5167d865-en

Égert, B. (2017), “The quantification of structural reforms: Extending the framework to emerging market economies”, OECD Economics Department Working Papers, No. 1442, OECD Publishing, París, http://dx.doi.org/10.1787/f0a6fdcb-en.

Égert, B. y P. Gal (2017), “The quantification of structural reforms in OECD countries: A new framework”, OECD Economics Department Working Papers, No. 1354, OECD Publishing, París. http://dx.doi.org/10.1787/2d887027-en.

Ennis, S., P. Gonzaga y C. Pike (2017), "Inequality: A hidden cost of market power”, www.oecd.org/daf/competition/inequality-a-hidden-cost-of-market-power.htm. 
Escobar, O. y L. Meehan (2018), "Setting the scene: An overview of Costa Rica's productivity performance”, in OECD Economic Survey of Costa Rica 2018: Research findings on productivity, OECD Publishing, París, por publicarse.

Estado de la Nación (2017), "Estado de la nación en desarrollo humano sostenible”, Programa Estado de la Nación, San José, Costa Rica, http://estadonacion.or.cr/2017/.

Estado de la Nación (2016), "Estado de la nación en desarrollo humano sostenible”, Programa Estado de la Nación, San José, Costa Rica, , https://www.estadonacion.or.cr/22/.

Estado de la Nación (2015), “Quinto informe estado de la educación 2015”, Estado de la Nación, San José, http://www.estadonacion.or.cr/educacion2015/index.html.

Estado de la Nación (2014), “Estado de la Nación en desarrollo humano sostenible”, Estado de la Nación, San José, https://www.estadonacion.or.cr/20/.

Fernández, C. y L. Villar (2016), “A taxonomy of Colombia’s informal labor market”, Fedesarrollo Working Paper, No. 73.

http://www.repository.fedesarrollo.org.co/bitstream/handle/11445/3304/WP_2016_No_73.pdf?sequen ce $=1$ \&isAllowed $=\mathrm{y}$.

Ferreira, F., C. Lakner, M. Lugo y B. Özler (2014), "Inequality of opportunity and economic growth: How much can cross-country regressions really tell us?”, Review of Income and Wealth, http://dx.doi.org/10.1111/roiw.12311.

Filho, F. y F. Veloso (2016), Causas e Consequências da Informalidade no Brasil, Elsevier, FGV-IBRE, Río de Janeiro.

FMI (2017), “Mexico: Selected issues and analytical notes”, IMF Country Report, No. 17/347, FMI, Washington DC.

Gal, P. y A. Theising (2015), "The macroeconomic impact of structural policies on labour market outcomes in OECD countries”, OECD Economics Department Working Paper, No. 1271, OECD Publishing, París, http://dx.doi.org/10.1787/5jrqc6t8ktjf-en.

Garicano, L., C. Lelarge y J. Van Reenen (2016), "Firm size distortions and the productivity distribution: Evidence from France”, American Economic Review, Vol. 2016/11, pp. 3439-3479.

Gindling, T.H. y K. Terrell (2007). "The effects of multiple minimum wages throughout the labor market: The case of Costa Rica”, Labour Economics, Vol. 14, pp. 485-511.

Gindling, T.H. y J.D. Trejos (2010). "Improving compliance with legal minimum wages in Costa Rica”. https://economics.umbc.edu/files/2014/09/wp_10_127.pdf.

González Pandiella, A. y M. Gabriel (2017), "Deconstructing income inequality in Costa Rica: An income source decomposition approach”, OECD Economics Department Working Papers, No. 1377, OECD Publishing, París, http://dx.doi.org/10.1787/77759015-en.

Hoeller, P. et al (2012), "Less income inequality and more growth - are they compatible? Part 1. Mapping income inequality across the OECD”, OECD Economics Department Working Papers, No. 924, OECD Publishing, París, http://dx.doi.org/10.1787/5k9h297wxbnr-en.

Hsieh, C. (2015), “Policies for productivity growth”, OECD Productivity Working Papers, No. 3, OECD Publishing, París, http://dx.doi.org/10.1787/5jrp1f5rddtc-en.

Hsieh, C. y P. Klenow (2009), "Misallocation and manufacturing TFP in China and India”, Quarterly Journal of Economics, Vol. 124/4, pp. 1403-1448. 
Hsieh, C. y E. Moretti (2015), "Why do cities matter? Local growth and aggregate growth”, NBER Working Papers, No. 21154, National Bureau of Economic Research, Cambridge, MA.

Jiménez, R. (2014), Educación Pública en Costa Rica: Políticas, Resultado y Gasto, No. 6, Academia de Centroamérica, San José.

LANAMME (2017), “Informe de Evaluación de la Red Vial Nacional Pavimentada de Costa Rica Años 2016-2017”, San José, http://www.lanamme.ucr.ac.cr/index.php/home/evaluaci\%C3\%B3n-red-vialnacional-rv/informes-evaluaci\%C3\%B3n-red-vial-nacional/informe-rvn-2016-2017.html.

Lanau, S. (2017) "The growth return of infrastructure in Latin America”. IMF Working Paper, No. WP/17/35, https://www.imf.org/en/Publications/WP/Issues/2017/02/14/The-Growth-Return-ofInfrastructure-in-Latin-America-44663.

López-Calva, L.F. y N. Lustig (2010), Declining Inequality in Latin America: A Decade of Progress?, Brookings Institution Press.

Lustig, N. (2017), "El impacto del sistema tributario y el gasto social en la distribución del ingreso y la pobreza en Améica Latina: Una aplicación del marco metodológico del proyecto Compromiso Con La Equidad (CEQ)”, Documento de Trabajo, No. 62, http://www.commitmentoequity.org/wpcontent/uploads/2017/08/CEQ_WP62_Lustig_July06_2017.pdf.

Mateo-Diaz, M. y L. Rodriguez-Chamussy (2013), “Childcare and women’s labor participation: Evidence for Latin America and the Caribbean”, Inter-American Development Bank Technical Note, No. IDB-TN-586, https://publications.iadb.org/handle/11319/6493?locale-attribute=en\&localeattribute $=$ es.

MICITT (2016), “Indicadores nacionales de ciencia, tecnología e innovación Costa Rica 2014”, Ministry of Science, Technology and Telecommunications, San José, www.conicit.go.cr/biblioteca/publicaciones/publicacionescyt/otros_documentosCyT/indicadoresCyT2014.pdf.

MIDEPLAN (2014), “Plan Nacional de Desarrollo 2015-2018”, Ministerio de Planificación Nacional y Política Económica, San José.

Monge-González, R. (2016), "Innovation, productivity, and growth in Costa Rica: Challenges and opportunities”, Technical Note, No. IDB-TN-920, BID, Washington DC, https://publications.iadb.org/handle/11319/7376.

Monge-González, R., L. Rivera y J. Rosales-Tijerino (2010) "Productive development policies in Costa Rica: Market failures, government failures, and policy outcomes”, IDB Working paper Series. No. IDB-WP-157.

Monge-González, R. y J.A. Rodríguez-Álvarez (2013), “Impact evaluation of innovation and linkage development programs in Costa Rica: The cases of PROPYME and CR Provee”, IDB Working Paper Series, No. IDB-WP-461, Washington DC.

Monteiro, G. et al. (2017), "Product markets deregulation: A more productive, more efficient and more resilient economy?”, OECD Productivity Working Papers, No. 9, OECD Publishing, París, http://dx.doi.org/10.1787/86cc3b5e-en.

MOPT (2011), Plan Nacional de Transportes 2011-2035, Ministerio de Obras Públicas y Transportes, San José.

Morales, L. y C. Medina (2017), “Assessing the effect of payroll taxes on formal employment: The case of the 2012 tax reform in Colombia”, Economía, Vol. 18/1, pp. 75-124. 
Nicoletti, G. y S. Scarpetta (2003), "Regulation, Productivity and Growth: OECD Evidence", OECD Economics Department Working Papers, No. 347, OECD Publishing, París, http://dx.doi.org/10.1787/078677503357.

OCDE (2017a), OECD Reviews of Health Systems: Costa Rica, OECD Publishing, París, http://dx.doi.org/10.1787/9789264281653-en.

OCDE (2017b), OECD Reviews of Labour Market and Social Policies: Costa Rica, OECD Reviews of Labour Market and Social Policies, OECD Publishing, París, http://dx.doi.org/10.1787/9789264282773-en.

OCDE (2017c), Education in Costa Rica, OECD Publishing, París. http://dx.doi.org/10.1787/9789264277335-en.

OCDE (2017d), Agricultural Policies in Costa Rica, OECD Publishing, París, http://dx.doi.org/10.1787/9789264269125-en.

OCDE (2017e), OECD Reviews of Innovation Policy: Costa Rica, OECD Publishing, París, http://dx.doi.org/10.1787/9789264271654-en.

OCDE (2017f), OECD Economic Surveys: Mexico 2017, OECD Publishing, París, http://dx.doi.org/10.1787/eco_surveys-mex-2017-en.

OCDE (2017g), OECD Tax Policy Reviews: Costa Rica 2017, OECD Publishing París, http://dx.doi.org/10.1787/9789264277724-en.

OCDE (2017h), OECD Economic Surveys: Argentina 2017: Multi-Dimensional Economic Survey, OECD Publishing, París, http://dx.doi.org/10.1787/eco_surveys-arg-2017-en.

OCDE (2017i), OECD Economic Surveys: Colombia 2017, OECD Publishing, París, http://dx.doi.org/10.1787/eco_surveys-col-2017-en.

OCDE (2017j), In-Depth Analysis of the Labour Market Relevance and Outcomes of Higher Education Systems: Analytical Framework and Country Practices Report, Enhancing Higher Education System Performance, OECD, París.

OCDE (2017k), "Secretariat progress note on Costa Rica: State ownership and privatisation practices”, Corporate Governance Committee, Directorate for Financial and Enterprise Affairs, OECD internal report prepared for the OECD accession review of Costa Rica.

OCDE (2017l), “Accession Review of Costa Rica”, Insurance and Private Pensions Committee, Directorate for Financial and Enterprise Affairs, OECD internal report prepared for the OECD accession review of Costa Rica.

OCDE (2017m), “Corporate Governance Accession Review of Costa Rica”, Corporate Governance Committee, Directorate for Financial and Enterprise Affairs, OECD internal report prepared for the OECD accession review of Costa Rica.

OCDE (2017n), “Accession Review of Costa Rica” Committee on Financial Markets, Directorate for Financial and Enterprise Affairs, OECD internal report prepared for the OECD accession review of Costa Rica.

OCDE (2017o), OECD Economic Outlook, Volume 2017 Issue 1, OECD Publishing, París, http://dx.doi.org/10.1787/eco_outlook-v2017-1-en.

OCDE (2017p), “Accession Examination of Costa Rica under the OECD Investment Instruments”, Investment Committee, Directorate for Financial and Enterprise Affairs, OECD internal report prepared for the OECD accession review of Costa Rica. 
OCDE (2017q), Getting Infrastruture Right: A Framework for Better Governance, OECD Publishing, París, http://dx.doi.org/10.1787/9789264272453-en.

OCDE (2017r), “PGC Accession Assessment Report: Costa Rica”, Public Governance Committee, Public Governance and Territorial Development Directorate, OECD internal report prepared for the OECD accession review of Costa Rica.

OCDE (2016a), The Productivity-Inclusiveness Nexus: Preliminary version, OECD Publishing, París, http://dx.doi.org/10.1787/9789264258303-en.

OCDE (2016b), OECD Economic Surveys: Costa Rica 2016, OECD Publishing, París, http://dx.doi.org/10.1787/eco_surveys-cri-2016-en.

OCDE (2016c), PISA 2015 Results (Volume I): Excellence and Equity in Education, OECD Publishing, París, http://dx.doi.org/10.1787/9789264266490-en.

OCDE (2016d), Reviews of National Policies for Education: Education in Colombia, OECD Publishing, París, http://dx.doi.org/10.1787/9789264250604-en.

OCDE (2016e), “Accession Review of Costa Rica”, Competition Committee, Directorate for Financial and Enterprise Affairs, OECD internal report prepared for the OECD accession review of Costa Rica.

OCDE (2015a), Costa Rica: Good Governance, from Process to Results, OECD Public Governance Reviews, OECD Publishing, Paris, http://dx.doi.org/10.1787/9789264246997-en.

OCDE (2015b), Universal Basic Skills: What Countries Stand to Gain, OECD Publishing, París, http://dx.doi.org/10.1787/9789264234833-en.

OCDE (2015c), OECD Economic Surveys: Mexico 2015, OECD Publishing, París, http://dx.doi.org/10.1787/eco_surveys-mex-2015-en.

OCDE (2015d), OECD Employment Outlook 2015, OECD Publishing, París, http://dx.doi.org/10.1787/empl_outlook-2015-en.

OCDE (2015e), OECD Guidelines on Corporate Governance of State-Owned Enterprises, OECD Publishing, París, http://dx.doi.org/10.1787/9789264244160-en

OCDE (2013), OECD Economic Surveys: Brazil 2013, OECD Publishing, París, http://dx.doi.org/10.1787/eco_surveys-bra-2013-en.

OCDE (2012a), Equity and Quality in Education: Supporting Disadvantaged Students and Schools, OECD Publishing, Paris, http://dx.doi.org/10.1787/9789264130852-en.

OCDE (2012b), "Recommendation of the Council on Principles for the Public Governance of PublicPrivate Partnerships”, OECD, Paris. http://www.oecd.org/gov/budgeting/oecd-principles-for-publicgovernance-of-public-private-partnerships.htm.

OCDE (2007), No More Failures: Ten Steps to Equity in Education, OECD Publishing, París. http://dx.doi.org/10.1787/9789264032606-en.

OECD/FUNDEVI (2017), Interrelations between Public Policies, Migration and Devleopment in Costa Rica, OECD Development Pathways, OECD Publishing, París. http://dx.doi.org/10.1787/9789264278967-en.

OECD y BID (2016), Boosting Productivity and Inclusive Growth in Latin America, OECD Publishing, París, http://www.oecd.org/latin-america/Boosting_Productivity_Inclusive_Growth.pdf. 
OIT (2014), "Policies for the formalization of micro and small enterprises in Costa Rica”, Notes on Policies for the Formalization of Micro and Small Enterprises, OIT, http://www.ilo.org/empent/whatsnew/WCMS_318212/lang--en/index.htm.

OIT (2013), "The formal and informal sectors in Colombia: Country case study on labour market segmentation”, Employment Working Paper, No. 146, OIT, Ginebra, http://www.ilo.org/wcmsp5/groups/public/---ed_emp/--ifp_skills/documents/publication/wcms_232495.pdf.

Pisu, M. y F. Villalobos (2016),“A bird-eye view of Costa Rica's transport infrastructure”, OECD Economics Department Working Papers, No. 1323, OECD Publishing, París, http://dx.doi.org/10.1787/5jlswbwvwqjf-en.

Ramírez Alfaro, L. (2010), "La informalidad y semiformalidad empresarial en Costa Rica: un acercamiento desde la mirada de personas expertas”, Serie Observatorio de MIPYMES, UNED, San José, Costa Rica.

Rodriguez-Clare, A. (2001), “Costa Rica’s development strategy based on human capital and technology: How it got there, the impact of Intel, and lessons for other countries", Journal of Human Development, Vol 2/2, United Nations Development Programme.

Ruhm, C. y J. Waldfogel (2011), “Long-term effects of early childhood care and cducation”, IZA Discussion Paper, No. 6149, Bonn.

Sandoval, C., et al (2017), “Employment dynamics in Costa Rica after the global financial crisis”, in Business Dynamics and Productivity, OECD Publishing, París. http://dx.doi.org/10.1787/9789264269231-en.

Sandoval, C. et al (2018), "FDI productivity spillovers to local firms in Costa Rica: From theory to evidence”, in OECD Economic Survey of Costa Rica 2018: Research findings on productivity, OECD Publishing, París, por publicarse.

Song, J. et al. (2015), Firming Up Inequality, National Bureau of Economic Research, Cambridge, MA. http://dx.doi.org/10.3386/w21199.

UCCAEP (2011), IV Encuesta Trimestral de Negocios “Pulso Empresarial” 2011, Unión Costarricense de Cámaras y Asociaciones del Sector Empresarial Privado, San José. http://uccaep.or.cr/images/content/pulso-empresarial/2011/IV\%20ETN\%202011\%20prensa.pdf. 